\title{
NUCLEAR ENGINEERING EDUCATION RESEARCH
}

\section{Heat Transfer Phenomena in Supercritical Water Nuclear Reactors}

PI:

Mark H. Anderson, University of Wisconsin - Madison

Department of Engineering Physics.

Collaborators: $\quad$ Michael L. Corradini, University of Wisconsin - Madison

Department of Engineering Physics

Riccardo Bonazza, University of Wisconsin - Madison

Department of Engineering Physics

Project Start Date: August 15, $2004 \quad$ End Date: August 14, 2007

Project Number: 04ID14602

\section{Final Technical Report: DE-FG07-04ID14602}

\author{
Prepared by: \\ Jeremy R. Licht, Mark H. Anderson, Michael L. \\ Corradini, Riccardo Bonazza
}




\section{Heat Transfer Phenomena in Supercritical Water Nuclear Reactors}

\section{ABSTRACT}

A supercritical water heat transfer facility has been built at the University of Wisconsin to study heat transfer in a circular and square annular flow channel. A series of integral heat transfer measurements has been carried out over a wide range of heat flux (up to $1.0 \mathrm{MW} / \mathrm{m}^{2}$ ), mass velocity $\left(200-1400 \mathrm{~kg} / \mathrm{m}^{2} \mathrm{~s}\right.$ ) and bulk water temperatures $\left(150-410^{\circ} \mathrm{C}\right)$ at a pressure of $25 \mathrm{MPa}$. The circular annular test section geometry is a $1.07 \mathrm{~cm}$ diameter heater rod within a $4.29 \mathrm{~cm}$ diameter flow channel. The square annular test section geometry is a $1.07 \mathrm{~cm}$ diameter heater rod within a $2.88 \mathrm{~cm}$ wide flow channel. A $76 \mathrm{~cm}$ development section precedes a $1.01 \mathrm{~m}$ long heated section, which includes 16 thermocouples for inner cladding temperature measurements. The accuracy and validity of selected heat transfer correlations and buoyancy criterion were compared with heat transfer measurements. Jackson's Nusselt correlation was able to best predict the test data, capturing $86 \%$ of the data within $25 \%$. Watts Nusselt correlation showed a similar trend but under predicted measurements by $10 \%$ relative to Jackson's. Comparison of experimental results with results of previous investigators has shown general agreement with high mass velocity data. Low mass velocity data has provided some insight into the difficulty in applying these Nusselt correlations to a region of deteriorated heat transfer. Geometrical differences in heat transfer were seen when deterioration was 
present. Jackson's buoyancy criterion predicted the onset of deterioration while modifications were applied to Seo's Froude number based criterion. 


\section{Table of Contents}

Notation and Symbols.............................................................................................................. 7

Chapter 1 - Introduction.............................................................................................. 12

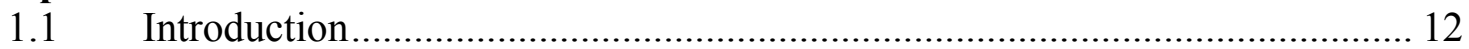

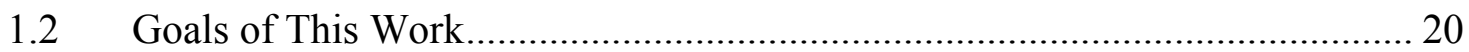

Chapter 2 - Background on Heat Transfer to Supercritical Pressure Fluids. .......... 23

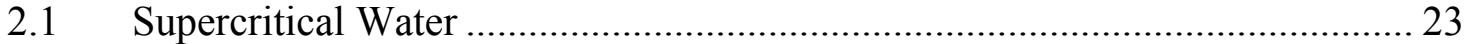

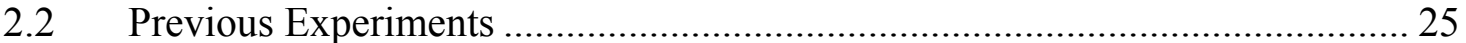

2.2.1 Nusselt Correlations....................................................................... 25

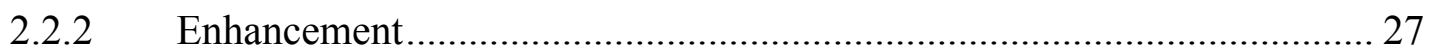

2.2.3 Buoyancy Influenced Deterioration .................................................... 28

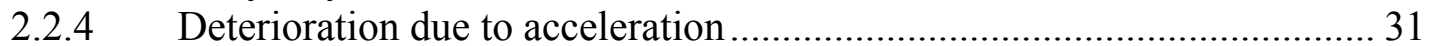

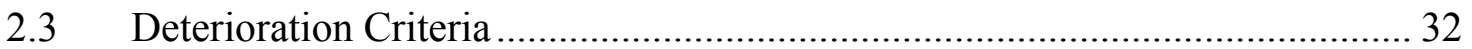

Chapter 3 - Heat Transfer Facility ........................................................................ 34

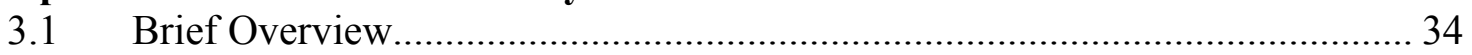

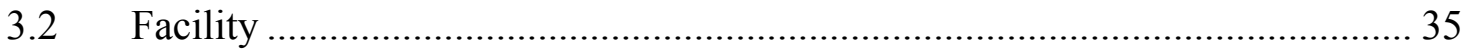

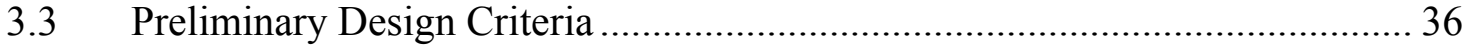

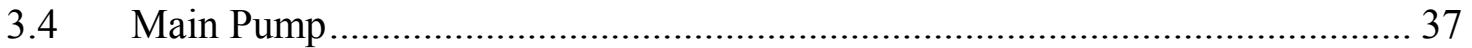

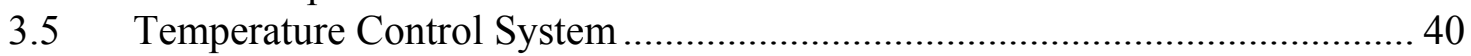

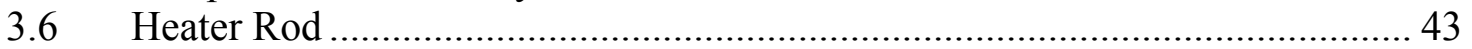

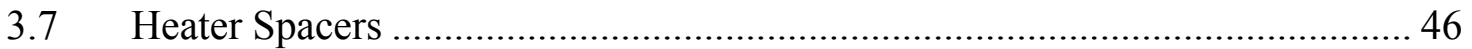

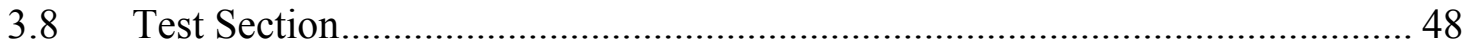

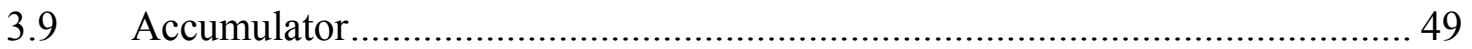

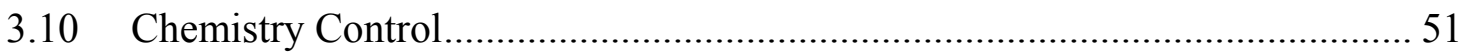

3.11 Data Acquisition, Motion, and Control........................................................... 53

3.12 Operating Procedure for Heat Transfer Measurements .................................... 54

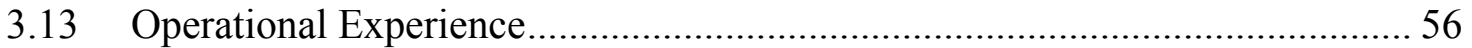

Chapter 4 - Experimental Method, Procedure, and Uncertainties............................... 58

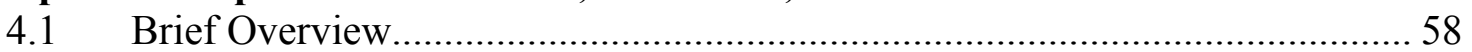

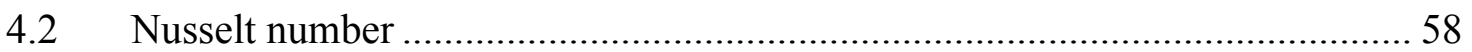

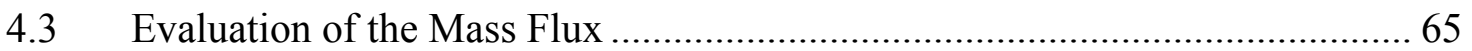

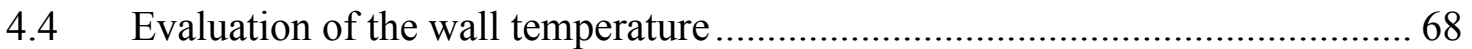

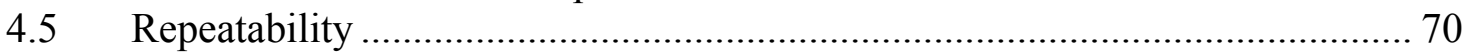

Chapter 5 - Heat Transfer Results and Discussion ........................................................ 72

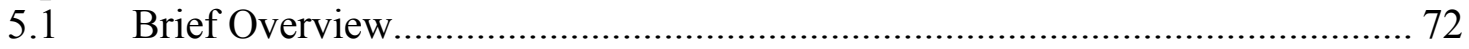

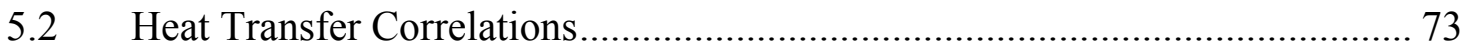

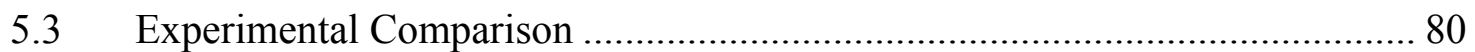

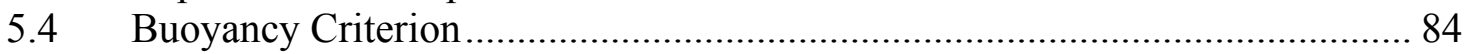

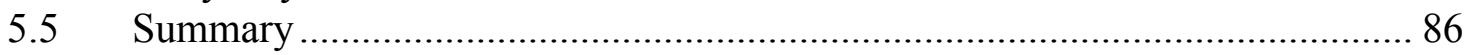

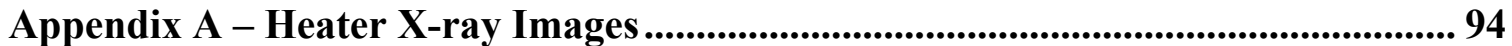

Appendix B - Heater End Dimensions........................................................................... 95

Appendix C - Facility Layout_.............................................................................................. 96

Appendix D - LabVIEW Code ......................................................................................... 98

Appendix E - Heater Surface Roughness Measurements.............................................. 104

Appendix F - Heat Transfer Uncertainty Example....................................................... 105 


\section{List of figures}

Figure 1-1 Operating Conditions of SCWR compared with BWR's and PWR's [6]. 13 Figure 1-2 Thermophysical property variation of water as a function of temperature at

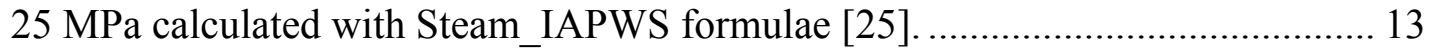

Figure 1-3 Experimental results of Yamagata et al. .............................................. 14

Figure 1-4 Experimental results of Shitsman. ................................................. 15

Figure 1-5 Description of heat transfer effects.................................................... 17

Figure 1-6 Variation in heat transfer correlations. Reproduced from [37].............. 19

Figure 2-1 Properties of water at various pressures calculated with IAPWS

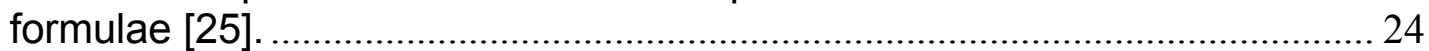

Figure 2-2 Comparison of CFD code [44] and Jackson Correlation [22] with data

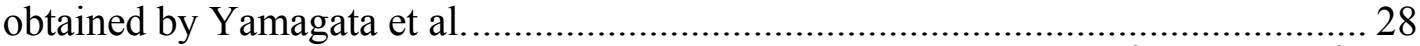

Figure 2-3 Comparison of wall temperature at two heat flux cases $\left(a: 31 \mathrm{~kW} / \mathrm{m}^{2}, \mathrm{~b}: 57 \mathrm{~kW} / \mathrm{m}^{2}\right.$ ) for $\mathrm{CO2}$ with upward and downward flow (solid and dashed line, respectively). ..................... 29

Figure 2-4 Experimental parameter of Shitsman. .......................................... 31

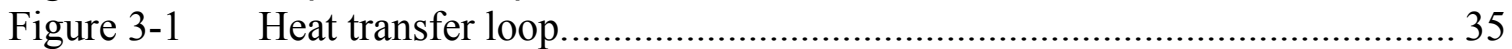

Figure 3-2 Expected deterioration region based on the Froude criterion................... 37

Figure 3-3 Main SCW pump. .................................................................... 38

Figure 3-4 Orientation of pump head and recirculation leg for upward and downward flow. $\quad 39$

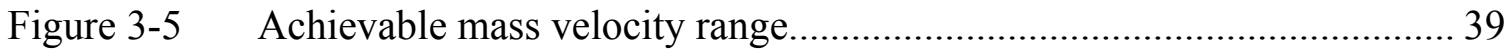

Figure 3-6 Distribution manifold................................................................... 41

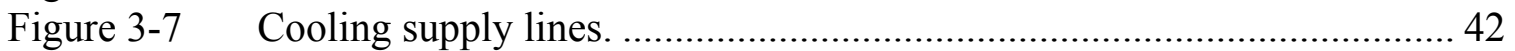

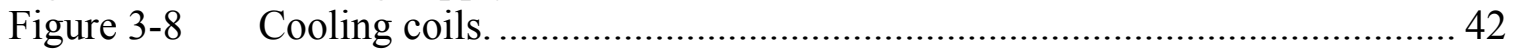

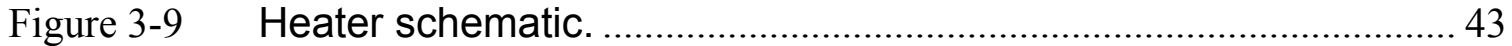

Figure 3-10 (a) Thermocouple grooves of the unrolled sheath. (b) Cartoon of the radial components of the heater (not to scale) . ........................................ 44

Figure 3-11 Pressure boundary holding heater in a fixed position............................ 45

Figure 3-12 Pressure boundary allowing for differential thermal expansion............. 46

Figure 3-13 Top: Spring clip designed to support heater rod in circular geometry.

Bottom: pins used to support heater rod in square geometry............................... 47

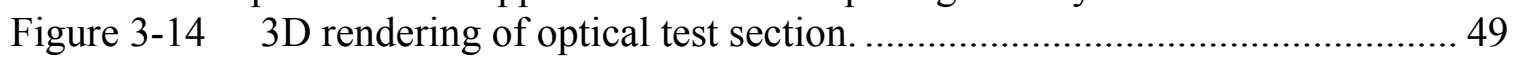

Figure 3-15 Picture of the pressure control components....................................... 50

Figure 3-16 Schematic of the pressure control system.......................................... 51

Figure 3-17 Picture of chemistry control components. ..........................................52

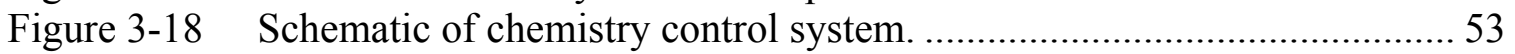

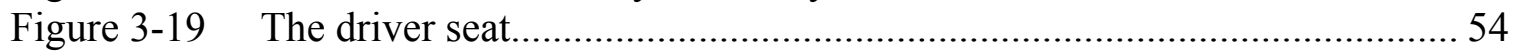

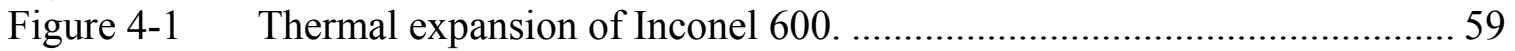

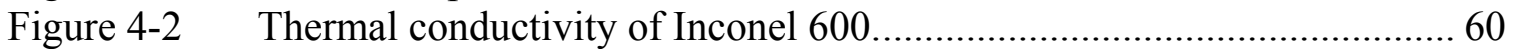

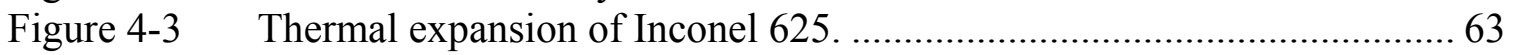

Figure 4-4 Orifice system schematic................................................................ 65

Figure 4-5 Measured discharge coefficient compared with measured. (a) $\beta=0.237$,

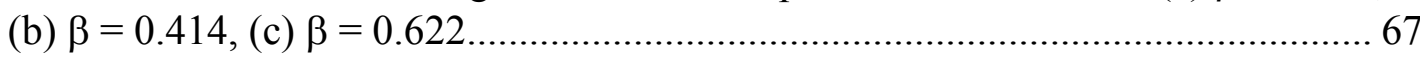


Figure 4-6 Surface temp variation of a section of heater rod with Q" $=1 \mathrm{MW} / \mathrm{m}^{2}$ and $\mathrm{Tb}=370{ }^{\circ} \mathrm{C}$ 68

Figure 4-7 Variation in radial thermocouple position assuming the position is the dominant factor in varying relative temperature measurements.............. 70

Figure 4-8 Repeatability of five experiments..................................................... 71

Figure 5-1 Completed experiments in relation to the buoyancy effected region. 73

Figure 5-2 Comparison of experimental Nusselt number and Dittus-Boelter correlation.

Figure 5-3 Comparison of experimental Nusselt number and Jackson's Nusselt correlation.

Figure 5-4 Comparison of experimental Nusselt number and Krasnoshchekov correlation

Figure 5-5 Comparison of experimental Nusselt number and Watts Nusselt correlation.

Figure 5-6 Comparison of Watts and Jackson Nusselt correlation (square geometry). 80

Figure 5-7 High mass velocity comparison of Yamagata et al. and UW data 81

Figure 5-8 (a) Example of the evolution in heat transfer deterioration (UW data). (b) Comparison of UW data and Shitsman data under similar conditions. (c) Example of multiple spikes in wall temperature.

Figure 5-9 Comparison of circle and square annular flow geometry heat transfer. ... 83

Figure 5-10 Buoyancy criterion evaluated at local conditions in UW experiment. ..... 85 


\section{Notation and Symbols}

\section{Letters}
A Flow Area
$\left[\mathrm{m}^{2}\right]$

A Local Q" Correction Factor

a Particle Diameter

[m]

B Position of $\mathrm{T}_{\text {ic }}$ (diameter)

[m]

$c_{p}$ Specific Heat

$[\mathrm{J} / \mathrm{kg}-\mathrm{K}]$

$\overline{c_{p}}$ Integrated Specific Heat, $\frac{i_{w}-i_{b}}{T_{w}-T_{b}}$

$[\mathrm{J} / \mathrm{kg}-\mathrm{K}]$

C Discharge Coefficient

$[-]$

D Diameter

[m]

D Fitting Parameter

$\left[\mathrm{m}^{-4}\right]$

d Diameter (Orifice)

[m]

dp Differential Pressure

[Pa]

E Fitting Parameter

$\left[\mathrm{m}^{-5}\right]$

f Frequency

$[\mathrm{Hz}]$

Fr Froude Number

$[-]$

g Gravity

$\left[\mathrm{m} / \mathrm{s}^{2}\right]$

G Mass Velocity

$\left[\mathrm{kg} / \mathrm{m}^{2}-\mathrm{s}\right]$

Gr Grashof Number $\frac{\left(\rho_{b}-\rho_{w}\right) D_{H}^{3} g}{\rho v^{2}}$

[-]

$\overline{G r}$ Grashof Number $\frac{\left(\rho_{b}-\bar{\rho}\right) D_{H}^{3} g}{\rho v^{2}}$ 
h Heat Transfer Coefficient

i Enthalpy

k Thermal Conductivity

L Heated Length

Nu Nusselt Number $\frac{h D_{H}}{k_{b}}$

P Pressure

$\mathrm{P}_{\mathrm{o}}$ Laser Power

Pr Prandtl Number

$\overline{\operatorname{Pr}} \frac{i_{w}-i_{b}}{T_{w}-T_{b}} \frac{\mu_{b}}{k_{b}}$

Q Heater Power

Q" Heat Flux

Re Reynolds Number

T Temperature

u' Fluctuating Axial Velocity

u Velocity

$\mathrm{u}^{+}$Non dimensional Velocity

V Velocity

v' Fluctuating Radial Velocity

y Distance

$\mathrm{y}^{+}$Non Dimensional Distance

yo Distance Bias

Greek
$\left[\mathrm{W} / \mathrm{m}^{2} \mathrm{~K}\right]$

$[\mathrm{J} / \mathrm{kg}]$

$[\mathrm{W} / \mathrm{m}-\mathrm{K}]$

[m]

$[-]$

[Pa]

[W]

$[-]$

$[-]$

[W]

$\left[\mathrm{W} / \mathrm{m}^{2}\right]$

[-]

$\left[{ }^{\circ} \mathrm{C}\right]$

[m/s]

[m/s]

[-]

[m/s]

[m/s]

[m]

[-]

[m] 
$\beta$ Diameter Ratio d/D

$\Delta \mathrm{F}$ Bandwidth Frequency

$[\mathrm{Hz}]$

$\Delta \rho$ Density Difference

$\left[\mathrm{kg} / \mathrm{m}^{3}\right]$

$v$ Kinematic Viscosity

$\left[\mathrm{m}^{2} / \mathrm{s}\right]$

$\mu$ Dynamic Viscosity

[kg/m-s]

$\rho$ Density

$\left[\mathrm{kg} / \mathrm{m}^{3}\right]$

$\rho$ ' Fluctuating Density

$\left[\mathrm{kg} / \mathrm{m}^{3}\right]$

$\bar{\rho}$ Integrated Density $\frac{1}{\left(T_{w}-T_{b}\right)} \int_{T_{b}}^{T_{w}} \rho d T$

$\left[\mathrm{kg} / \mathrm{m}^{3}\right]$

$\rho_{\mathrm{T}}\left(\rho_{\text {in }}-\rho_{f}\right) /\left(T_{\text {in }}-T_{f}\right)$

$\left[\mathrm{kg} / \mathrm{m}^{3}-\mathrm{K}\right]$

$\tau$ Shear Stress

$\left[\mathrm{kg} / \mathrm{m}^{2} \mathrm{~s}\right]$

Subscripts

b Bulk

DB Dittus-Boelter

in Inlet

f $\quad$ Film, based on $\left(T_{b}+T_{w}\right) / 2$

H Hydraulic

ic Inner Cladding

in Inlet Temperature

i Inlet Temperature

p Particle

pc Pseudocritical

rod Heater Rod 
s $\quad$ Film, based on $\left(T_{i n}+T_{p c}\right) / 2$

S Settling Velocity

w Wall

$\tau \quad$ Shear

Abbreviations

2D Two Dimensional

3D Three Dimensional

ASME American Society of Mechanical Engineers

BWR Boiling Water Reactor

CFD Computational Fluid Dynamics

DNS Direct Numerical Simulations

DB Dittus-Boelter

GPM Gallons Per Minute

HPLC High Pressure Liquid Chromatography

INEEL Idaho National Environmental Engineering Laboratory

Ja Jackson

$\mathrm{Kr} \quad$ Krasnoshchekov

LDV Laser Doppler Velocimetry

LES Large Eddy Simulation

LWR Light Water Reactor

MIR Matched Index of Refraction

PDM Photo Detector Module

PIV Particle Image Velocimetry 


$\begin{array}{ll}\text { PMT } & \text { Photomultiplier Tube } \\ \text { PTFE } & \text { PolyTetraFluoroEthylene } \\ \text { RANS } & \text { Reynolds Averaged Navier Stokes } \\ \text { RPM } & \text { Rounds Per Minute } \\ \text { SCW } & \text { SuperCritical Water } \\ \text { SCW } & \text { SuperCritical Water Reactor } \\ \text { SCFW } & \text { Supercritical Fast Reactor } \\ \text { SCLWR } & \text { Supercritical Light Water Reactor } \\ \text { SNR } & \text { Signal to Noise Ratio } \\ \text { UW } & \text { University of Wisconsin }\end{array}$




\section{Chapter 1 - Introduction}

\subsection{Introduction}

In an effort to improve the efficiency of current Light Water Reactors (LWR's), the Generation IV initiative has included the conceptual design of Supercritical Water Reactor (SCWR) as one of the next steps in future nuclear reactors [8]. A SCWR will achieve efficiencies of about $44 \%$, compared with current LWR efficiencies of about $34 \%$, by operating its coolant at higher temperature $\left(500{ }^{\circ} \mathrm{C}\right)$ and pressure (25 MPa) than current LWR's (Figure 1-1 and Table 1). These operating conditions are above the pseudo-critical temperature of water (defined as the temperature, for a given pressure, at which the specific heat exhibits a maximum) and thus the coolant of SCW reactors will undergo large thermo-physical property changes (Figure 1-2).

\begin{tabular}{|l|c|c|c|c|}
\hline Reactor Type & BWR & PWR & SCLWR-H & SCFR-H \\
\hline Efficiency (\%) & 34.1 & 33.7 & 43.8 & 44.4 \\
\hline Inlet Temperature (oC) & 269 & 300 & 280 & 280 \\
\hline Outlet Temperature (oC) & 286 & 332 & 508 & 526 \\
\hline Pressure (MPa) & 7 & 15.5 & 25 & 25 \\
\hline Ave Heat Flux (kW/m2) & 653 & 692 & 624 & 800 \\
\hline Mass Flux (kg/m2s) & 1201 & 3373 & 965 & 1286 \\
\hline
\end{tabular}

Table 1 Note worthy parameters of current and proposed water-cooled reactors [10][34]. 


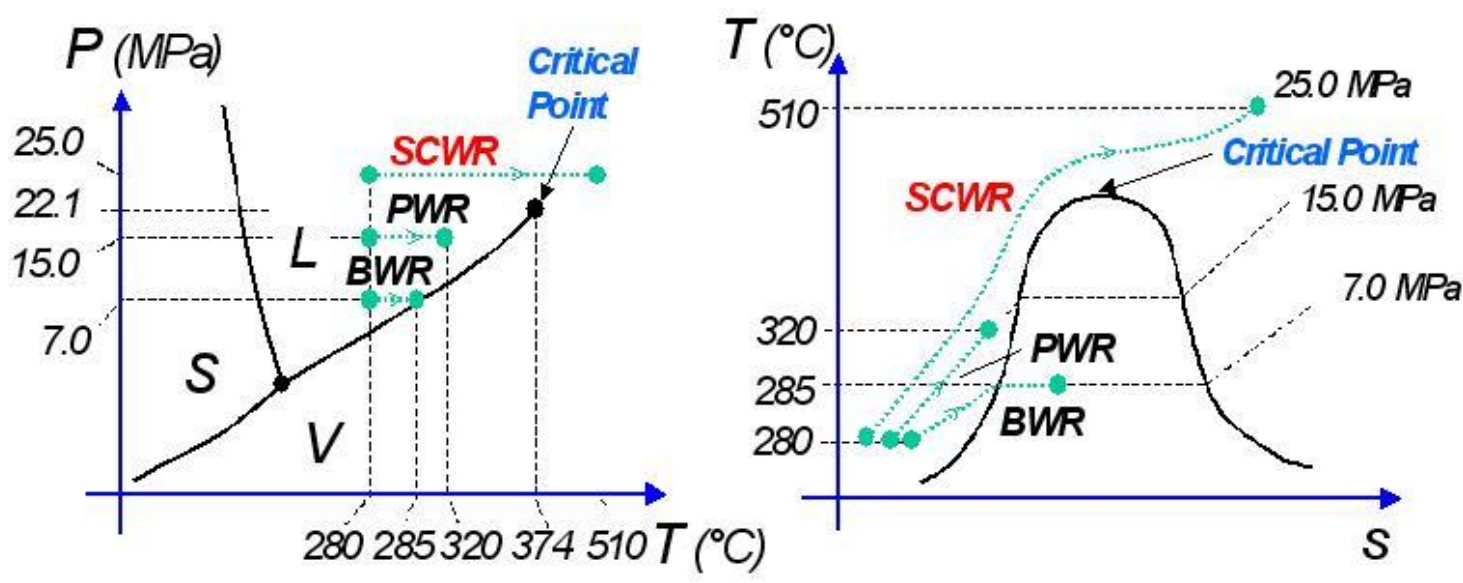

Figure 1-1 Operating Conditions of SCWR compared with BWR's and PWR's [6].

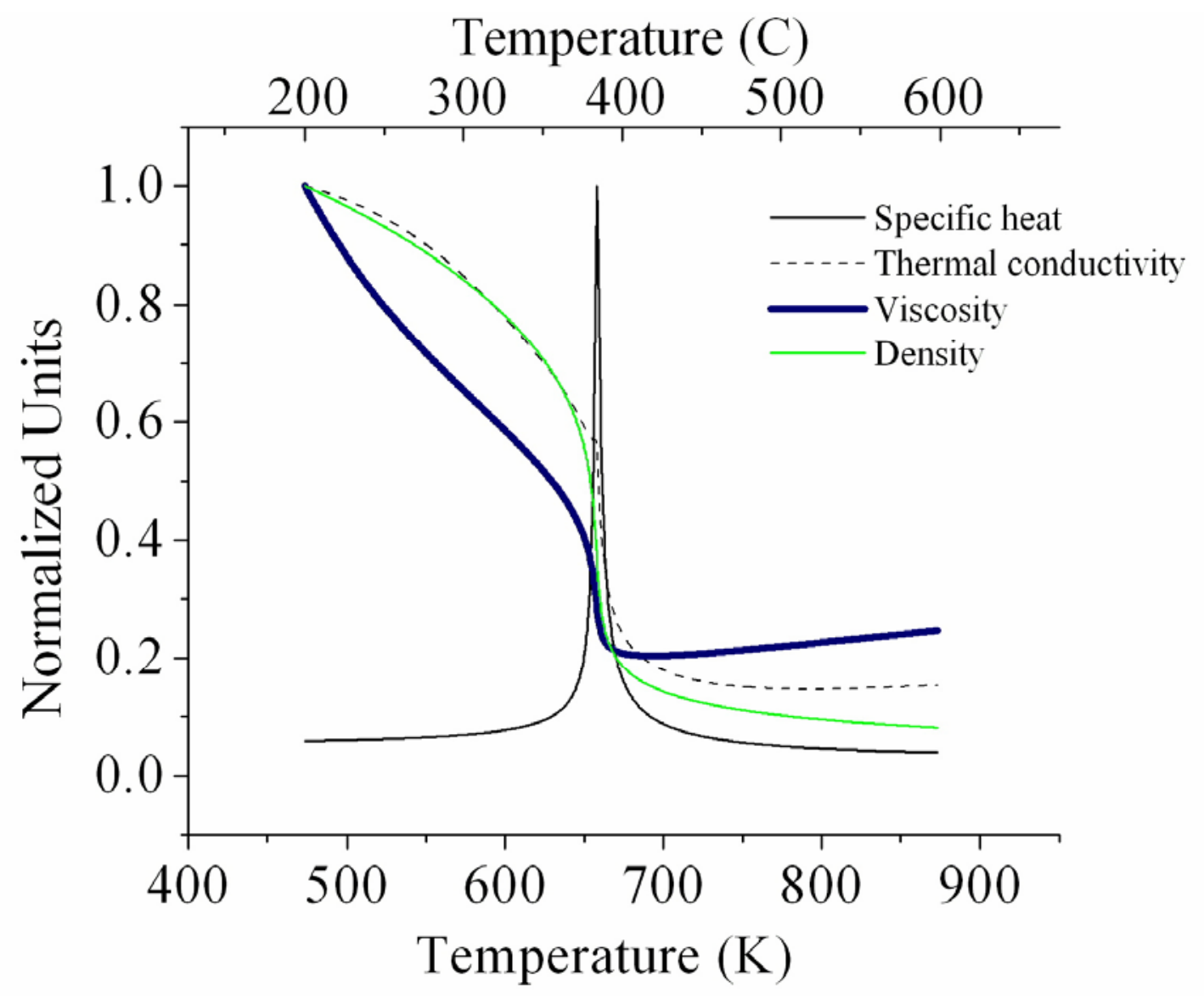

Figure 1-2 Thermophysical property variation of water as a function of temperature at $25 \mathrm{MPa}$ calculated with Steam_IAPWS formulae [25]. 
Two key experiments performed by Yamagata et al. [53] and Shitsman [48] investigated the thermophysical property variation effects on SCW heat transfer in a heated up-flow tube geometry at high and low mass velocities. Yamagata's data was performed at a relatively high mass velocity of (1260 $\mathrm{kg} / \mathrm{m}^{2} \mathrm{~s}$ ) with varying heat flux. Yamagata's data shows that as the bulk enthalpy is increased through the pseudo-critical temperature an enhancement in heat transfer occurs (Figure 1-3). This enhanced heat transfer is diminished by increasing heat flux and suggests that at some critical heat flux, the enhancement will be completely inhibited.

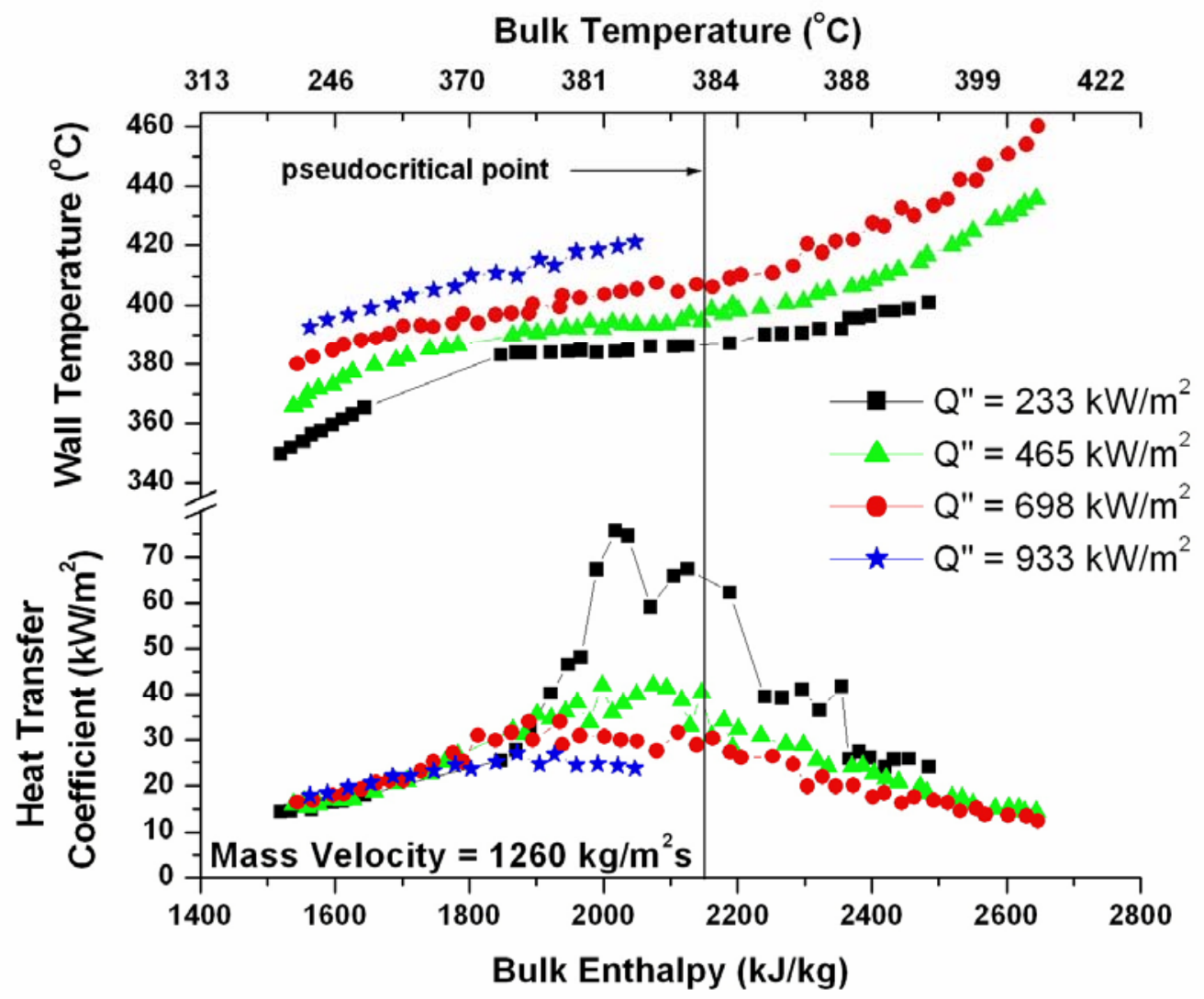

Figure 1-3 Experimental results of Yamagata et al. 
Shitsman's data (low mass velocity, $\left(430 \mathrm{~kg} / \mathrm{m}^{2} \mathrm{~s}\right)$ ) indicates that as the bulk coolant enthalpy is increased through the pseudocritical temperature, deterioration in heat transfer can occur (Figure 1-4). At a low heat flux there is indication of a localized enhancement in heat transfer. As the heat flux is increased, the heat transfer progresses from an enhanced condition to a deteriorated condition. In fact at the highest heat flux case, the heat transfer is so poor that it resulted in a localized temperature spike from 400 to $600{ }^{\circ} \mathrm{C}$. However, it should be noted that in difference to two-phase critical heat flux phenomena, the heat transfer recovers after either an enhancement or deterioration.

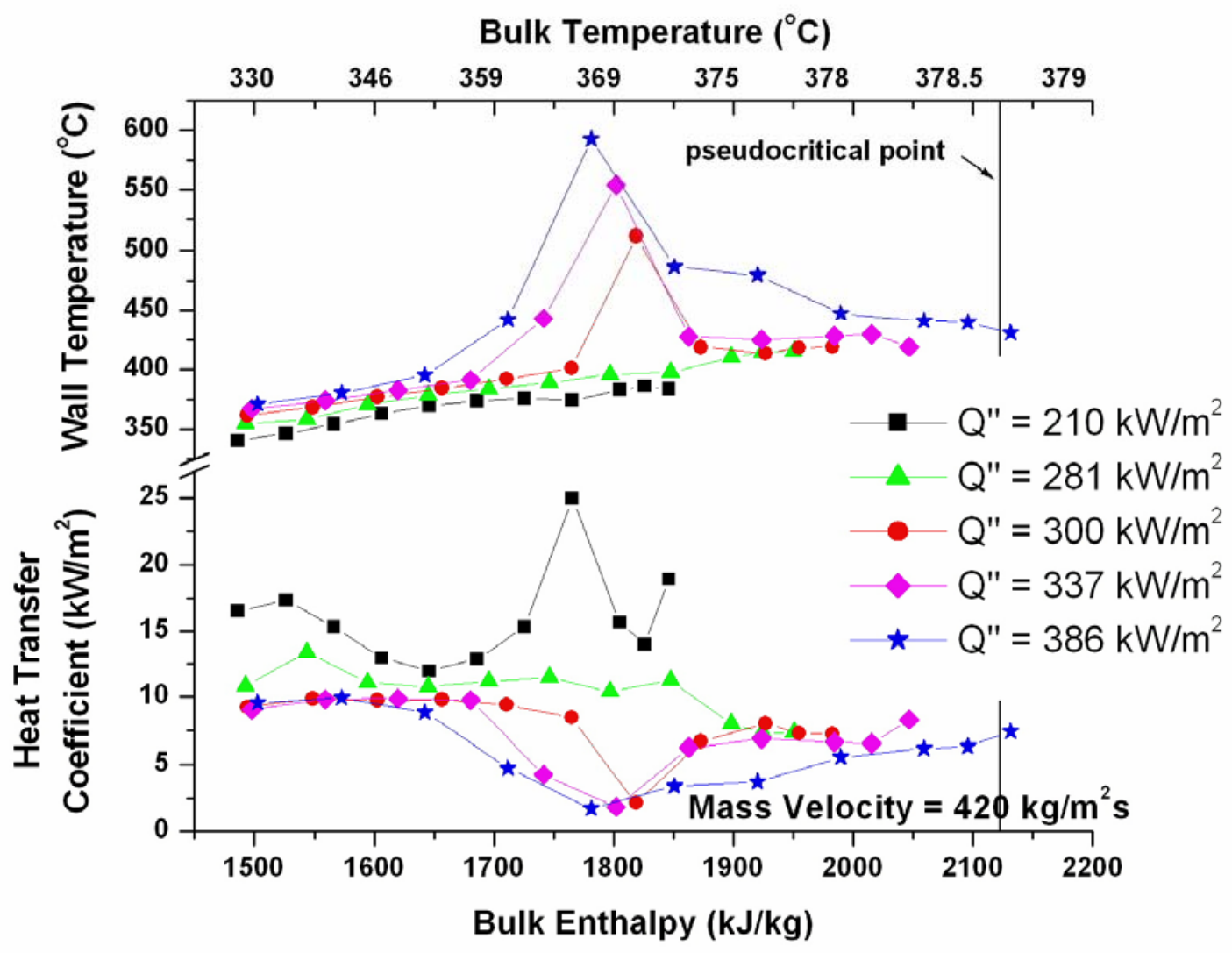

Figure 1-4 Experimental results of Shitsman. 
Many of the previous heat transfer experiments with supercritical fluids, both for water and carbon dioxide (a surrogate fluid typically used due its lower critical temperature and pressure), have shown similar deviations from normal heat transfer. In general, deviations from normal heat transfer have been found to occur when the wall temperature is greater than the pseudo-critical temperature and the bulk temperature is less than the pseudo-critical temperature $\left(T_{w}>T_{p c}>T_{b}\right)$ [7]. This condition indicates that large property variations occur within the near heated-wall region, which one might expect would greatly impact the heat transfer.

The enhancement and deterioration of heat transfer have been described by Jackson and Hall [23] and can be explained with the help of Figure 1-5. For reference, typical heat transfer (no property variation) to pipe flow has a parabolic velocity profile and for simplicity, a linear temperature profile in the near wall region (Figure 1-5a). Enhanced heat transfer occurs at a low heat flux with bulk temperatures near the pseudo-critical temperature. At these conditions, the energy input is not large enough to overcome the large values of specific heat and thus a low gradient in wall to bulk temperature is achieved (Figure 1-5b).

The impairment of enhanced heat transfer due to an increased heat flux can be explained as follows. Where at a low heat flux the large value of specific heat is felt across most of the boundary layer, an increase in heat flux will produce enough energy input to overcome the large values of specific heat, 
resulting in an increase in temperature gradient across the boundary layer. Thus, the large values of specific heat will become more localized within the boundary layer, impairing the enhanced heat transfer by reducing the integrated effect of the specific heat (Figure 1-5c).
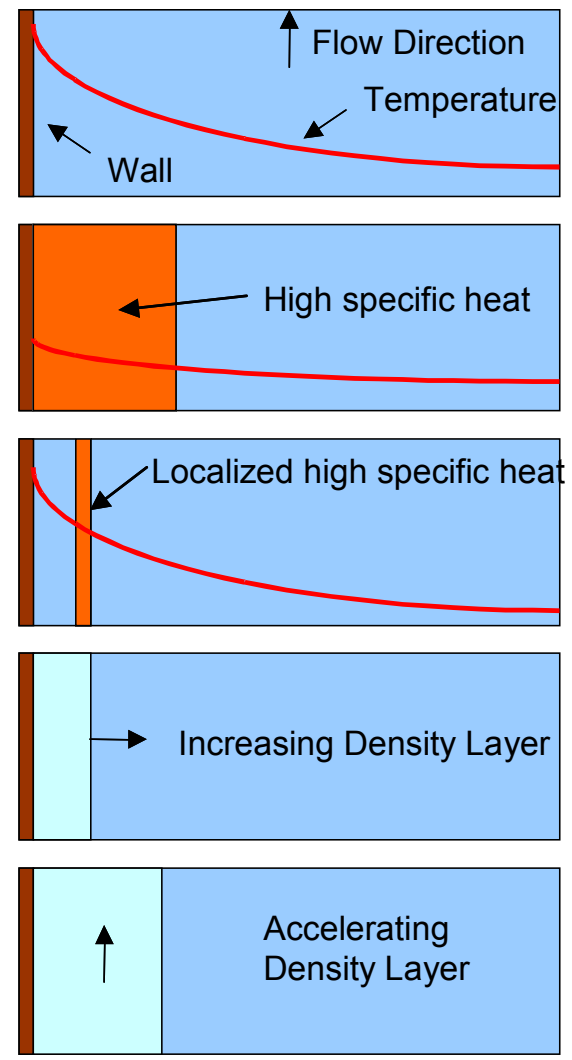

a) Normal heat transfer (No property variation)

b) Enhanced heat transfer (Large G, low Q")

c) Impairment of enhanced heat transfer

(Large G, increasing Q")

d) Deteriorating heat transfer (Low G)

e) Recovering heat transfer (Low G)

Figure 1-5 Description of heat transfer effects.

In the case where the heat flux is high compared to the mass velocity, it is possible that buoyancy effects can dominate and cause a deterioration and recovery of the heat transfer in upward flow. Hall and Jackson state that the turbulent diffusivity is reduced for upward flow when the low-density wall layer 
becomes thick enough to reduce the shear stress in the region where energy is typically fed into the turbulence, thus effectively reducing the heat transfer. As the process develops along the tube, the increasing wall temperature further increases the density difference between the near wall region and the core (Figure 1-5d). This density difference eventually becomes significant enough to cause an upward acceleration of the boundary layer, restoring the turbulence production and hence, the heat transfer (Figure 1-5e).

In the case where the mass flow rate is high enough that near wall buoyancy effects do not occur, another type of heat transfer impairment can occur. Impairment due to acceleration occurs, in a tube geometry for example, when the exit density is much lower than the inlet density. Under these conditions, maintaining a constant mass flow rate along the tube requires that the fluid accelerate in the direction of the flow, altering the near wall shear stress in a manner that causes a reduction in heat transfer. The fact that this effect is different from buoyancy effects has been shown theoretically [21] and experimentally [47]. Experiments have shown that acceleration effects cause an impairment in heat transfer in both upward and downward flow, whereas buoyancy effects cause an impairment in upward flow and an enhancement in downward flow.

There are many previous investigations of the heat transfer phenomena with water as the coolant, as cited by Pioro [38], however, the correlations that 
were derived from these studies vary wildly (Figure 1-6). Several investigators have tried to further understand the heat transfer phenomena with radial velocity and temperature profiles in pipe flow with supercritical carbon dioxide as the coolant [5][29][32][52], however, the results of these experiments do not completely agree with each other.

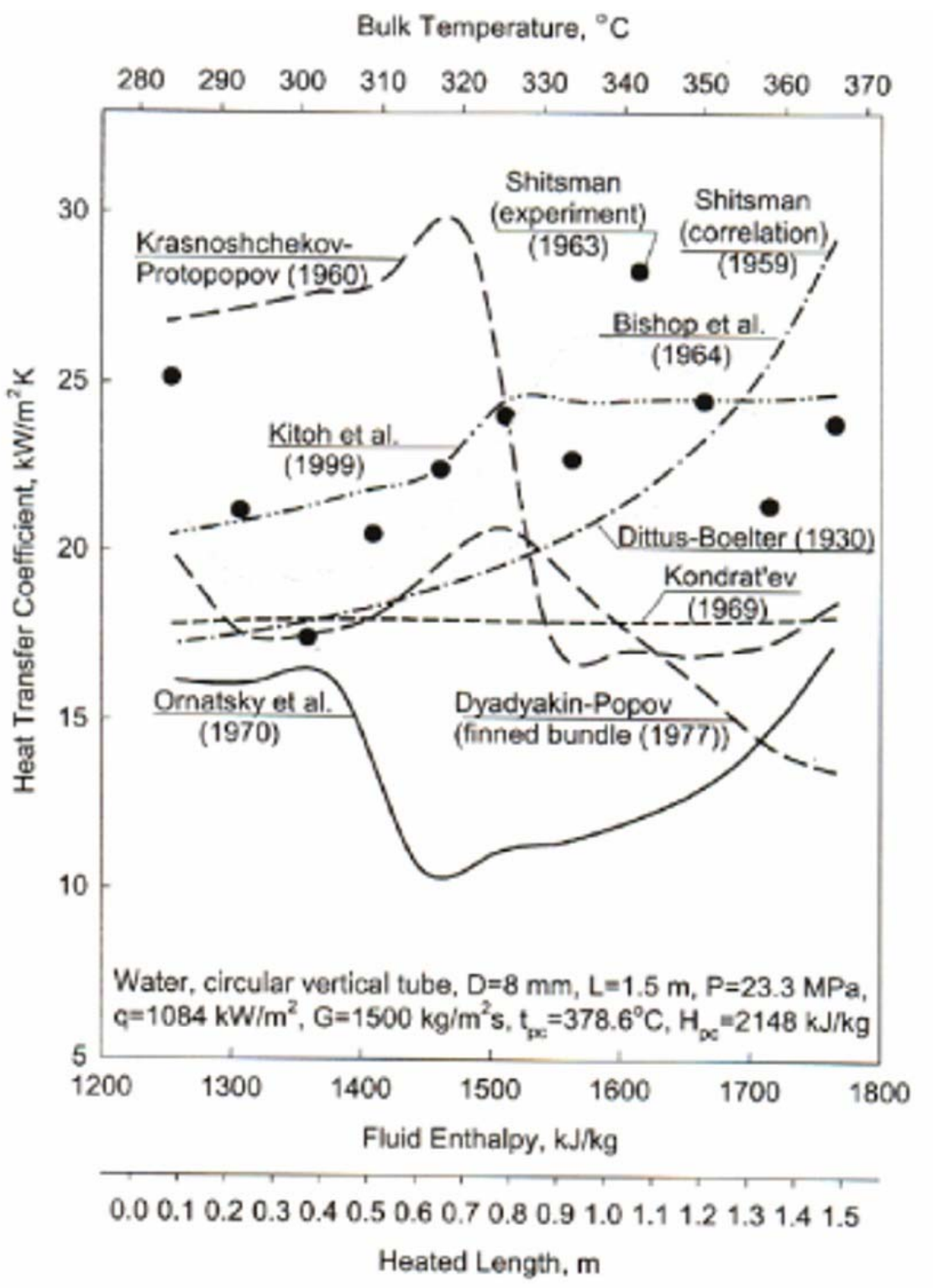

Figure 1-6 Variation in heat transfer correlations. Reproduced from [37]. 
Seo et al. [45] used the CFD code FLUENT to attempt to model the supercritical water heat transfer. The numerical scheme used a standard kepsilon model to simulate Yamagata's and Shitsman's data. The results showed that FLUENT was able to predict Yamagata's data but completely missed the deterioration in heat transfer of Shitsman's data. The failure of the k-epsilon model is believed to be due to an inaccurate, oversimplified wall function model. The wall function model relates the first meshed cell values to wall values. In other words, the wall function attempts to bridge the law of the wall region in the flow to the wall values, neglecting any thermophysical property changes within the viscous sub-layer. Since the standard wall function used in FLUENT was developed for constant property flows, it failed to capture the correct flow characteristics. Seo et al. [44] therefore developed a new wall function model that included previously neglected terms to account for the property changes. The new wall function model that was developed requires input from experimental data under a set of appropriate conditions to determine key constants. To obtain these constants, details of the momentum and thermal boundary layer thickness and turbulence levels in the momentum and thermal boundary layer are needed i.e., the fluctuating velocities and density as a function of radial position ( $u^{\prime}, v^{\prime}$, and $\left.\rho^{\prime}\right)$.

\subsection{Goals of This Work}

No detailed velocity, density, or turbulence profiles have been made in water at critical pressures. In order to progress the development of SCW reactors, 
mechanisms of heat transfer to supercritical fluids need to be further clarified to improve heat transfer calculations. The purpose of this experimental investigation is to develop a set of heat transfer measurements and compare them with selected heat transfer correlations and distinguish which conditions require further analysis. The experimental results will serve as a database to compare existing models and to further understand the physical phenomena so that improved models can be developed. This work is broken down into four tasks:

1. Design and build a facility for prototypic heat transfer to supercritical water with the ability to optically visualize the flow.

2. Perform heat transfer measurements at supercritical pressures in a circular and square annular flow channel at varying conditions. These results are compared with several selected heat transfer correlations and criteria. This information will be used to select conditions in need of further investigation.

The first task is partially simplified due to experience in design, construction, and operation of a similar facility used in studying materials corrosion with water at supercritical pressures.

The second task provides a database of heat transfer measurements at conditions similar to current SCWR designs and allows comparison to previous 
experiments. The conditions of these experiments will provide measurements in three heat transfer regimes (normal, deteriorated, and enhanced). The results of these heat transfer measurements are to be compared with selected heat transfer correlations and criteria to aid in selection of heat transfer conditions for further study with optical measurements. 


\section{Chapter 2 - Background on Heat Transfer to}

\section{Supercritical Pressure Fluids.}

\subsection{Supercritical Water}

For future reference it may be helpful to first have a closer look at the properties of water at and above the critical pressure (Figure 2-1). At pressures and temperatures above the critical point, a pseudo-critical line is formed by the line connecting the maximum of the specific heat for varying pressures. Density, viscosity, and conductivity all drop significantly near the pseudo-critical point, however, the conductivity exhibits a small peak near the critical temperature. For all properties, it can be seen that an increase in pressure results in a reduction in the magnitude of property variation. However, at the proposed pressure of 25 $\mathrm{MPa}\left(\mathrm{T}_{\mathrm{pc}}=385{ }^{\circ} \mathrm{C}\right)$ for SCWR, there still exists a significant property variation. An interesting phenomena called critical opalescence has been found to occur for near critical fluids [50]. Near the pseudo-critical temperature, the molecular randomness cause water to fluctuate between vapor-like and liquid-like volumes. These fluctuations approach a scale of a fraction of a micron, strongly scattering visible light, possibly causing the fluid to appear cloudy. Based on work conducted by Allex [3], this should not restrict optical measurements, since he was able to optically measure density throughout the operating conditions of SCW. 

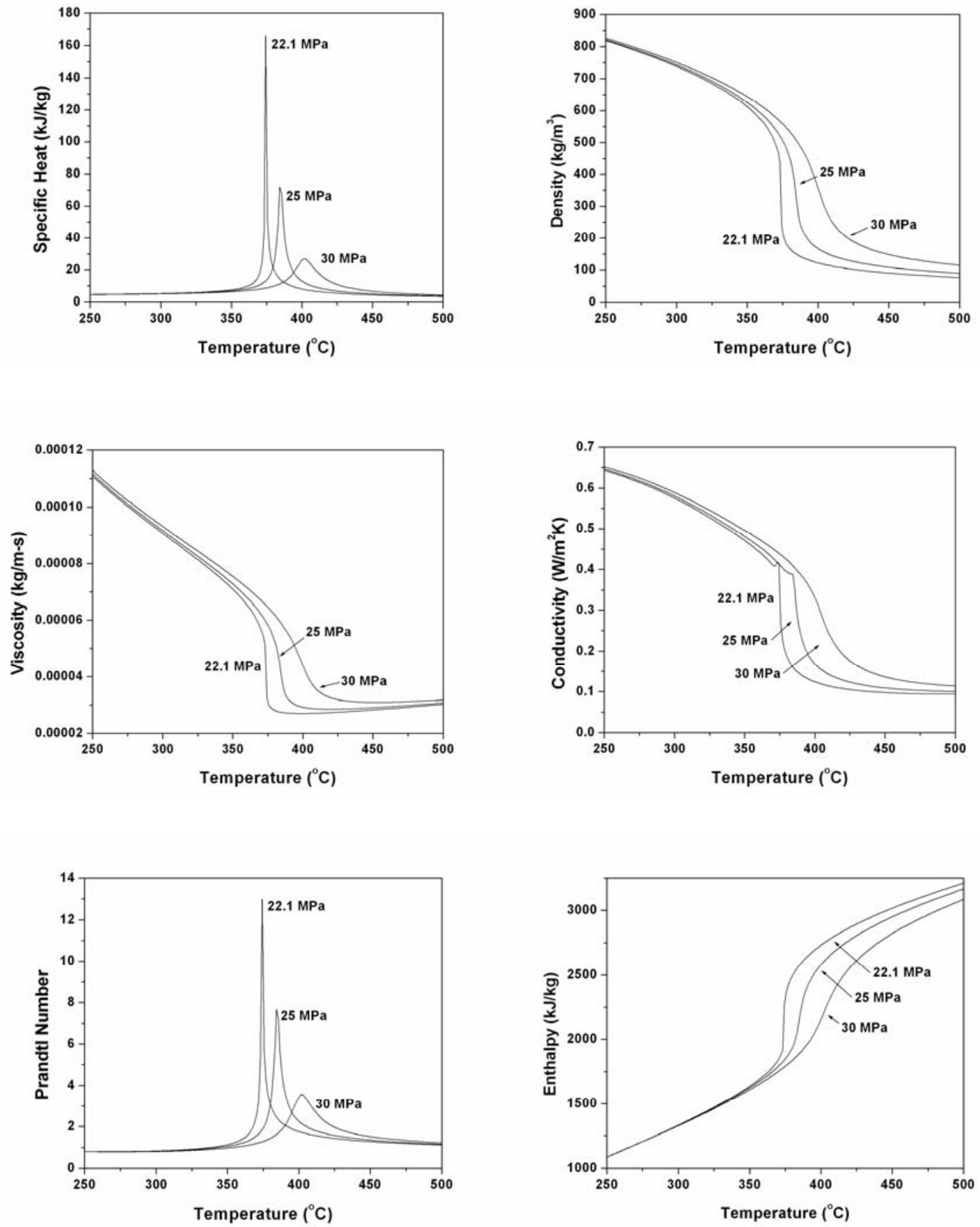

Figure 2-1 Properties of water at various pressures calculated with IAPWS formulae [25]. 


\subsection{Previous Experiments}

There are over 450 papers on the subject of heat transfer to fluids at critical pressures. Recently there have been several literature review papers that summarize previous work [7][37][38][39][40][41]. Pioro et al. [37][38][39] have given the most complete reviews of previous work. They found that there are over 100 papers involving heat transfer to water at critical pressures. Geometries used in previous experiments have included vertical and horizontal tubes, annuli, and bundles. The majority of the experiments have been performed in tubes, where as 5 experiments used annuli and only 2 used bundles.

\subsubsection{Nusselt Correlations}

The correlations that were derived from these studies vary wildly. Of the available pipe correlations, two stand out as best being able to capture the heat transfer in tubes in the absence of buoyancy effects. Jackson's correlation [22], Equation 1, and the Krasnoshchekov et al. correlation [28], Equation 2, has been found to perform best based on 2000 data points with $\mathrm{CO} 2$ (25\% of data) and water $(75 \%$ of data) as the coolant [21]. Each of these correlations has been found to correlate $97 \%$ of the data with an accuracy of $25 \%$. The Jackson correlation is given by:

Equation 1

$$
N u_{b}=0.0183 \operatorname{Re}_{b}^{0.82} \operatorname{Pr}_{b}^{0.5}\left(\frac{\rho_{w}}{\rho_{b}}\right)^{0.3}\left(\frac{-}{c_{p}}\right)^{n}
$$

Where the exponent $n$ is (T in Kelvin): 


$$
\begin{aligned}
& \mathrm{n}=0.4 \text { for } \mathrm{T}_{\mathrm{b}}<\mathrm{T}_{\mathrm{w}}<\mathrm{T}_{\mathrm{pc}} \text { and for } 1.2 \mathrm{~T}_{\mathrm{pc}}<\mathrm{T}_{\mathrm{b}}<\mathrm{T}_{\mathrm{w}} ; \\
& \mathrm{n}=0.4+0.2\left(\frac{T_{w}}{T_{p c}}-1\right) \text { for } \mathrm{T}_{\mathrm{b}}<\mathrm{T}_{\mathrm{w}}<\mathrm{T}_{\mathrm{pc}} ; \\
& \mathrm{n}=0.4+0.2\left(\frac{T_{w}}{T_{p c}}-1\right)\left[1-5\left(\frac{T_{b}}{T_{p c}}-1\right)\right] \text { for } \mathrm{T}_{\mathrm{pc}}<\mathrm{T}_{\mathrm{b}}<1.2 \mathrm{~T}_{\mathrm{pc}}
\end{aligned}
$$

The Krasnoschekov et al. correlation is given by:

Equation 2

$$
N u_{b}=N u_{o}\left(\frac{\rho_{w}}{\rho_{b}}\right)^{0.3}\left(\frac{-}{c_{p}}\right)^{n}
$$

$N u_{o}$ is given by:

$$
\begin{aligned}
& N u_{o}=\frac{(\xi / 8) \operatorname{Re}_{b} \overline{\operatorname{Pr}}}{12.7 \sqrt{\xi / 8}\left(\overline{\operatorname{Pr}}^{2 / 3}-1\right)+1.07} ; \\
& \xi=1 /\left(1.82 \log _{10} \operatorname{Re}_{b}-1.64\right)^{2} .
\end{aligned}
$$

Where the exponent $n$ is (T in Kelvin):

$$
\begin{aligned}
& n=0.4 \text { for }\left(T_{w} / T_{p c}\right) \leq 1 \text { or }\left(T_{b} / T_{p c}\right) \geq 1.2 ; \\
& n=n 1=0.22+0.18\left(T_{w} / T_{p c}\right) \text { for } 1 \leq\left(T_{w} / T_{p c}\right) \leq 2.5 ; \text { and } \\
& n=n 1+(5 n 1-2)\left(1-\left(T_{b} / T_{p c}\right)\right) \text { for } 1 \leq\left(T_{b} / T_{p c}\right) \leq 1.2 .
\end{aligned}
$$

A particularly interesting correlation, which has gained some recent attention in work performed by Komita et al. [27], was developed by Watts et al. [51]. This correlation is interesting in that it takes advantage of Jackson's buoyancy criteria (to be discussed later). The Watts correlation for normal heat transfer is given by: 
Equation 3

$$
\begin{aligned}
& N u=N u_{\operatorname{var} P}\left[1-\frac{3000 \overline{G r}_{b}}{\operatorname{Re}_{b}^{2.7} \cdot \overline{\operatorname{Pr}}_{b}^{0.5}}\right]^{0.295} \text { for } \frac{\overline{G r}_{b}}{\left(\operatorname{Re}_{b}^{2.7} \cdot \overline{\operatorname{Pr}}_{b}^{0.5}\right)}<10^{-4} \text { and } \\
& N u=N u_{\operatorname{var} P}\left[\frac{7000 \overline{G r}_{b}}{\operatorname{Re}_{b}^{2.7} \cdot \overline{\operatorname{Pr}}_{b}^{0.5}}\right]^{0.295} \text { for } \frac{\overline{G r}_{b}}{\left(\operatorname{Re}_{b}^{2.7} \cdot \overline{\operatorname{Pr}}_{b}^{0.5}\right)}>10^{-4}
\end{aligned}
$$

Where

$$
N u_{\mathrm{var} P}=0.021 \operatorname{Re}_{b}^{0.8} \cdot \overline{\operatorname{Pr}}_{b}^{0.55}\left(\frac{\rho_{w}}{\rho_{b}}\right)^{0.35}
$$

Although these correlations have been found to work reasonably well in the absence of heat transfer deterioration, some SCWR design and analysis work has included the simpler, less accurate Dittus-Boelter correlation [9]:

$$
\begin{aligned}
& \text { Equation } 4 \quad N u_{D B, f}=0.023 \operatorname{Re}_{f}^{0.8} \operatorname{Pr}_{f}^{0.4}
\end{aligned}
$$

\subsubsection{Enhancement}

Supercritical heat transfer experiments performed at relatively high mass velocities and low heat flux have been found to exhibit an enhancement in heat transfer. Increasing the heat flux from low to high heat flux has been found to

\begin{tabular}{|c|c|c|c|c|c|}
\hline Case & $\begin{array}{l}\text { Mass Velocity } \\
\left(\mathrm{kg} / \mathrm{m}^{2} \mathrm{~s}\right)\end{array}$ & $\begin{array}{l}\text { Heat Flux } \\
\left(\mathrm{kW} / \mathrm{m}^{2}\right)\end{array}$ & $\begin{array}{c}\text { Pressure } \\
\text { (MPa) }\end{array}$ & $\begin{array}{c}\text { Tube Diameter } \\
(\mathrm{mm})\end{array}$ & Key notes \\
\hline 1 & \multirow{4}{*}{1260} & 230 & \multirow{4}{*}{24.5} & \multirow{4}{*}{7.5} & \multirow{4}{*}{$\begin{array}{l}\text {-High mass } \\
\text { velocity } \\
\text {-Low to high } \\
\text { heat flux }\end{array}$} \\
\hline 2 & & 465 & & & \\
\hline 3 & & 698 & & & \\
\hline 4 & & 933 & & & \\
\hline
\end{tabular}
impair enhanced heat transfer. These characteristics in heat transfer have best been observed in experiments performed by Yamagata et al. (Figure 1-3,Table 2).

Table 2 Experimental parameters of Yamagata et al. 
Heat transfer correlations have been developed that adequately capture this type of heat transfer. This has been accomplished by modifying typical heat transfer correlations like Dittus-Boelter and multiplying them by property ratios evaluated at the wall and the bulk and raising this to a suitable power. A literature review on this subject has been performed by Pioro [39]. In general, CFD codes and some Nusselt correlations are in reasonable agreement with these experiments (Figure 2-2).

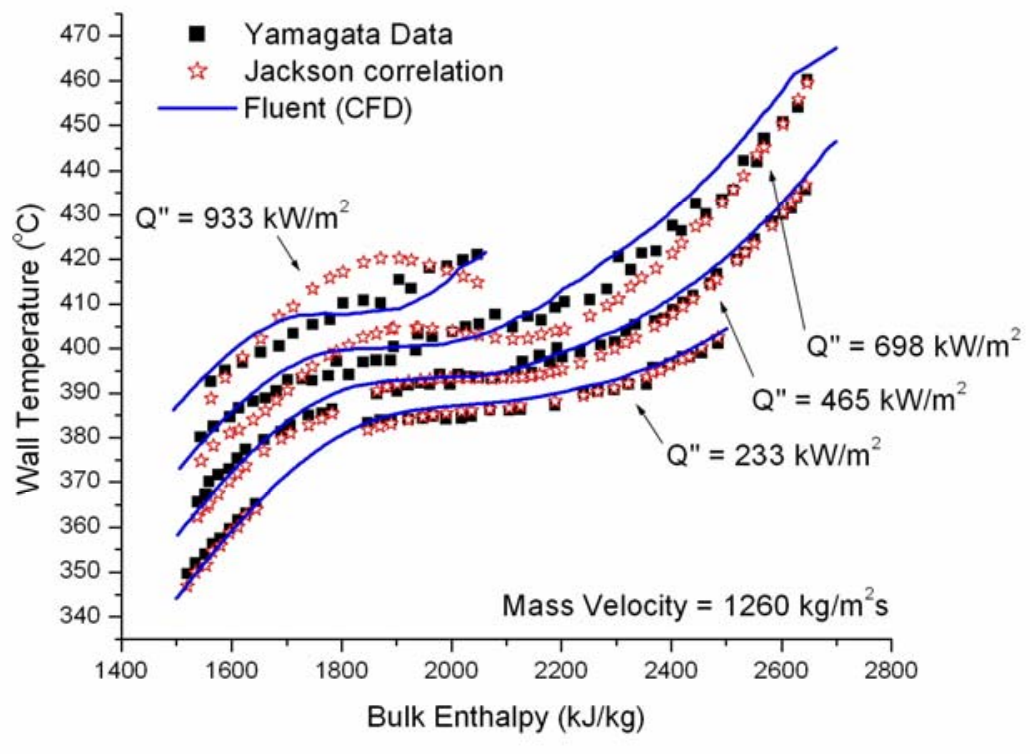

Figure 2-2 Comparison of CFD code [44] and Jackson Correlation [22] with data obtained by Yamagata et al.

\subsubsection{Buoyancy Influenced Deterioration}

A significant amount of work on buoyancy influenced heat transfer has been produced over the last four decades and is summarized by Jackson [24]. Experiments have shown that the buoyancy effects are not limited to supercritical 
pressure fluids and can be seen, for example, in heat transfer to water and air at atmospheric pressure, however, in a less dramatic form due to the smaller variation in properties as compared to supercritical fluids. Experiments have included both buoyancy aided flow (upward flow) and buoyancy opposed (downward flow) conditions. The fact that deterioration in heat transfer is due to buoyancy was shown by work carried out by Jackson et al. They demonstrated that conditions which caused deteriorated heat transfer in upward flow, led to enhanced heat transfer in downward flow, suggesting buoyancy effects (Figure 2-3).

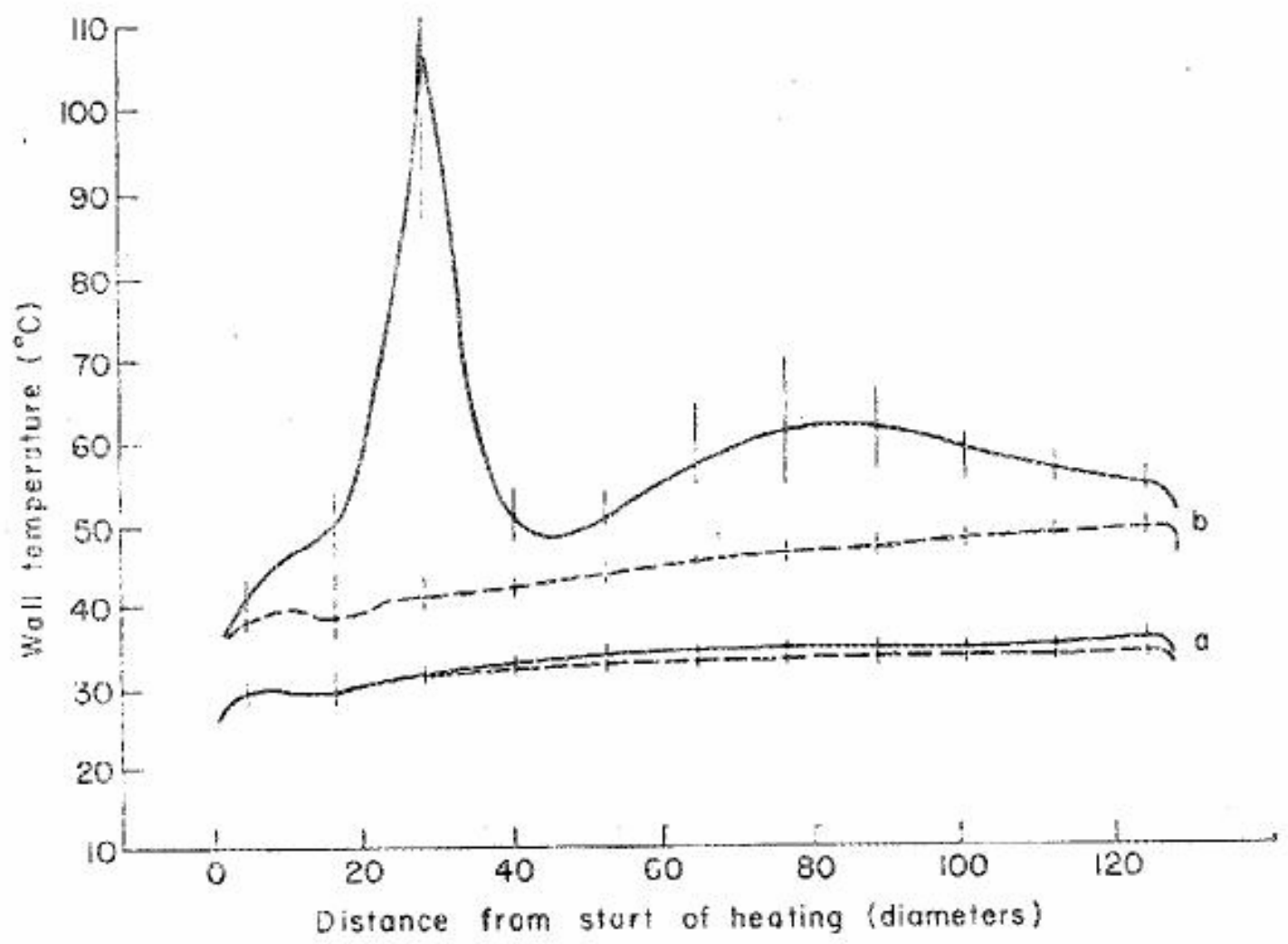

Figure 2-3 Comparison of wall temperature at two heat flux cases (a: $31 \mathrm{~kW} / \mathrm{m}^{2}, \mathrm{~b}: 57$ $\mathrm{kW} / \mathrm{m}^{2}$ ) for $\mathrm{CO} 2$ with upward and downward flow (solid and dashed line, respectively). 
Velocity measurements have been taken for buoyancy influenced heat transfer to low-pressure fluids has shown how the mean values are altered. For buoyancy aided flow, the peak in velocity becomes skewed towards the heated wall, whereas for downward, the near wall velocity becomes lower. Turbulence measurements verified the turbulence production was changing in a manner that effected the turbulent diffusion of heat.

The deterioration in heat transfer has been observed at conditions of a relatively low mass velocity at low to moderate heat fluxes. Increasing the heat flux to even modest values can cause a severe reduction in heat transfer (Figure 1-4, Table 3). This effect has not yet been adequately captured with any CFD method (Figure 2-4).

\begin{tabular}{|c|c|c|c|c|c|c|}
\hline Case & $\begin{array}{c}\text { Mass } \\
\text { Velocity } \\
\text { (kg/m2s) }\end{array}$ & $\begin{array}{l}\text { Heat Flux } \\
(\mathrm{kW} / \mathrm{m} 2)\end{array}$ & $\begin{array}{c}\text { Pressure } \\
(\mathrm{MPa})\end{array}$ & $\begin{array}{c}\text { Tube } \\
\text { Diameter } \\
\text { (mm) }\end{array}$ & Deterioration & Key notes \\
\hline 5 & \multirow{5}{*}{430} & 210 & \multirow{5}{*}{23.3} & \multirow{5}{*}{8} & no & \multirow{5}{*}{$\begin{array}{c}\text {-low mass } \\
\text { velocity } \\
\text {-low heat } \\
\text { flux }\end{array}$} \\
\hline 6 & & 281 & & & maybe & \\
\hline 7 & & 300 & & & yes & \\
\hline 8 & & 337 & & & yes & \\
\hline 9 & & 386 & & & yes & \\
\hline
\end{tabular}

Table 3 Experimental parameters of Shitsman. 


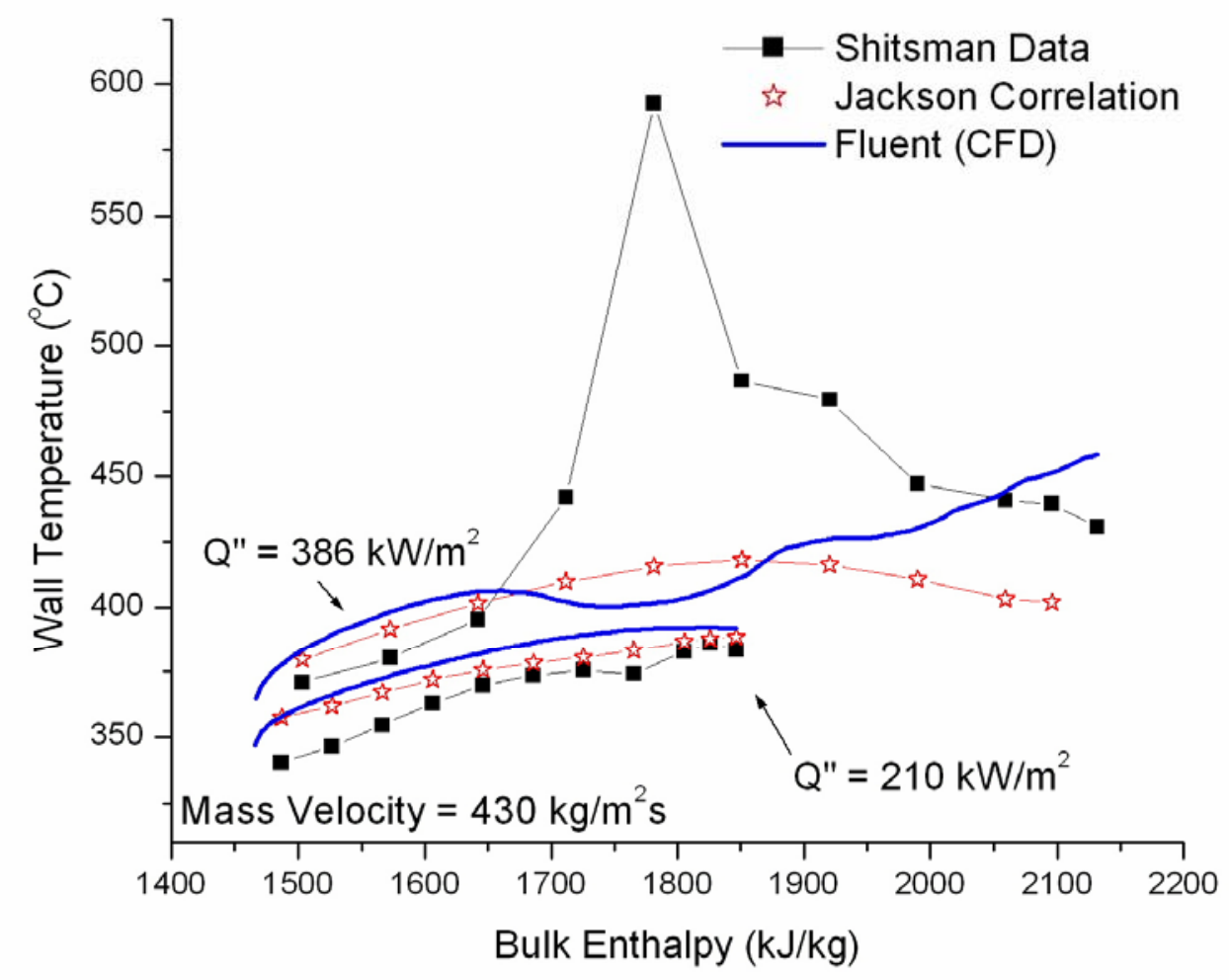

Figure 2-4 CFD and Nusselt correlation in comparison to Shitsman experiment.

\subsubsection{Deterioration due to acceleration}

Unlike buoyancy-influenced deterioration, deterioration due to acceleration occurs only with supercritical fluids. The reason for this is need for large variation in properties to achieve large differences in inlet and exit densities. Additionally, deterioration is present for both upward and downward flows. However, like buoyancy-influenced deterioration, CFD calculations have not been able to capture acceleration effects. There has not been much work beyond typical integral heat transfer measurements, like there has been for buoyancy-influenced flow. This is likely due geometry limitations. In order to 
achieve a large density difference between the inlet and exit, a small hydraulic diameter is needed, however, velocity measurements may require the use of a larger hydraulic diameter.

\subsection{Deterioration Criteria}

Due to the inability of heat transfer correlations (Equation 1 - Equation 4) to accurately capture heat transfer deterioration, investigators have tried to develop criterion to predict weather or not it will occur for a given experimental condition.

Initially, investigators defined deterioration with a heat flux to mass velocity ratio such as:

Equation $5 \quad Q^{\prime \prime} / G^{<c o n s} \tan t$

However, these equations were only valid for a particular experiment since the constant was different for each geometry. Yamagata et al. developed a criterion that appeared to work better (Equation 6).

Equation 6

$$
Q^{\prime \prime} / G^{1.2}<0.2
$$

A comparison of Yamagata's correlation with data from Shitsman and Yamagata shows good agreement for the prediction of deterioration. However, the downfall to this equation is that it has no temperature dependence. This means that this deterioration in heat transfer would occur at any bulk temperature. If this heat transfer deterioration were to be a buoyancy effect this cannot be true since, for 
example, at bulk temperatures above and well below the pseudo-critical temperature there wouldn't be a large density difference to drive the buoyancy.

Jackson and Hall [20][21][23] developed the most accurate criteria derived from simple boundary layer theory. The results of the derivation showed that two additional components to the shear stress could be found when considering supercritical fluids; one due to buoyancy and the second due to acceleration. The buoyancy criterion is given here (Equation 7).

Equation 7

$$
\overline{G r} b / \operatorname{Re}_{b}^{2.7}<10^{-5}
$$

While Equation 7 has been found to work well, it is difficult to use from an experimental design standpoint. Seo et al. [43] recently developed a criterion based on the Froude number (Equation 8), which can be defined as the ratio of inertial forces to buoyant forces.

Equation 8

$$
\frac{1}{\mathrm{Fr}} \approx \frac{1}{\rho_{\mathrm{b}}} \frac{\rho_{b}-\rho_{s}}{T_{S}-T_{b}} \frac{\mathrm{Q}^{\prime \prime} \mathrm{D}_{\mathrm{H}}}{\mathrm{k}_{\mathrm{s}}} \frac{\mathrm{gD}_{\mathrm{H}}^{3}}{v_{\mathrm{s}}^{2}} \frac{1}{\mathrm{Re}_{\mathrm{s}}^{2.8} \mathrm{Nu}}<0.03
$$

Here, the properties are evaluated at a film temperature based on the inlet and pseudo-critical temperatures and the only other inputs are geometry, heat flux, and mass velocity. The fact that the inputs to this equation are based on known variables makes this equation easy to use in development of an experiment. It should be noted that this equation has not been adequately tested. Comparison with data of Shitsman and Yamagata et al. suggests that an inverse Froude number less than 0.03 is needed for negligible buoyancy effects [43]. 


\section{Chapter 3 - Heat Transfer Facility}

\subsection{Brief Overview}

The UW has built a SCW heat transfer facility to allow for a detailed study of heat transfer to SCW in a circular and square annular geometry. The loop (Figure 3-1) has dimensions of approximately $2 \mathrm{~m}$ wide by $3 \mathrm{~m}$ tall and is made of 4.29 $\mathrm{cm}$ inner diameter Inconel 625 piping. A $3.3 \mathrm{~m}$ long heater rod with a diameter of $1.07 \mathrm{~cm}$ spans the entire right leg of the loop and protrudes out both ends. This design permits the use of 16 thermocouples evenly spaced along the inner cladding of the $1.01 \mathrm{~m}$ heated length. The center portion of the right leg of the loop serves as the test section, allowing a $76 \mathrm{~cm}$ entrance length for both upward and downward flow studies. The circular annular test section geometry is a 1.07 $\mathrm{cm}$ diameter heater rod within a $4.29 \mathrm{~cm}$ diameter flow channel. The square annular test section geometry is a $1.07 \mathrm{~cm}$ diameter heater rod within a $2.88 \mathrm{~cm}$ wide flow channel. The heater is centered within the flow channel with six spacers; four of which are located on either side of the tees and two that are 5 $\mathrm{cm}$ from either end of the heated section. The heater can generate up to $50 \mathrm{~kW}$, giving a maximum heat flux of $1.5 \mathrm{MW} / \mathrm{m}^{2}$. A pump capable of operating at supercritical conditions generates mass velocities in the range of 200 to 2000 $\mathrm{kg} / \mathrm{m}^{2} \mathrm{~s}$. The current configuration is up-flow, however the facility was designed for flows in either direction with only minor modification. The facility is capable of operating at any steady state heat flux condition by using a variable heat removal system made up of copper cooling coils. Eight copper coils of various contact 
area are tightly wrapped to the Inconel piping. Heat removal by the cooling coils can be set to match that supplied by the heater by simply controlling the number of coils receiving cooling water and controlling their respective flow rates.

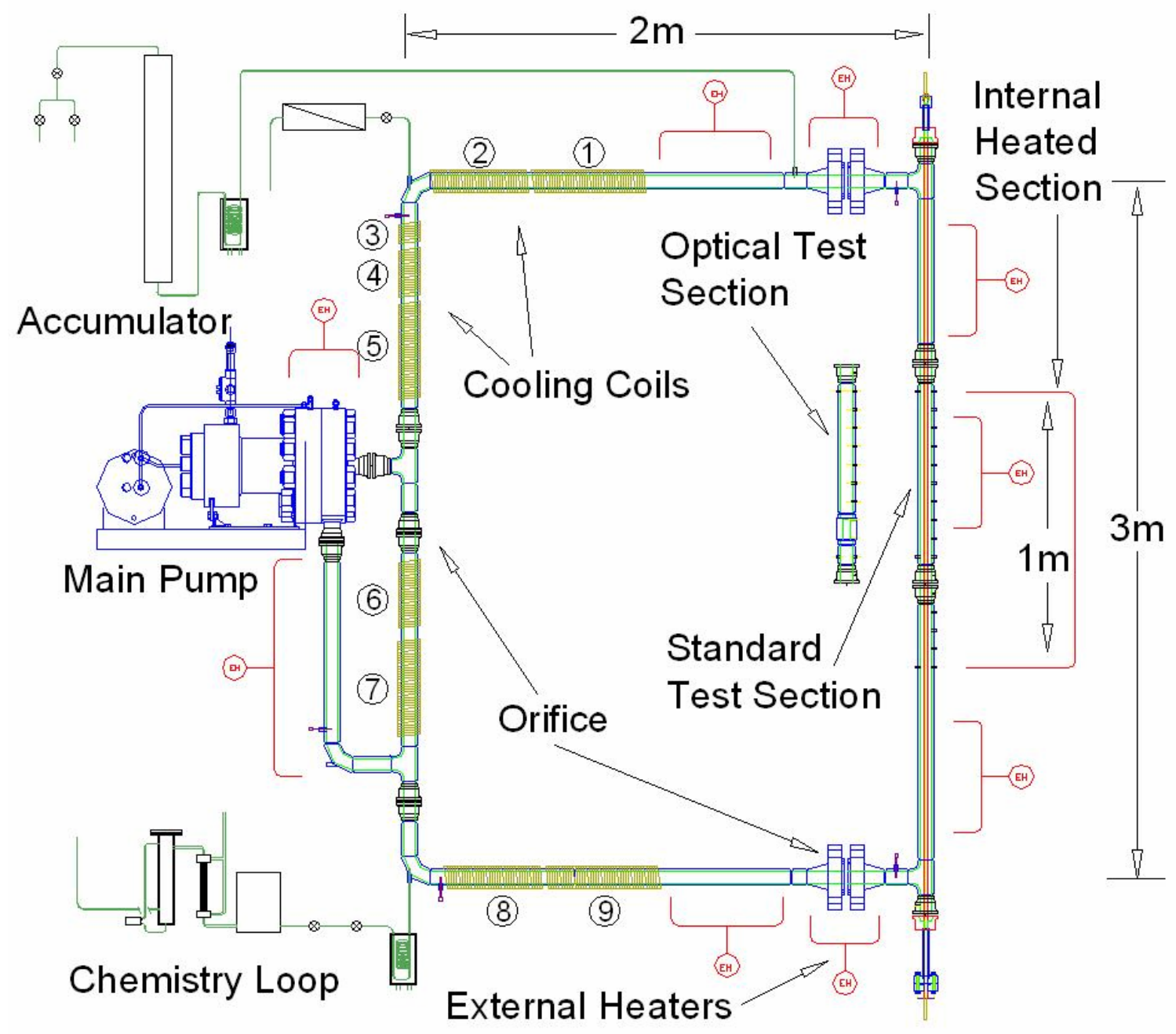

Figure 3-1 Heat transfer loop.

\subsection{Facility}

The UW SCW heat transfer facility is located in an underground laboratory at the UW's Tantalus laboratory due to safety issues associated with the high temperature and pressure. All materials operated at supercritical temperatures 
and pressures are made of Inconel 625. The main loop piping has a inner and outer diameter of $4.29 \mathrm{~cm}$ and $6.03 \mathrm{~cm}$, respectively (2" schedule 160). Pipe connections are made with either Grayloc fittings or standard 2500 pound flanges. The loop stands 3 meters tall by 2 meters wide and is enclosed within concrete barriers. The loop itself is fixed in position at the location of the pump, while the rest of the loop is attached to a steel structure with springs to allow for thermal expansion (Appendix C - Facility Layout).

\subsection{Preliminary Design Criteria}

In order to design an experiment for heat transfer to SCW, there needs to be some initial idea as to what conditions will exhibit enhancement and deterioration. The general Froude number criterion was applied to the predetermined geometry of our experiment in order to find the temperature, mass velocity, and heat flux that would produce deterioration. Using a Froude number of 0.03 , a 3 dimensional plot of the three variables was produced (Figure 3-2). Operating conditions that result in a location above the plane, i.e. $1 / \mathrm{Fr} \ll 1$, indicate that buoyancy effects will be negligible. Conditions below this plane, i.e. $1 / \mathrm{Fr}>>1$, will result in buoyancy effected flow. 


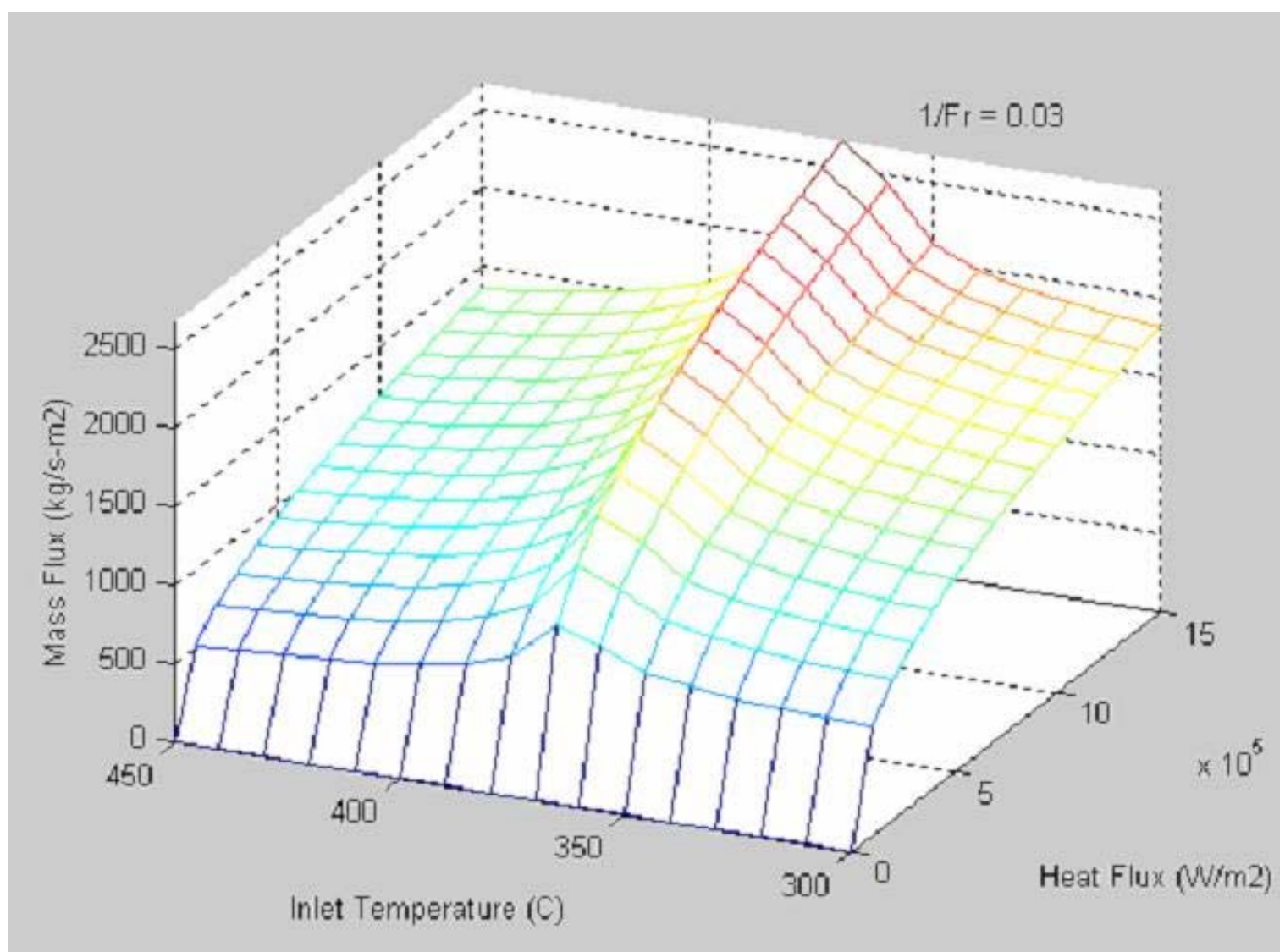

Figure 3-2 Expected deterioration region based on the Froude criterion.

\subsection{Main Pump}

A Chempump brand impeller pump (model GCT-5k 36I) (Figure 3-3) is capable of operating at SCW conditions (3600 PSI at $593{ }^{\circ} \mathrm{C}$ ). The materials for pressureretaining parts are made of Inconel (ASTM B--564, UNS N06600). The pump has a $12.7 \mathrm{~cm}(5 \mathrm{in})$ impeller powered by a $5.9 \mathrm{~kW}$ motor with spike-resistant motor windings, which allow for a variable-frequency drive. The pump is driven with a VLT 5000 series frequency inverter. The pump has a maximum flow rate of $41 \mathrm{~m}^{3} \mathrm{hr}(180 \mathrm{GPM})$. 


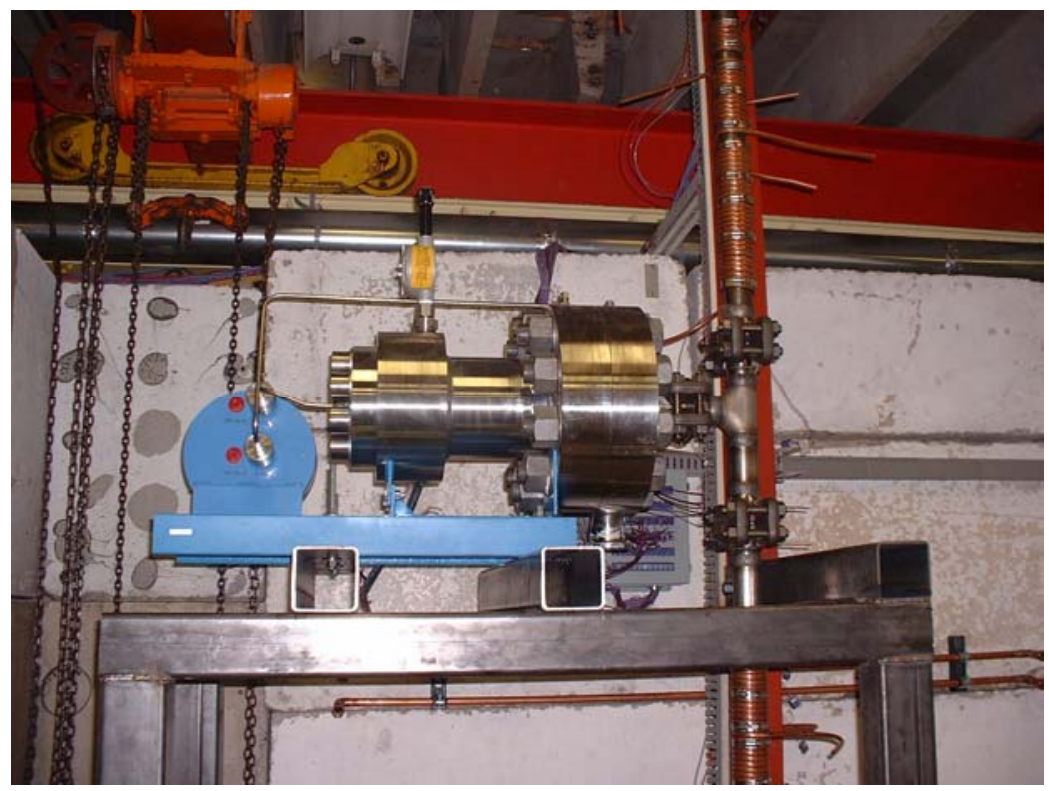

Figure 3-3 Main SCW pump.

The experiment was designed for both upward and downward flow through the test section (Figure 3-4). In the upward flow configuration, as shown in Figure 3-1, flow is discharged from the pump head in a downward direction. At the tee, the flow splits to go upward through the re-circulation leg, and downward through the test section leg. This split in flow is needed to cover the wide range of flow rates. Reversed flow is achieved by rotating the pump head and recirculation leg 180 degrees. The pump stand was designed to easily accommodate either configuration. Flow rates in both the recirculation and test section leg are regulated with orifice plates and a frequency inverter. ASME piping specs were followed for proper upstream lengths, downstream lengths, and pressure tap locations, however, required flange and orifice plate designs could not be followed due to costs. Chapter 4.3 Evaluation of the Mass Flux discusses the details of the orifice design and the results of the calibration test. The 
achievable mass flux range through the test section at 3450 RPM as function of temperature is shown in Figure 3-5.
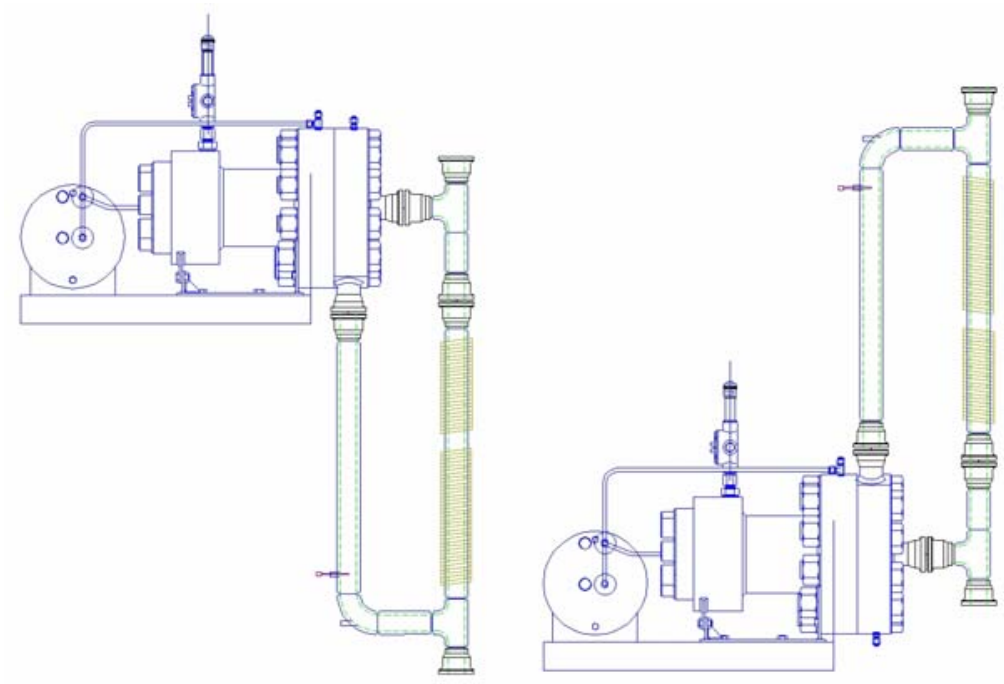

Figure 3-4 Orientation of pump head and recirculation leg for upward and downward flow.

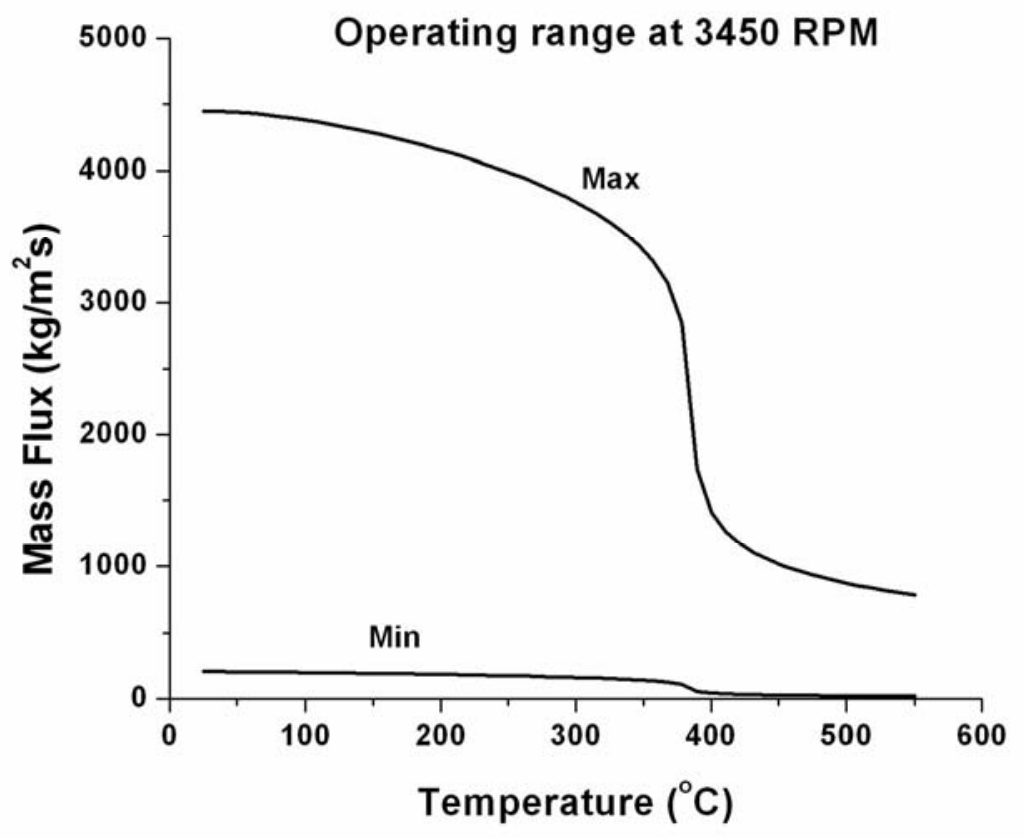

Figure 3-5 Achievable mass velocity range. 


\subsection{Temperature Control System}

The temperature control system consists of both external heating and cooling.

Twenty $1.3 \mathrm{~kW}$ external wrap heaters (model AWH-102-080D) $2.54 \mathrm{~cm}(1 \mathrm{in})$ in width and $2.44 \mathrm{~m}$ (8 feet) in length are tightly wrapped to the Inconel piping and controlled with LabVIEW ${ }^{\mathrm{TM}}$. These wrap heaters serve to bring the bulk fluid to operating temperatures and to maintain steady state conditions. The cooling system can only operate at discrete power removal rates, so external wrap heaters are used to match cooling and heating powers.

The Cooling system was designed to be able to remove $2 / 3$ rds of the 50 $\mathrm{kW}$ power input at $300{ }^{\circ} \mathrm{C}$ and $25 \mathrm{MPa}$. Building water is passed through two parallel water filters before entering the facilities cooling system. A Dayton booster pump (model 4YC12) is used to boost the pressure to 6.89 bar (100 PSI) giving a 30 GPM flow rate through the cooling system. An overpressure safety valve prevents against excessive pressure by redirecting flow to the building drain. The pump feeds water to the distribution manifold (Figure 3-6). The distribution manifold has thirteen discharge lines (one of which is a bypass line), of which each uses a globe valve to control flow and a flow meter (0-4 GPM) to monitor flow. The return distribution manifold empties to the building drain. 


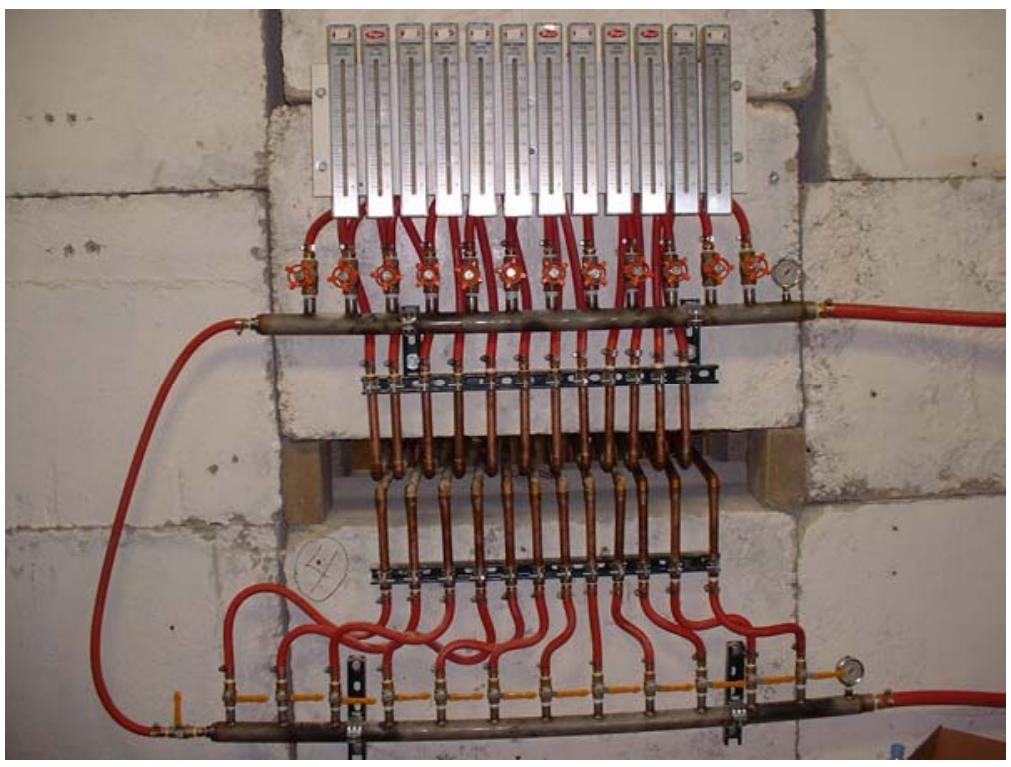

Figure 3-6 Distribution manifold.

Twelve (feed and return) $1.9 \mathrm{~cm}$ (3/4 in) copper feed tubes provide cooling water for various applications (Main pump cooling, Chemistry line and Accumulator cooling baths, Aspirator, and copper cooling coils) (Figure 3-7). Twenty-four custom-made grounded E-type thermocouples provide bulk coolant temperatures for both feed and return lines to monitor heat removal. Main pump cooling, cooling baths, and aspirator transmission lines are also $1.9 \mathrm{~cm}(3 / 4 \mathrm{in})$ copper tubing. Main copper cooling coil transmission lines are $9.5 \mathrm{~mm}$ (3/8 in) soft copper tubing. 


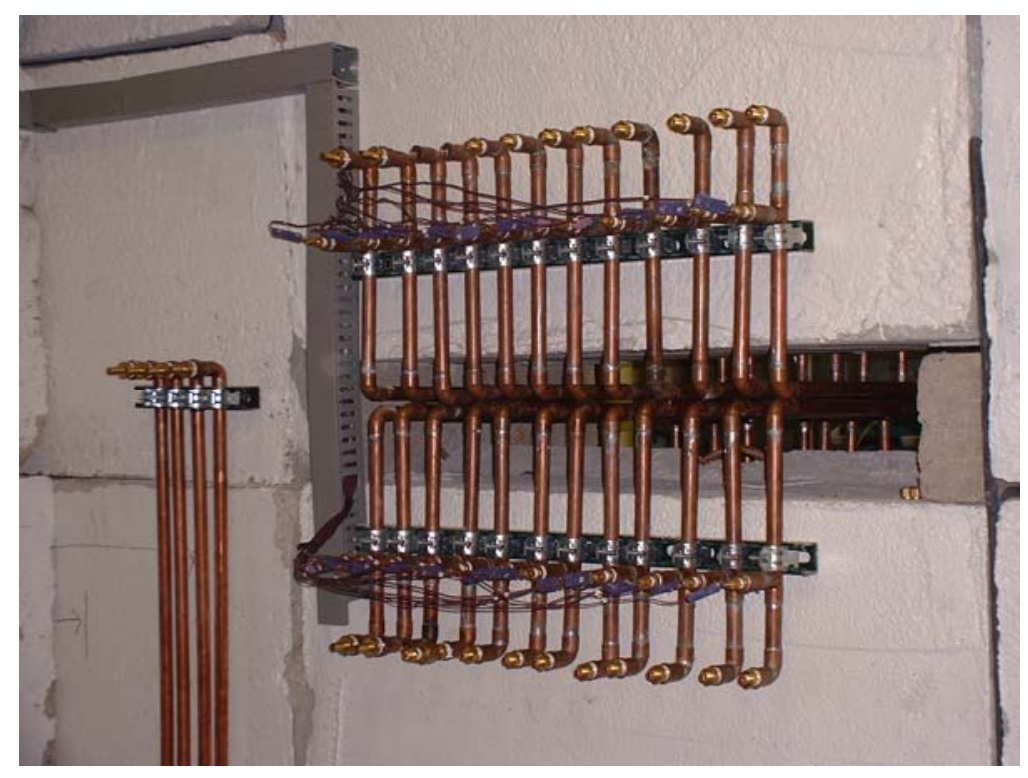

Figure 3-7 Cooling supply lines.

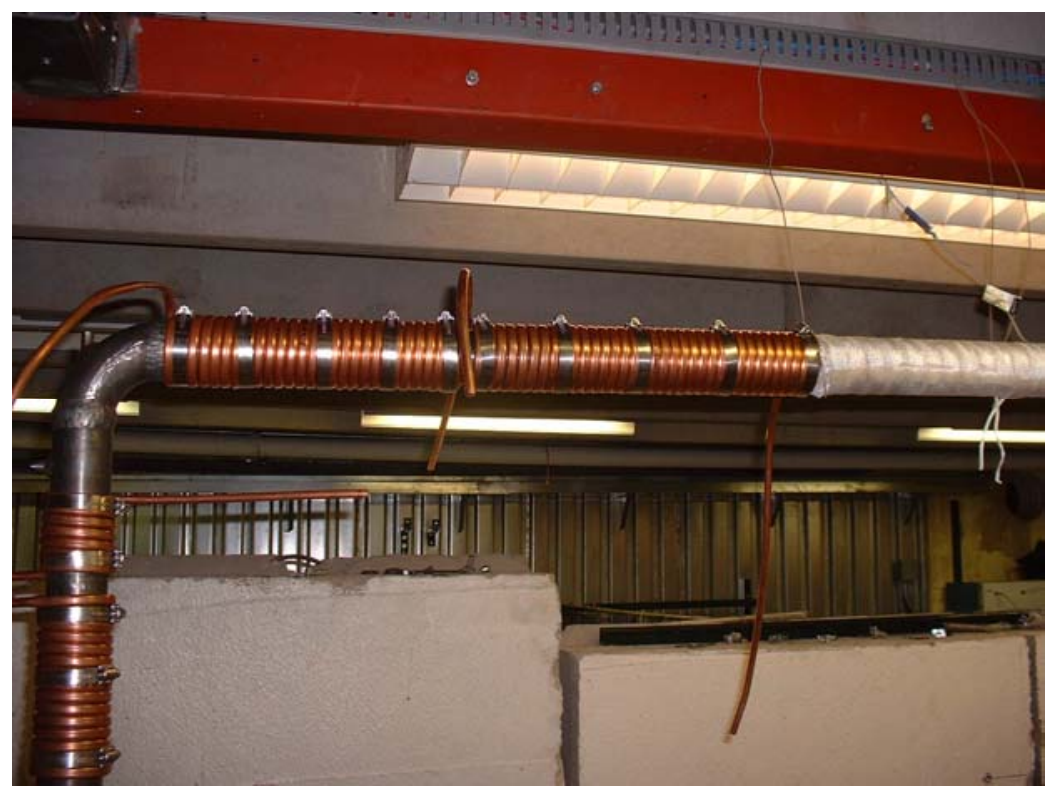

Figure 3-8 Cooling coils.

Main copper cooling coils are made from 3/8" soft copper tubing (Figure 3-8). Enhanced thermal contact between the soft copper tubing and Inconel 625 piping was achieved by running the copper tubing through a roller to create a flattened edge. Hose clamps are also used to further compress the copper coils onto the 
Inconel piping. Nine total cooling coils were used and configured as shown in Figure 3-1. Two sets of cooling coils were combined to form cooler 1 and cooler 7. Flow rates through each of the cooling lines averages about 2 GPM. Additional cooling is supplied to the main pump at 3 GPM, cooling baths at 3 GPM, aspirator at 1.5 GPM, and heater rod pressure boundaries at $1 \mathrm{GPM}$ each.

\subsection{Heater Rod}

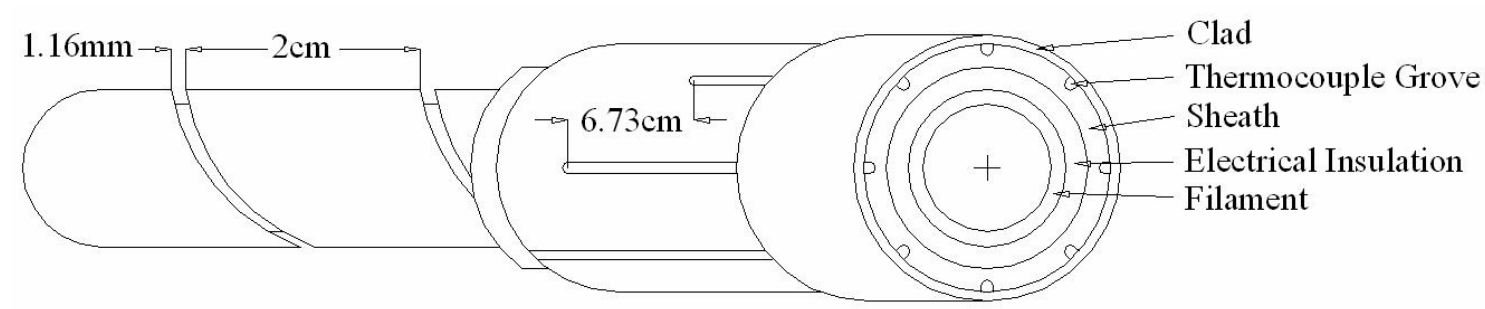

Figure 3-9 Heater schematic.

\begin{tabular}{|c|c|c|c|}
\hline Heater Description & Materials & \multicolumn{2}{|c|}{ (I.D.) Dimensions (mm) (O.D.) } \\
\hline Filament & Monel K500 & 5.13 & 6.325 \\
\hline Electric Insulation & Boron Nitride & 6.325 & 8.076 \\
\hline Sheath & Inconel 600 & 8.076 & 9.93 \\
\hline Clad & Inconel 600 & 9.93 & $10.725 \pm 0.019$ \\
\hline Thermocouple Clad & Inconel 600 & $0.374(\mathrm{~min})$ & 0.526 \\
\hline Thermocouple filler & Boron Nitride & & 0.1 \\
\hline Thermocouple Wire & K-type & & $0.076-0.127$ \\
\hline Approx. Wire Junction & K-type & & \\
\hline
\end{tabular}

Table 4 Heater component dimensions and materials.

The heater design is based on that of a typical fuel pin and was made by Stern Laboratories (Figure 3-9). Relevant dimensions and materials are listed in Table 4. The heater has a diameter of $1.07 \mathrm{~cm}$ with a heated length of $1.01 \mathrm{~m}$ and an overall length of about $3.3 \mathrm{~m}$. It was designed to produce a maximum heat flux of $1500 \mathrm{~kW} / \mathrm{m}^{2}$ (50.4 kW total power), which is slightly higher than that expected under transient conditions in either fossil or nuclear power designs. Heater 
power is supplied by a Miller Thermal Inc. DC power supply providing variable control up to 600 amps and 95 volts. Current is monitored with a 1000 Amp 100 $\mathrm{mV}$ shunt. Heat is generated by a ribbon shaped filament cut from Monel K-500 tubing. The filament is electrically insulated from its environment with boron nitride. The filament and insulation are enclosed within a two-piece cladding consisting of an inner sheath and outer wall cladding, both made of Inconel 600 . Inconel 600 was chosen due to its corrosion resistance and similarity to Inconel 625. The outer diameter of the sheath contains axial grooves that contain the thermocouple wire (Figure 3-10a). The heater contains 16 thermocouples equally spaced (every $66.67 \mathrm{~mm}$ ) axially along the heated section between the cladding and the sheath. The thermocouple wire itself has a cladding made of Inconel 600 , which surrounds a boron nitride insulation that encloses the thermocouple leads (Figure 3-10b).

\begin{tabular}{|c|c|l|c|c|}
\hline TC & $\mathrm{x}[\mathrm{mm}]$ & & TC & $\mathrm{x}[\mathrm{mm}]$ \\
\hline 1 & 0 & & 16 & 1010 \\
\hline 2 & 67.33 & & 15 & 942.67 \\
\hline 3 & 134.66 & & 14 & 875.34 \\
\hline 4 & 201.99 & & 13 & 808.01 \\
\hline 5 & 269.32 & & 12 & 740.68 \\
\hline 6 & 336.65 & & 11 & 673.35 \\
\hline 7 & 403.98 & & 10 & 606.02 \\
\hline 8 & 471.31 & & 9 & 538.69 \\
\hline
\end{tabular}

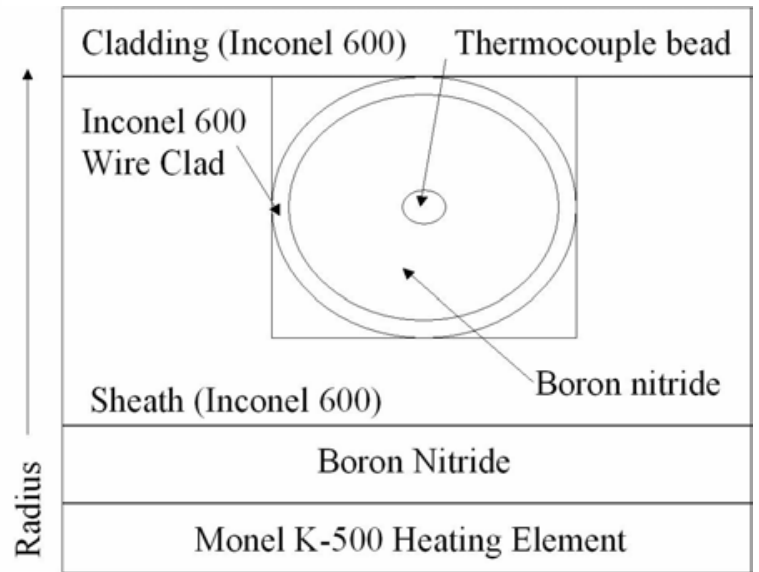

Figure 3-10

(a) Thermocouple grooves of the unrolled sheath. (b) Cartoon of the radial components of the heater (not to scale). 
The use of 16 thermocouples requires that thermocouple wires exit out both ends of the heater (Eight out each end). Thermal expansion issues require that one end of the heater is fixed in place while the other end is allowed to slide with respect to the piping. In the configuration shown in Figure 3-1, the top heater rod pressure boundary is fixed (Figure 3-11). This is accomplished by first reducing the pipe diameter (1/2 in schedule 160) and cooling the fluid with a cooper coiling coil. An end mounted through bolt compresses a washer, which in turn compresses graphite into the heater rod and fitting wall, effectively forming a fixed pressure barrier (it should be noted that while graphite is rated for 10,000 PSI and $1000{ }^{\circ} \mathrm{C}$, it is not compatible with SCW). Detailed drawings can be found in Appendix B - Heater End Dimensions.

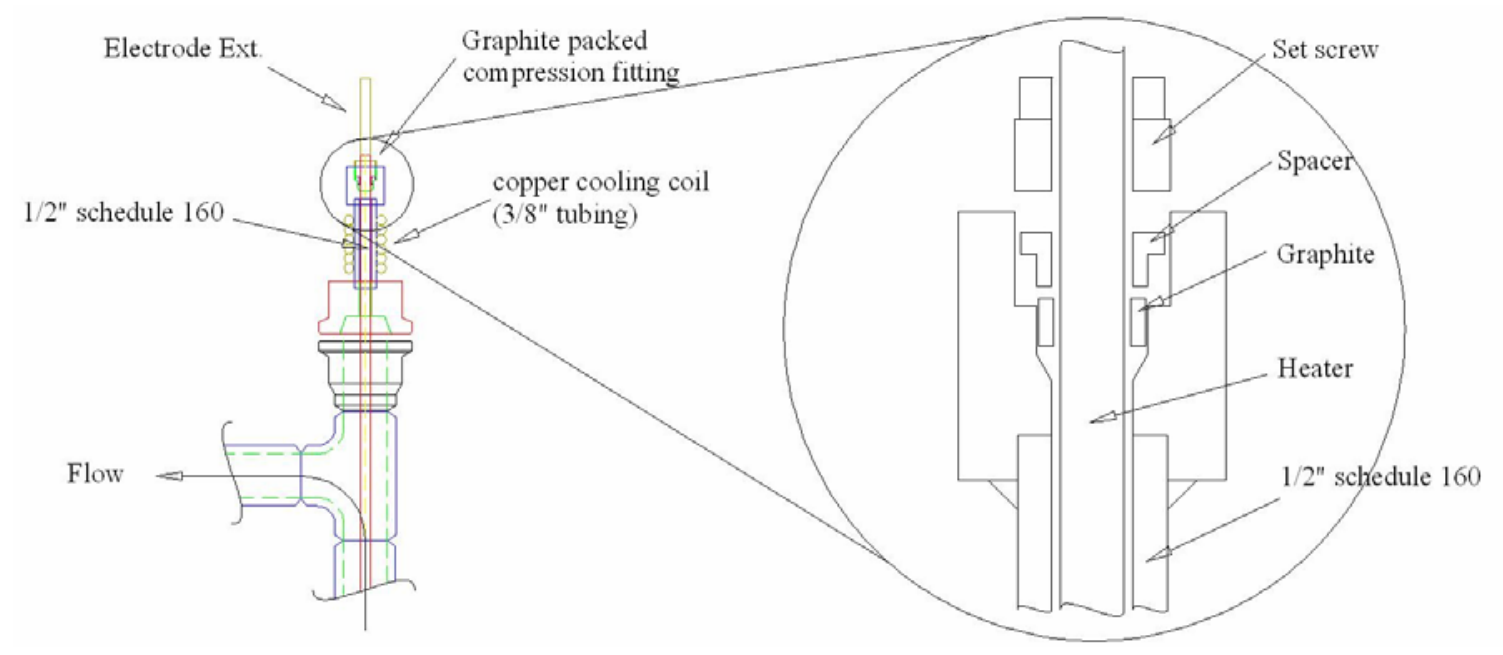

Figure 3-11 Pressure boundary holding heater in a fixed position.

The bottom heater rod pressure boundary allows the heater to move with respect to the loop while maintaining a pressure boundary (Figure 3-12). This is accomplished again by first reducing the pipe diameter (1/2 in schedule 160) and cooling the fluid with a cooper coiling coil. A set of O-rings within a flange where 
selected and designed based on a static seal following the Parker O-ring handbook [42]. A PTFE O-ring (AS568A-905) is used to form a seal between the flange faces. A Viton O-ring (AS568A-012) and a urethane Backup-ring (U1002013, 90D hardness) are used to form a seal between the flange and the heater rod. Details can be found in Appendix B - Heater End Dimensions.

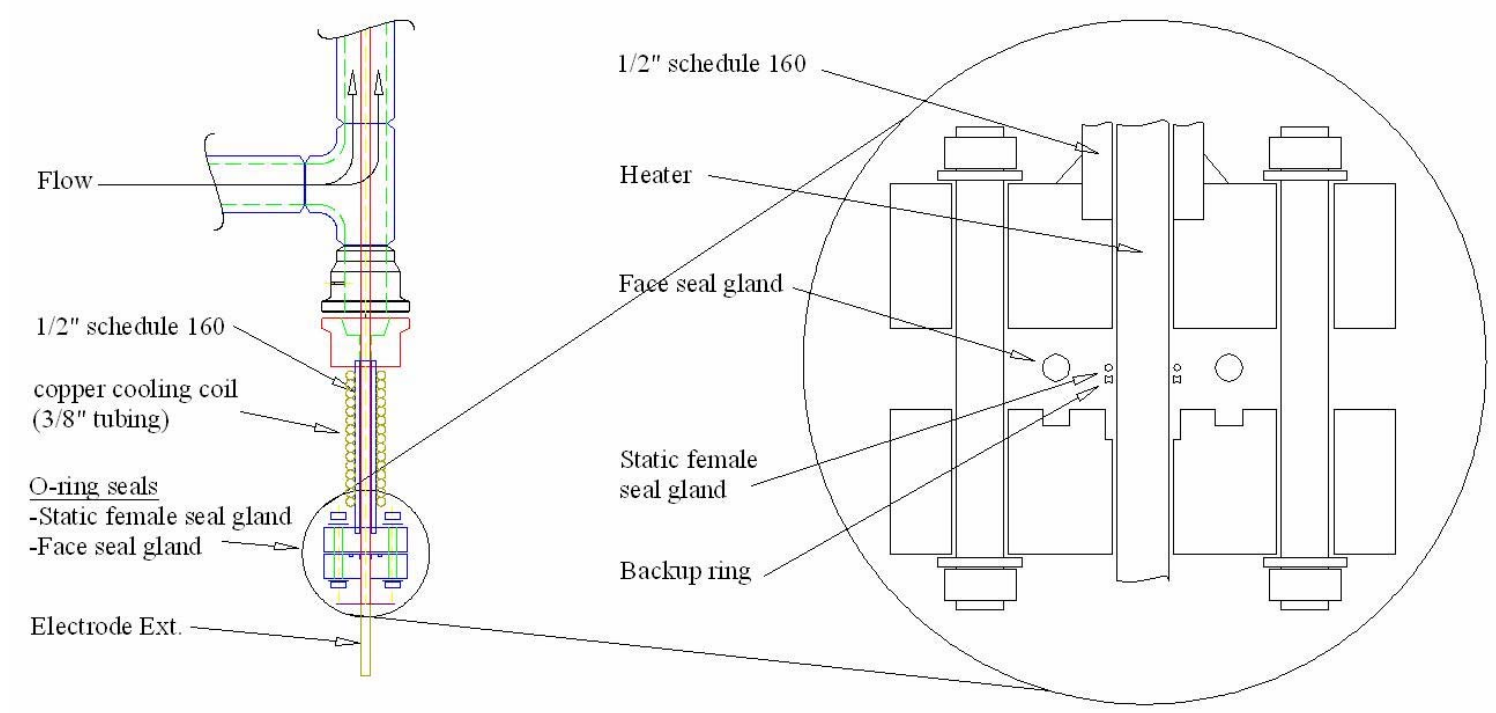

Figure 3-12 Pressure boundary allowing for differential thermal expansion.

\subsection{Heater Spacers}

Due to the length and flexibility of the heater rod, a method was required to minimize vibrations and center the heater within the outer piping. It was estimated that, in the worst case, that supports should be placed every 3 feet. Supports (Figure 3-13) were placed $5 \mathrm{~cm}$ (2 in) away from the heated section and at the tees at the beginning and end of the test section leg. The supports, or spring clips, were made of 410 stainless steel due to its spring like properties and ability to withstand SCW. The thickness of the metal was chosen so that the 
spring clip could flex without permanently yielding. The clip works by using the four corners of the larger lobes to hold itself within the tube. As is, the inner points used to hold the heater are not separated enough to allow the heater to penetrate through the middle. Pulling the smaller two lobes outward opens up the center allowing the heater to slide through. Releasing the lobes causes the inner four points to close down on the heater, firmly securing it in place.
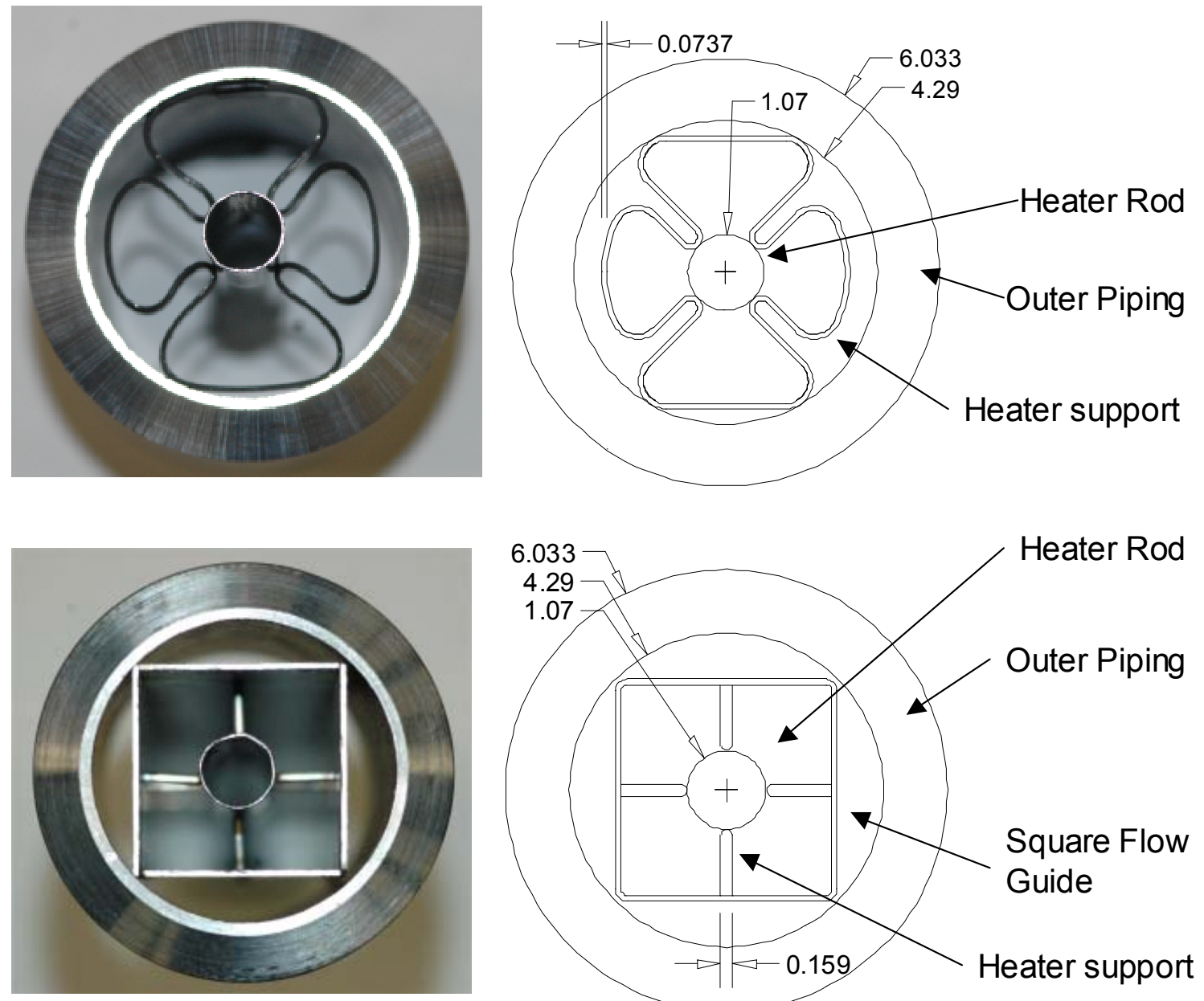

Figure 3-13 Top: Spring clip designed to support heater rod in circular geometry. Bottom: pins used to support heater rod in square geometry. 
Due the smaller flow area, the square geometry required a different method for supporting the heater rod. A four pin system made of $1.59 \mathrm{~mm}(0.0625$ ") Inconel welding rod was used with placement similar to that of the circular geometry. An additional set of pins was placed $6 \mathrm{~cm}$ downstream of the optical test section for improved positioning. It should be noted that the pins were designed to have $0.15 \mathrm{~mm}(0.006 ")$ gap between itself and the wall to allow for thermal expansion and dimensional uncertainty.

\subsection{Test Section}

Two test sections were created, one for standard heat transfer measurements in a circular annular flow, and another for square annular flow with optical access. Two test sections were made so that heat transfer measurements could be performed while details of the density measurement could be investigated with the optical test section.

Only $1.01 \mathrm{~m}$ of the $3.3 \mathrm{~m}$ heater rod is heated (Figure $3-1$ ). The removable section is offset of the heated section due to the uncertainty in behavior of the heat transfer during deterioration. It was not known if the deterioration would occur across the entire axis of the heated section or if it would occur at a localized section. With the current design the optical access can be placed in the center as shown, or the removable piece can be flipped allowing a view of the near-end heat transfer. The entrance region can be observed by rotating the entire right half the loop 180 degrees. To minimize optical distortion (flat window rather than curved), the chosen geometry was a square annular flow. The optical 
test section was designed to allow laser light from various optical instruments to enter and exit at 90 degrees of separation. The viewing window section is square while the ends transition to connect with the normal piping (Figure 3-14). Square flow guides are inserted above and below the optical window creating a square flow channel along the entire test section leg.

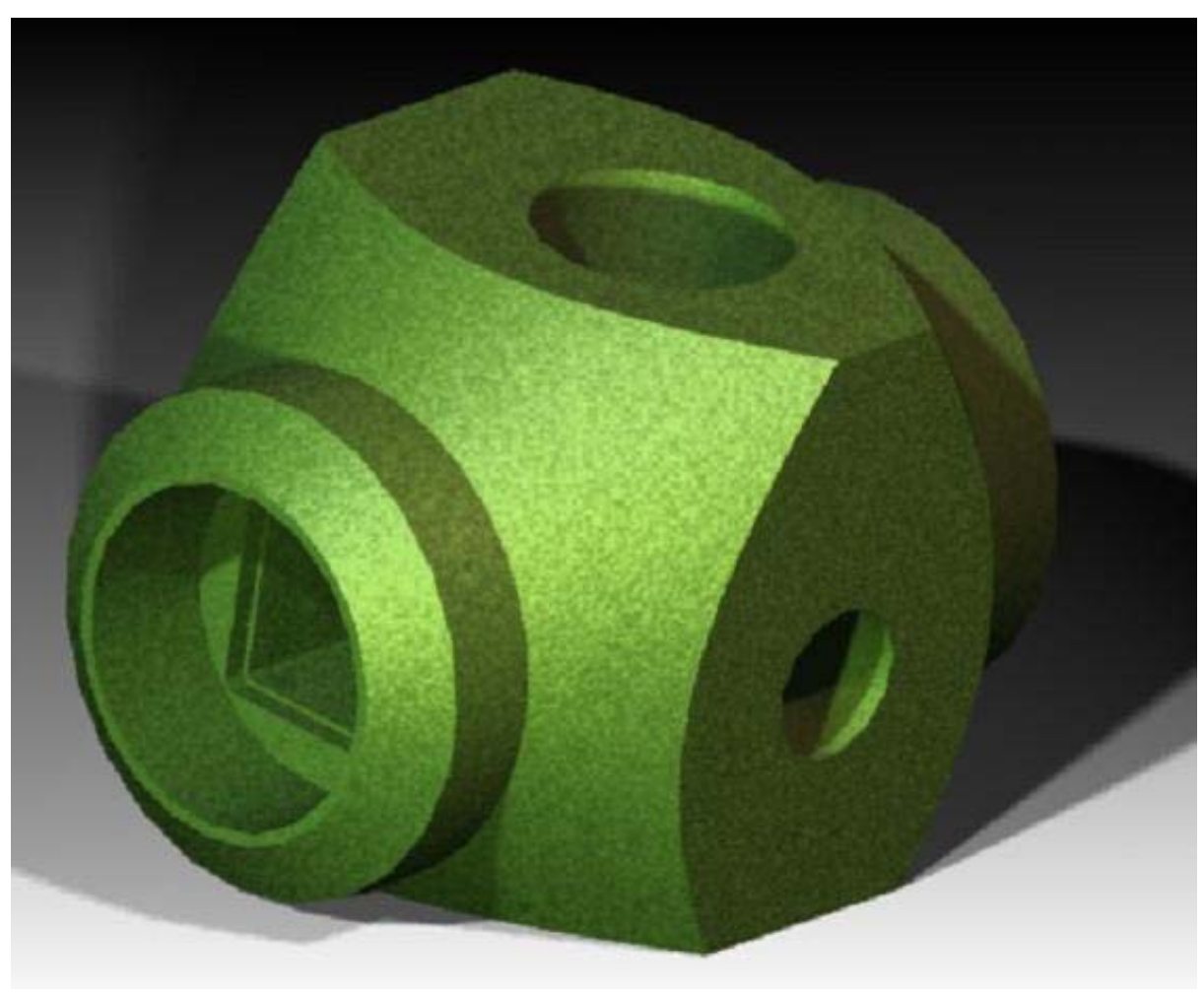

Figure 3-14 3D rendering of optical test section.

\subsection{Accumulator}

An accumulator is used to control pressure and dampen pressure oscillations (Figure 3-15, Figure 3-16). The volume of the accumulator is similar to that of the main loop (3.33 gallons). A $3.2 \mathrm{~mm} \mathrm{(1/8} \mathrm{in)} \mathrm{stainless} \mathrm{steel} \mathrm{tube} \mathrm{is} \mathrm{used} \mathrm{to}$ connect the main loop to the accumulator. The line is passed through a cooling bath to keep the accumulator fluid at room temperature. The water level in the 
reservoir is monitored with a Siemens differential pressure gauge (model 7MF4532-1EA32-1NC1-), with a case pressure of 420 bar and differential of 20-600 mbar. The pressure inside the reservoir is measured with Siemens sitrans $P$ pressure gauge (model 7MF4032-1GA10-1NC1-Z) rated for 13--400 bar. Pressure can be automatically or manually controlled with LabVIEW ${ }^{\mathrm{TM}}$.

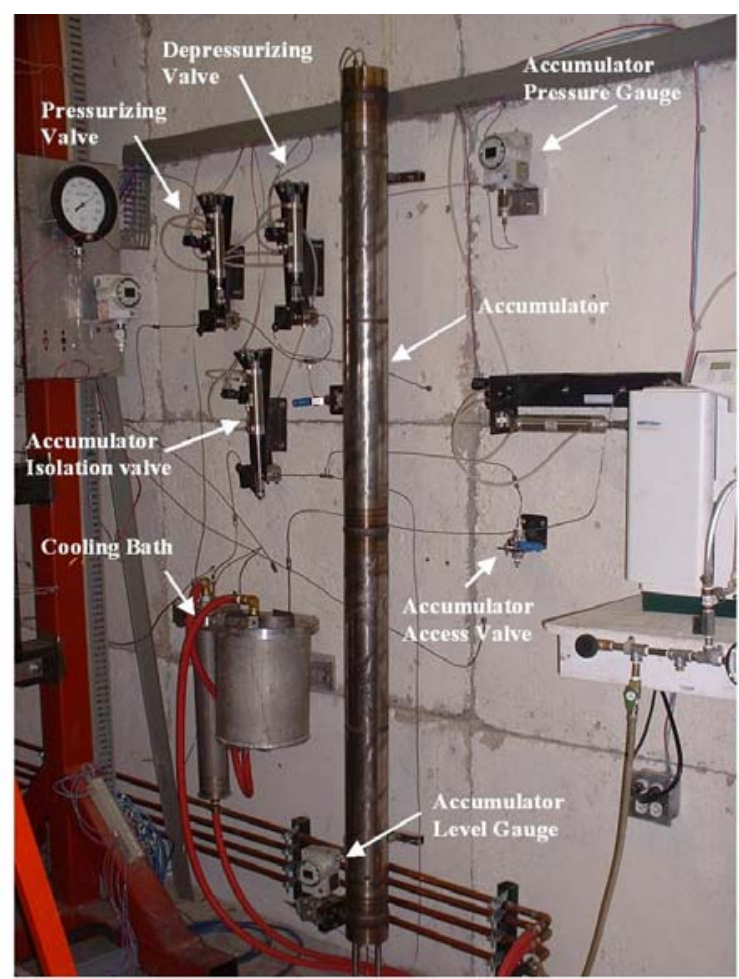

Figure 3-15 Picture of the pressure control components. 

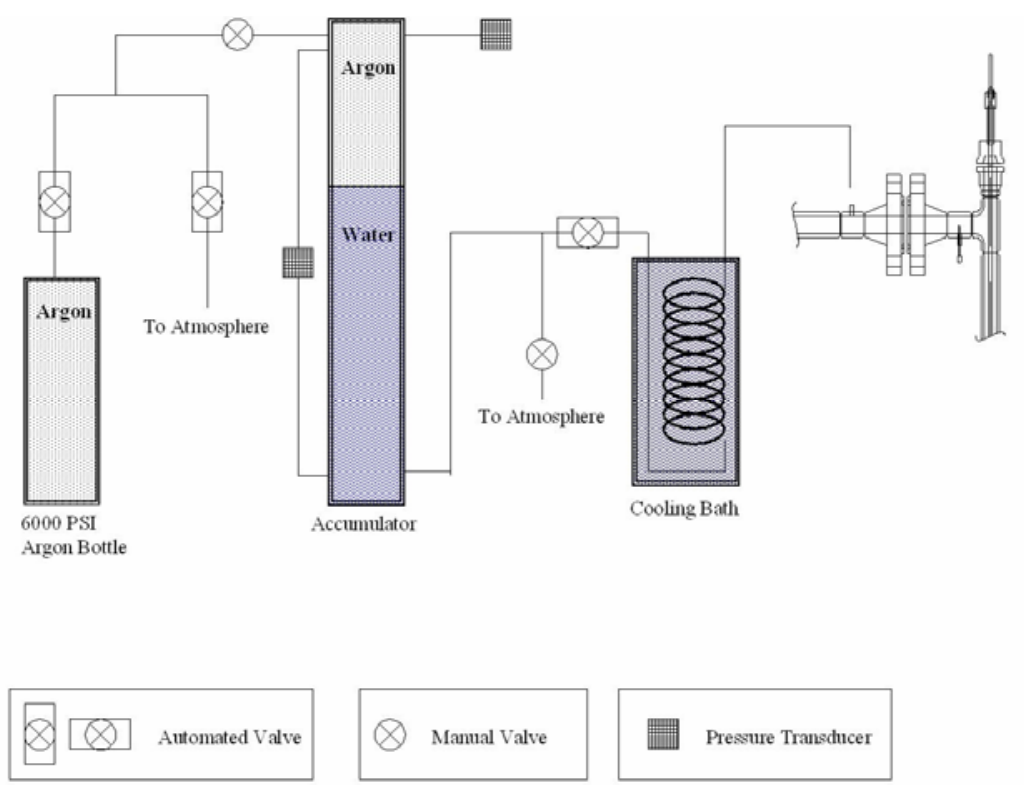

Figure 3-16 Schematic of the pressure control system.

\subsection{Chemistry Control}

Water chemistry is controlled by removing dissolved oxygen and filtering (Figure 3-17, Figure 3-18). A $3.2 \mathrm{~mm}$ (1/8 in) stainless steel line from the loop is passed through a cooling bath prior to entering the chemistry control line. A needle valve controls flow through chemistry line. A $5 \mu \mathrm{m}$ particle filter is used to clean the water. A mini module membrane contactor made by liqui-cel (model G478), allows water to flow around a mesh of oxygen permeable tubular membranes. A vacuum is used to draw the oxygen through the membranes. This system can bring the dissolved oxygen content down to $\sim 20$ parts per billion.

The dual chrome tech prep 100 digital pump can produce flow rates of 0.1 to $100 \mathrm{ml} / \mathrm{min}$. A reservoir precedes the pump in order to provide some flexibility in pump speed. The pump is controlled both manually and via a RS232C serial 
communication. The reservoir water height is monitored with a Siemens Sitrans $\mathrm{P}$ (model 7MF4432-1CA22-9316782) pressure transmitter with a measuring span of 2 mbar- $60 \mathrm{mbar}$. The flow rate through the chemistry line can be controlled automatically by either holding the main loop pressure constant or maintaining constant water level in the chemistry reservoir. The chemistry line contains automated valves at both the inlet and exit for isolation.

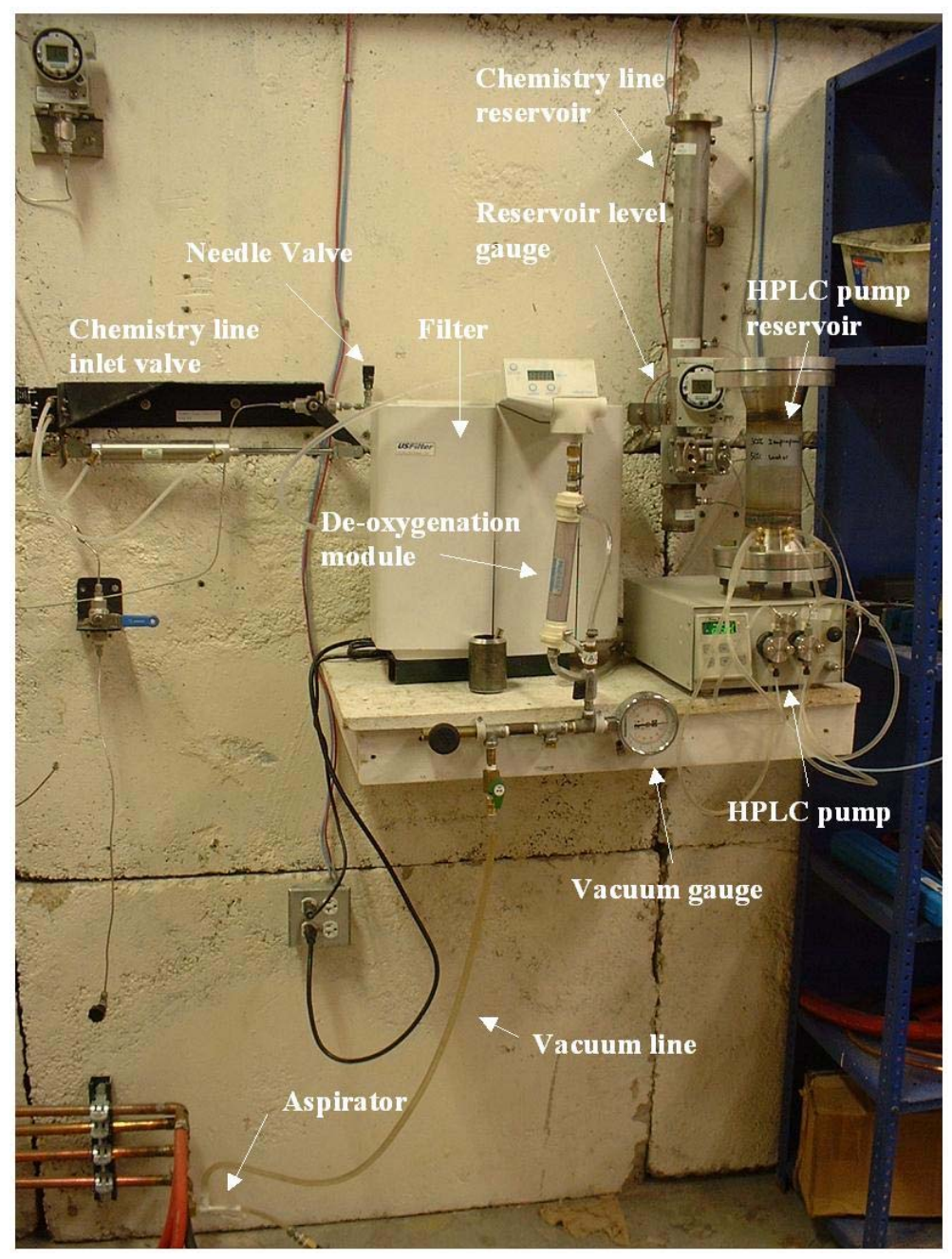

Figure 3-17 Picture of chemistry control components. 


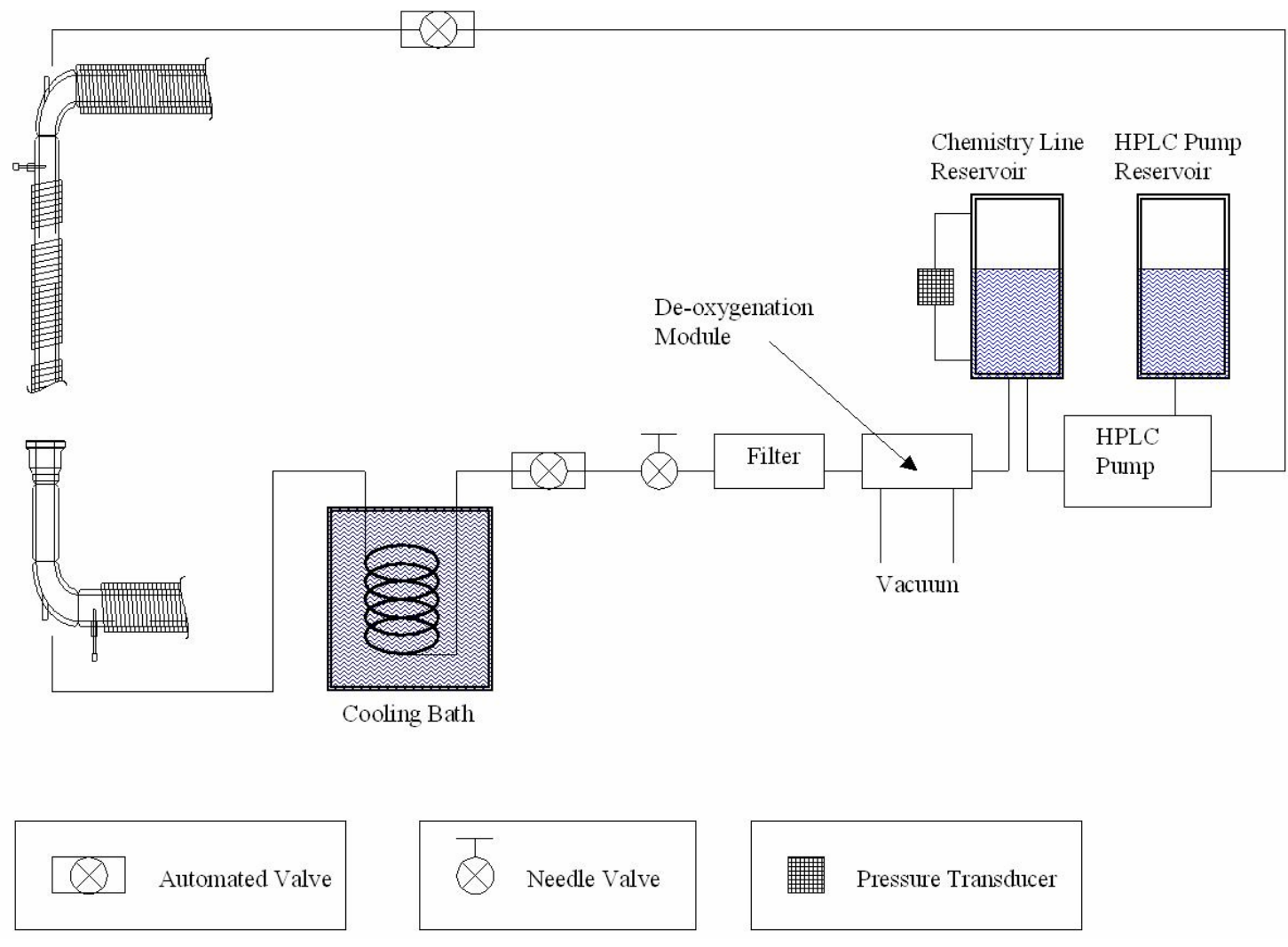

Figure 3-18 Schematic of chemistry control system.

\subsection{Data Acquisition, Motion, and Control}

The data acquisition system for the loop is currently a National Instrument system along with LabVIEW ${ }^{\mathrm{TM}}$ interface. This system consists of a 16 bit 333 $\mathrm{kHz}$ A/D converter (6052E) connected to a SCXI 1001 chassis that can hold up to 12 SCXI modules. The chassis powers the SCXI modules and handles all timing, triggering, and signal routing between the digitizer and SCXI modules. Currently there are four 32 channel 1102 high accuracy thermocouple modules used for temperature and voltage measurements around the loop and four 1160 general-purpose switching modules consisting of 16 independent relays with power capabilities of up to $2 \mathrm{~A}$ at $250 \mathrm{Vrms}$ to control valves and external heaters 
on the loop. Two PCl-7342 motion control cards control the two two-axis National instrument nuDrive power amplifiers (model 2SX-411). LabVIEW 7.1 software is used to monitor, control, and record facility parameters. This program is outlined in Appendix D - LabVIEW Code.

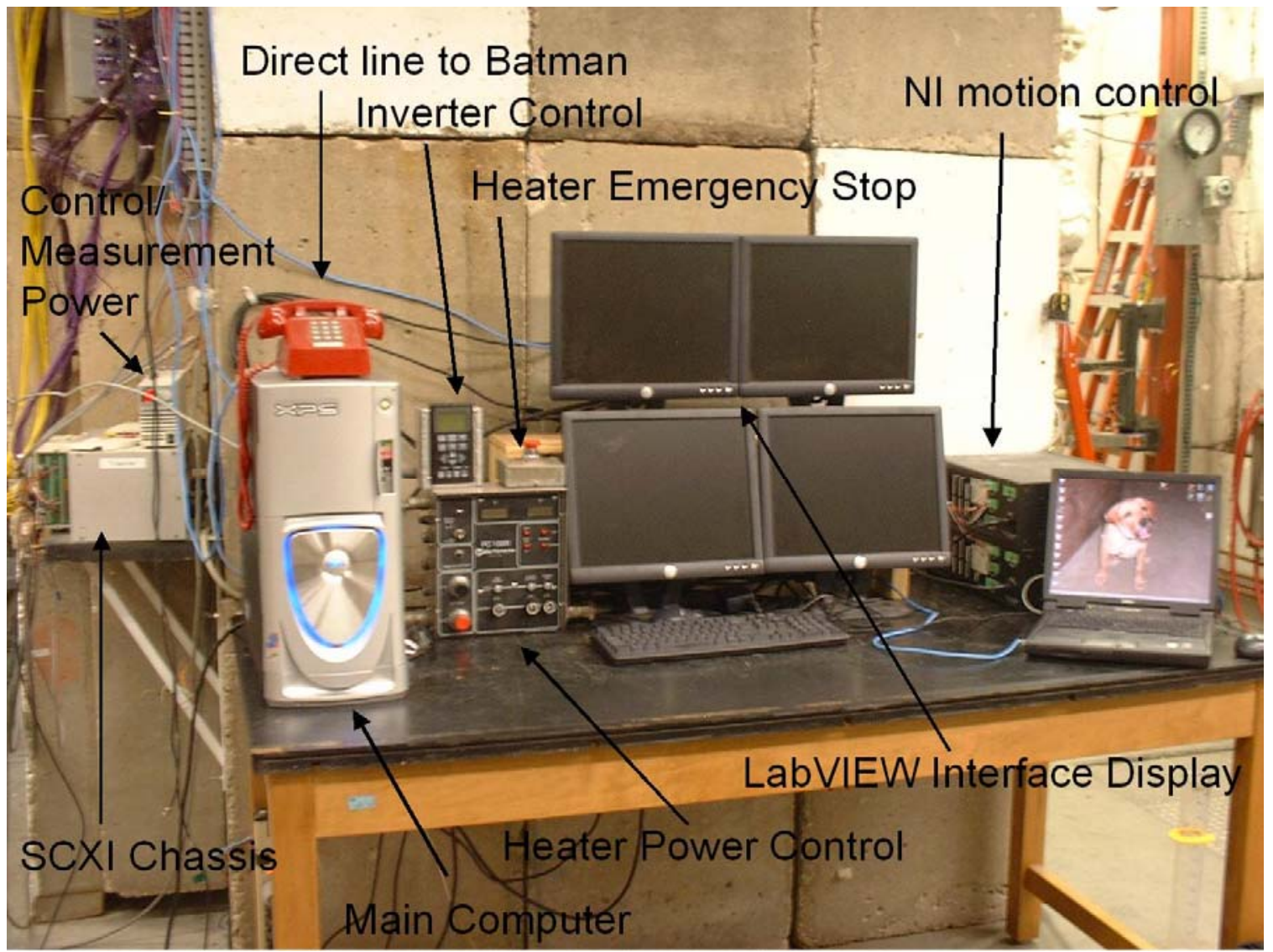

Figure 3-19 The driver seat.

\subsection{Operating Procedure for Heat Transfer Measurements}

The method for operating an experiment is as follows.

- Replace faulty gasket in main pump.

- Electroplate faulty seal rings.

- Install proper orifice plates. 
- Fill loop with distilled water and pressure test to $26 \mathrm{MPa}$ at room temperature.

- If pressure test fails, fix leak and repeat pressure test. Else continue.

- Run the chemistry line one-three day to remove dissolved oxygen from loop water.

- With most of the oxygen removed, initialize both loop and accumulator pressure to 8--12 MPa and open interconnecting valve.

- Begin cooling on pressure boundary ends, cooling baths, and the main pump.

- Start main pump flow.

- Began external heating at $1{ }^{\circ} \mathrm{C} / \mathrm{min}$ with external heating control.

- Maintain and adjust chemistry line flow to drive excess water to accumulator.

- Adjust pressure as needed by injecting argon or dumping excess water.

- As desired temperature is approached, turn on internal heater and ramp down external heater to reach steady state.

- Adjust internal and external heaters and add external cooling to reach desired bulk temperature and heat flux.

- Adjust pressure and flow rate as necessary.

- When steady state conditions are reached, save data for 5 minutes.

- Maintain steady state.

- Adjust internal heating, external heating and cooling power as necessary to achieve desired conditions. 
- Shut down: Phase out internal heating and external cooling and adjust external heating to hold at steady state.

- Ramp down temperature at $1{ }^{\circ} \mathrm{C} / \mathrm{min}$ with external heating control.

- When external heating temperature equals internal bulk temperature (typically at a bulk temperature of $180^{\circ} \mathrm{C}$ ), shut off experiment by turning off pump, external heating, and all cooling except for pressure boundary ends and pump cooling.

- Next day shut off all cooling water.

Modifications needed for use of optical windows:

- Window seals require an internal pressure of about $15 \mathrm{MPa}$, and thus this must be maintained during start up and shut down.

- Windows must be polished prior to every run with a minimum of $1 \mu \mathrm{m}$ diamond paste on a polishing machine (Buehler).

\subsection{Operational Experience}

Currently the heat transfer facility has been found to operate exceptional well and has been operated up to bulk temperatures of $400{ }^{\circ} \mathrm{C}$, with external piping approaching $600{ }^{\circ} \mathrm{C}$. Pressure boundaries have been maintained up to $30 \mathrm{MPa}$ at room temperature and $26 \mathrm{MPa}$ at $400{ }^{\circ} \mathrm{C}$. Changing to and from different steady state conditions is easily accomplished and steady state operating conditions are easily sustained. The pressure boundaries between the protruding heater and the loop have also tested successfully to $30 \mathrm{MPa}$. The static seal allowing for thermal expansions has also been successfully tested for proper expansion. One major issue is that supercritical water has been found to 
degrade the gasket material (graphite) of the main pump while operating near and above the pseudo-critical point. However, this has not yet inhibited operation near and above critical temperatures. Pressure tests following near or exceeding supercritical temperature experiments have always failed, resulting in disassembly of the pump and replacement of the main gasket. A new gasket material, vermiculite, has been inserted, however it has yet to be tested beyond $350^{\circ} \mathrm{C}$.

SCW has also been found to have the ability to etch the sapphire windows. Experience suggests that the combination of flowing SCW with modest amounts of dissolved oxygen leads to the etching of sapphire. Keeping the dissolved oxygen content as low as possible minimized this effect. 


\section{Chapter 4 - Experimental Method, Procedure, and}

\section{Uncertainties}

\subsection{Brief Overview}

This chapter discusses the main measurement variables, calculations, and the associated uncertainties. The main experimental variables are mass flux, heater power, and fluid and cladding temperatures. Calculations include wall temperature and Nusselt number.

\subsection{Nusselt number}

The heat transfer to a fluid from a cylinder with internal temperature measurements is defined by:

$$
\alpha Q=\frac{\left(T_{i c}-T_{b}\right)}{\frac{\ln \left(d_{h} / d_{i c}\right)}{2 \pi L K}+\frac{1}{\pi d_{h} L h}}
$$

This can be rearranged to find the Nusselt number:

$$
N u=\frac{\left(D_{p}-d_{h}\right)}{\pi d_{h} L k}\left(\frac{\left(T_{i c}-T_{b}\right)}{\alpha Q}-\frac{\ln \left(d_{h} / d_{i c}\right)}{2 \pi L K}\right)^{-1}
$$

This equation now must be rewritten in terms of primitive (measured) variables.

For simplicity, the heater diameter is evaluated based on the temperature of the inner cladding temperature. The Stern Lab inspection report states the 
diameter $\left(d_{h}{ }^{\prime}\right)$ to be $10.725 \mathrm{~mm}$ with the minimum being $10.7061 \mathrm{~mm}$ and the maximum being $10.7442 \mathrm{~mm}$. The diameter $\left(d_{h}\right)$ is defined as:

$$
\left.d_{h}=d_{h}^{\prime} \mid 1+\alpha_{600\left(T_{i c}\right)}\left(T_{i c}-T_{\text {room }}\right)\right\rfloor
$$

The thermal expansion of Inconel 600 is shown in the following figure (data source: High temp metals data base)

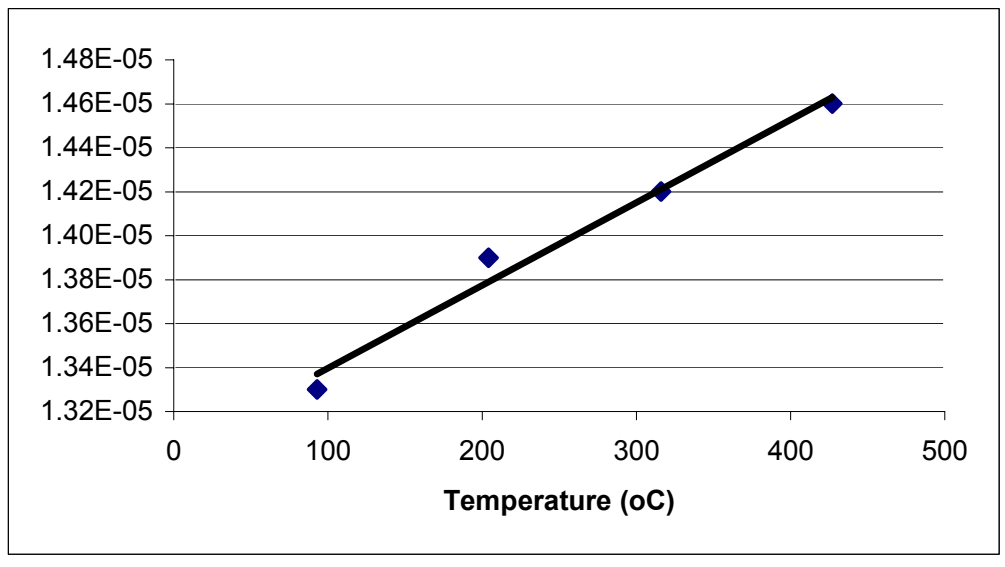

Figure 4-1 Thermal expansion of Inconel 600.

$$
\begin{aligned}
& \alpha_{600}=1.3 \mathrm{e}-5 \pm 1.11 \mathrm{e}-7+(3.77 \mathrm{e}-9 \pm 3.84 \mathrm{e}-10) \times \mathrm{T} \\
& \alpha_{600}=\mathrm{C} 1+\mathrm{C} 2 \times \mathrm{T}
\end{aligned}
$$

The Uncertainties are based on the linear fit and the coefficients are defined as C1 and C2.

The calculated heated length is based on the thermal expansion of Monel $\mathrm{K}-500$, where the expansion is evaluated based on the temperature of the inner cladding temperature measurement:

$$
L=L^{\prime}\left\lfloor 1+\alpha_{K 500\left(T_{i c}\right)}\left(T_{i c}-T_{\text {room }}\right)\right\rfloor
$$


$\mathrm{L}^{\prime}$ is found to be $1010 \mathrm{~mm}$ based on the Stern Lab inspection report. The thermal expansion coefficient $\alpha_{K 500}$ is $13.7 \mathrm{e}^{-6}$ as found from the ESPI metals data base.

The thermal conductivity of Inconel 600 is based on the High Temp Metals data base and evaluated at the inner cladding temperature measurement.

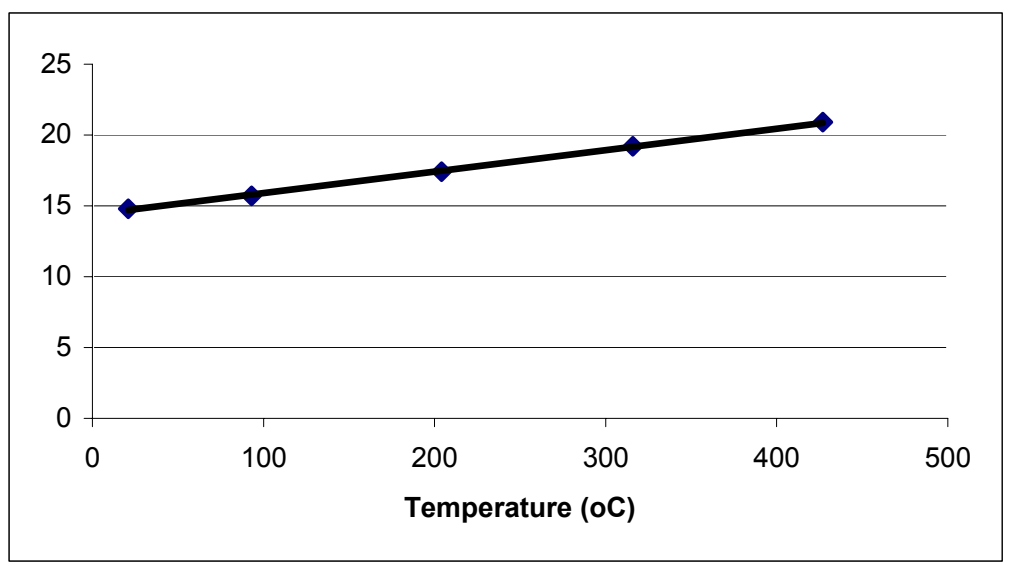

Figure 4-2 Thermal conductivity of Inconel 600.

$$
\begin{aligned}
& k=14.37 \pm 0.07+(0.0152 \pm 0.0003) \times \mathrm{T} \\
& k=\mathrm{C} 3+\mathrm{C} 4 \times \mathrm{T}
\end{aligned}
$$

Again, the uncertainties are based on the linear fit and coefficients are defined as C3 and C4.

Method for calculating heater power (assuming uniform power distribution):

$$
\mathrm{Q}=\mathrm{V} \mathbf{I}
$$

Current (I) found from voltage drop across a 1000 amp shunt (max power supply current $=600$ amps, max used $=400$ amps).

$$
I=\frac{V_{s}}{R_{s}}
$$


The Shunt resistance $\left(R_{s}\right)$ is 0.00005 ohms $\pm 0.1 \%$. The shunt voltage $\left(V_{s}\right)$ is too large to be measured directly so a voltage divider is used (measure voltage $\left.V_{2}\right)$.

$$
\begin{aligned}
& V_{s}=V_{1}+V_{2} \\
& V_{s}=\left(R_{1}+R_{2}\right) I_{v} \\
& I_{v}=\frac{V_{2}}{R_{2}}
\end{aligned}
$$

So, putting it together:

$$
\begin{aligned}
& Q=\left(R_{1}+R_{2}\right) \frac{V_{2}}{R_{2}} \frac{V_{s}}{R_{s}} \\
& R_{1}=7660 \text { ohms, } 5 \mathrm{~W} \text { resistor } \\
& R_{2}=711 \text { ohms, } 5 \mathrm{~W} \text { resistor } \\
& V_{2} \text { Measured with NI data acq: } \pm 0.04 \% \text { of reading }
\end{aligned}
$$

Inner cladding temperature measurements are made with K-type thermocouples made from $100 \mu \mathrm{m}(0.004$ ") diameter wire (XL-K-MO-020) with an uncertainty of $\pm 1.1^{\circ} \mathrm{C}$ or $0.4 \%$, which ever is greater.

The bulk axial temperature is found from the from:

$$
Q=\dot{m}\left(i_{x}-i_{\text {inlet }}\right)
$$

Which can be rewritten

$$
\left(R_{1}+R_{2}\right) \frac{V_{2}}{R_{2}} \frac{V_{s}}{R_{s}}=\dot{m}\left(i_{x}-i_{\text {inlet }}\right)
$$

This is then rearranged to find the bulk enthalpy as a function of position: 


$$
i_{x}=\left(R_{1}+R_{2}\right) \frac{V_{2}}{R_{2}} \frac{V_{s}}{R_{s}} \frac{1}{\dot{m}}+i_{\text {inlet }}
$$

Two variables to left to find, $\dot{m}$ and $i_{\text {inlet }}$. The inlet enthalpy $i_{\text {inlet }}$ is evaluated at the inlet temperature $\left(T_{\text {inlet }}\right)$ and pressure. The inlet temperature is measured with an E-type thermocouple (GEMQIN-0625-12) with an uncertainty of $\pm 1.0^{\circ} \mathrm{C}$ or $0.4 \%$, which ever is greater.

The mass flow rate is found with an orifice and differential pressure transducer combination with the following equation:

$$
\dot{m}=C_{d} \frac{\pi}{4} d_{o}^{2} \sqrt{\frac{2 \Delta P \rho}{\left(1-\left(d_{o} / D_{p}\right)^{4}\right)}}
$$

The discharge coefficient $\left(C_{d}\right)$ is dependent on orifice the orifice diameter, both of which are discussed in greater detail in the following section (Section 4.3

Evaluation of the Mass Flux). The orifice diameter is evaluated based in the bulk inlet temperature:

$$
d_{o}=d_{0}^{\prime}\left\lfloor 1+\alpha_{625\left(T_{b}\right)}\left(T_{b}-T_{\text {room }}\right)\right\rfloor
$$

The thermal expansion of Inconel 625 is based on data from High Temp Metals. 


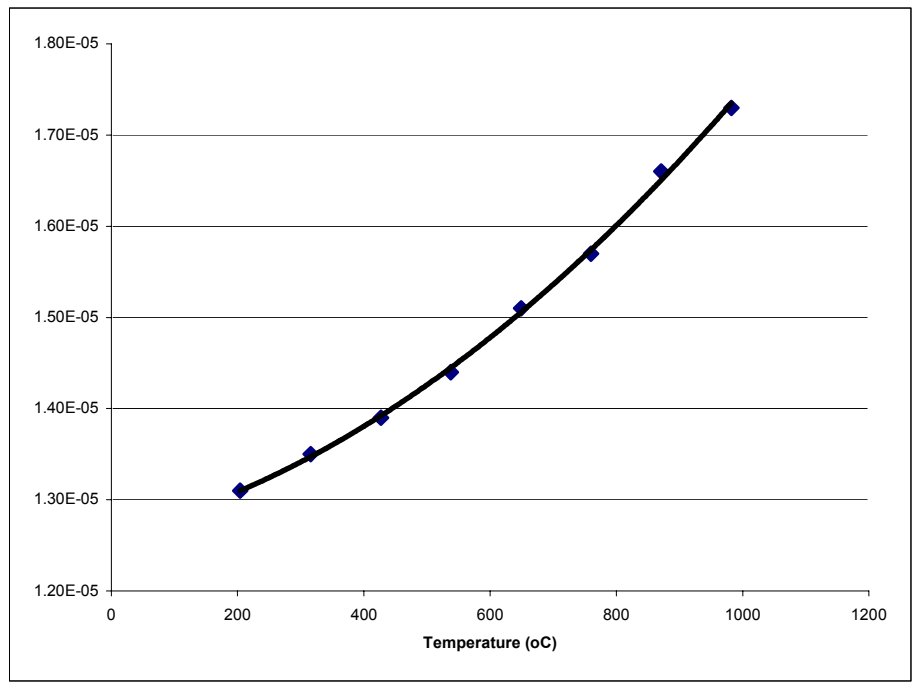

Figure 4-3 Thermal expansion of Inconel 625.

$$
\begin{aligned}
\alpha_{625\left(T_{b}\right)} & =(1.26 \mathrm{e}-5 \pm 1.22 \mathrm{e}-7)+(1.67 \mathrm{e}-9 \pm 4.59 \mathrm{e}-10) \mathrm{x} \\
& \mathrm{T}+(3.2 \mathrm{e}-12 \pm 3.81 \mathrm{e}-13) \times \mathrm{T}^{2} \\
\alpha_{625\left(T_{b}\right)} & =\mathrm{C} 5+\mathrm{C} 6 \mathrm{x} \mathrm{T}+\mathrm{C} 7 \times \mathrm{T}^{2}
\end{aligned}
$$

The uncertainties are based on the fit and three new coefficients are obtained. The room temperature orifice diameters $\left(d_{0}^{\prime}\right)$ are $0.01778,0.01016$, and 0.02667 $\mathrm{m}$.

The pipe diameter is found by:

$$
\begin{aligned}
& D_{p}=D_{p}^{\prime}\left\lfloor 1+\alpha_{625\left(T_{b}\right)}\left(T_{b}-T_{\text {room }}\right)\right\rfloor \\
& D_{p}^{\prime}=0.0429 \mathrm{~m}
\end{aligned}
$$

The pressure drop $(\Delta P)$ is measured with a Siemens differential pressure transducer with an uncertainty $\pm 0.1 \%$, although uncertainties are dominated by experimental fluctuations. The signal is acquired by measuring the voltage across a resistor: 


$$
\begin{aligned}
& \Delta P=\frac{V_{o}}{R_{o}}(\text { Convert })=\frac{V_{o}}{R_{o}}(18.75)-75 \\
& \mathrm{C} 8=18.75, \mathrm{C} 9=75 \\
& 4 \mathrm{ma}=0 \mathrm{kPa}, 20 \mathrm{ma}=300 \mathrm{kPa} \\
& R_{o}=306 \text { ohms } \\
& V_{o} \pm 0.04 \% \text { of reading }
\end{aligned}
$$

And finally, if you're still diligently following along, the final result is:

$$
\begin{aligned}
& N u=\frac{\left(D_{p}-d_{h}\right)}{k}\left(\frac{1}{\pi\left(d_{h}^{\prime}\left[1+\left(\mathrm{C} 1+\mathrm{C} 2 T_{i c}\right)\left(T_{i c}-T_{\text {room }}\right)\right]\right)\left(L^{\prime}\left[1+\alpha_{K 500}\left(T_{i c}-T_{\text {room }}\right)\right]\right)}\right) \times \\
& \left(\frac{\left(T_{i c}-T\left(p,\left[\left(R_{1}+R_{2}\right) \frac{V_{2}}{R_{2}} \frac{V_{s}}{R_{s}} \frac{1}{\dot{m}}+i_{\text {inlet }\left(T_{\text {inlet }}\right)}\left(p, T_{\text {inlet }}\right)\right]\right)\right)}{\alpha\left(\left(R_{1}+R_{2}\right) \frac{V_{2}}{R_{2}} \frac{V_{s}}{R_{s}}\right)}-\right. \\
& \left.\frac{\ln \left(d_{h}^{\prime} / d_{i c}^{\prime}\right)}{2 \pi\left(L^{\prime}\left[1+\alpha_{K 500}\left(T_{i c}-T_{\text {room }}\right)\right]\right)\left(\mathrm{C} 3+\mathrm{C} 4 T_{\text {ic }}\right)}\right)^{-1}
\end{aligned}
$$

where

$$
\dot{m}=C_{d} \frac{\pi}{4}\left(d_{0}^{\prime}\left[1+\alpha_{625\left(T_{\text {in }}\right)}\left(T_{\text {in }}-T_{\text {room }}\right)\right]\right)^{2} \sqrt{\frac{2\left(\frac{V_{o}}{R_{o}}(C 8)-C 9\right) \rho_{T_{\text {in }}}\left(p, T_{\text {inlet }}\right)}{\left(1-\left(d_{0}^{\prime} / D_{p}^{\prime}\right)^{4}\right)}}
$$

and

$\alpha_{625\left(T_{b}\right)}=C 5+C 6 \cdot T_{i n}+C 7 \cdot T_{i n}^{2}$ 
Appendix F - Heat Transfer Uncertainty Example, gives an example of the uncertainty found from typical experiments at various operating conditions (normal heat transfer high mass velocity, normal heat transfer low mass velocity, deteriorated heat transfer, and enhanced heat transfer).

\subsection{Evaluation of the Mass Flux}

As previously stated, the ASME standard could not be followed in the design of the orifice plates, and with custom plates (Figure 4-4) the discharge coefficients needed to be experimentally determined. Four different orifice plates were used to achieve the desired mass velocity at different temperatures (Table 5).

\section{Test Section Orifice}

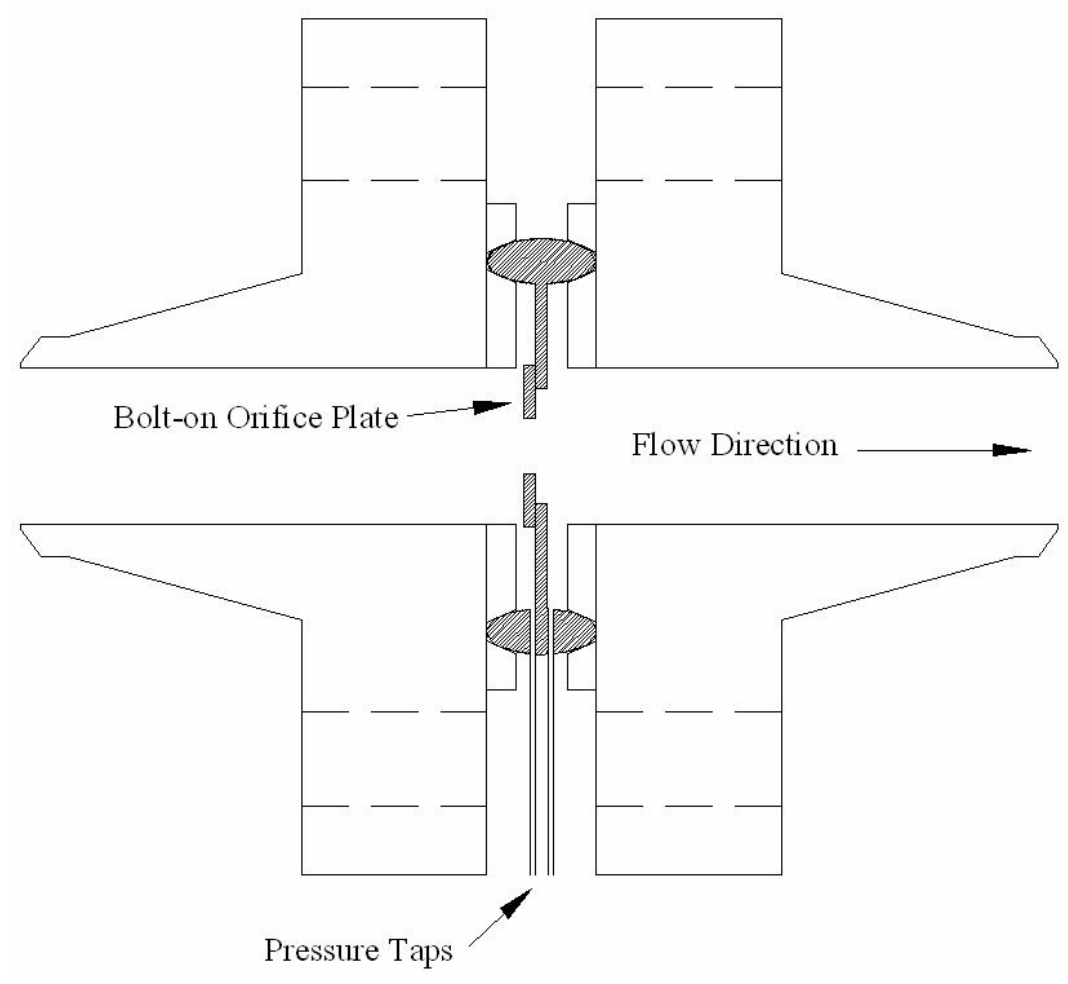

Figure 4-4 Orifice system schematic. 


\begin{tabular}{|c|c|c|c|c|}
\hline Case & $\mathrm{T}\left({ }^{\circ} \mathrm{C}\right)$ & $\mathrm{G}\left(\mathrm{kg} / \mathrm{m}^{2} \mathrm{~s}\right)$ & Test Section $\beta$ & Recirculation leg $\beta$ \\
\hline $\mathrm{A}, \mathrm{B}, \mathrm{C}, \mathrm{D}, \mathrm{E}$ & Subcritical & High & 0.414 & 0.622 \\
\hline $\mathrm{G}, \mathrm{H}, \mathrm{M}-\mathrm{U}$ & Subcritical & Low & 0.237 & 0.681 \\
\hline $\mathrm{K}, \mathrm{L}$ & Subcritical & Low & 0.237 & 0.622 \\
\hline I, J & Supercritical & High & 0.622 & Closed \\
\hline $\mathrm{F}$ & Supercritical & Low & 0.414 & 0.622 \\
\hline
\end{tabular}

Table 5 Orifice plate configuration for varying conditions.

Calibration of the discharge coefficient for each orifice plate was performed by removing the center test section piece and replacing it with a Foxboro (model 83) vortex flow meter. The fluid used was water at room temperature, pressure of 1 $\mathrm{MPa}$, and with dissolved gases removed via the chemistry line.

For $\beta=0.237$, the discharge coefficient was estimated at $0.61 \pm 0.04$. Figure 4-5 shows the experimentally measured discharge coefficient as function of Reynolds Number compared with the expected value had ASME standards been followed. Uncertainties shown are due to experimental fluctuations. A large uncertainty of the discharge coefficient was chosen based on both the measured values and the fact that the maximum Reynolds number achievable at room temperature is an order of magnitude lower than typical operating conditions. However, the values expected, had ASME standards been followed, indicate that there should be little change in the discharge coefficient at larger Reynolds numbers. An uncertainty of 0.04 is assumed to be very conservative. 

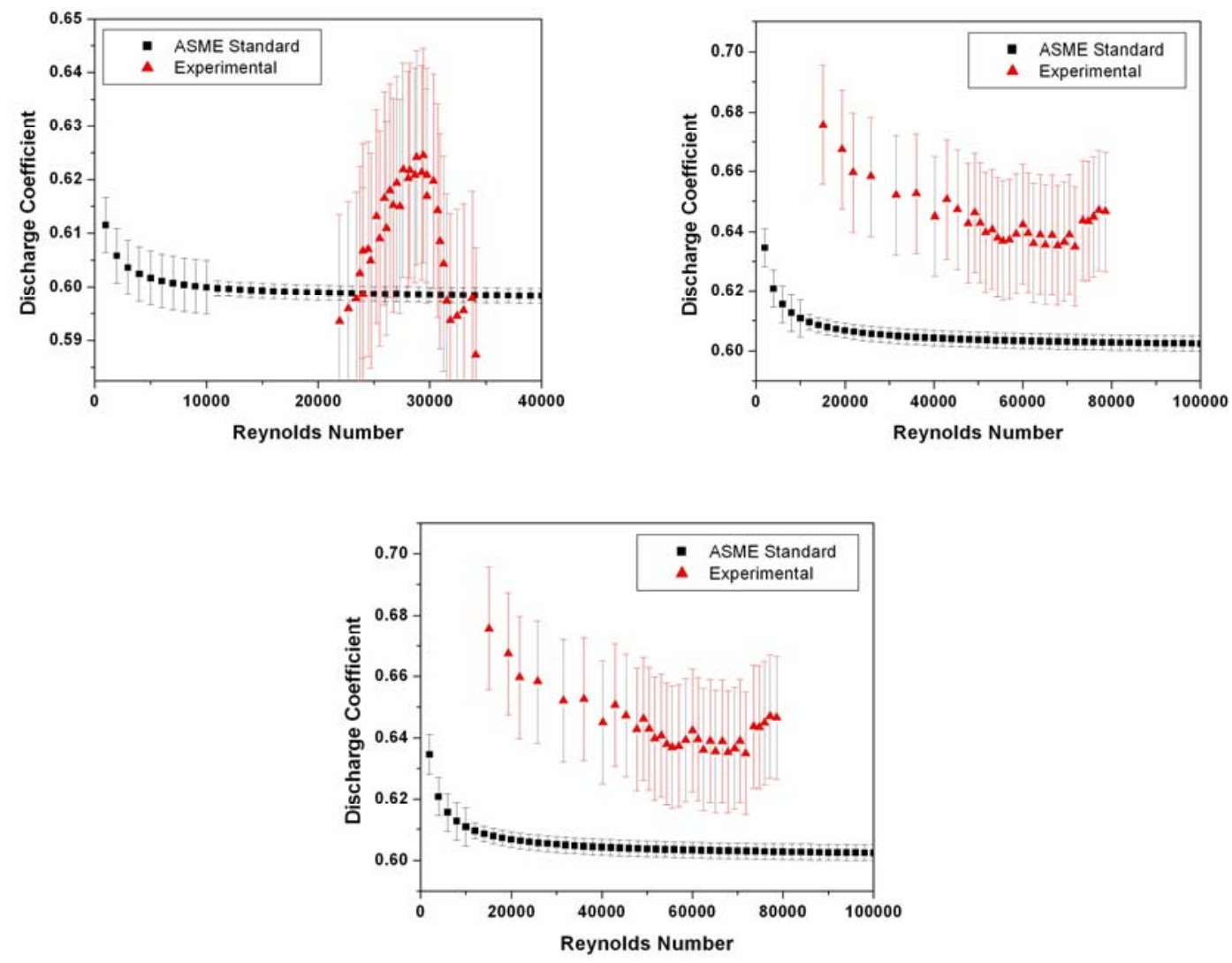

Figure 4-5 Measured discharge coefficient compared with measured. (a) $\beta=0.237$, (b) $\beta=0.414$, (c) $\beta=0.622$.

For $\beta=0.414$, the discharge coefficient was estimated at $0.64 \pm 0.04$. Again the uncertainty was obtained as described above.

The pressure drop across the orifice is measured with a Siemens differential pressure transducer (model: 7MF4032-1GA10-1NC1-Z) with an instrumental uncertainty of $0.1 \%$, however, fluctuations typically dominated the uncertainty.

In the end, the mass velocity uncertainty was dominated by the uncertainty in the discharge coefficient. 


\subsection{Evaluation of the wall temperature}

The calculation of the wall temperature from inner cladding temperature measurements becomes complicated by an interesting design issue associated with the heating element of the heater rod. The heating element is shaped as a ribbon producing an oscillating temperature profile along its axis. ANSYS calculations performed by Carl Martin show this temperature fluctuation (Figure $4-6)$.
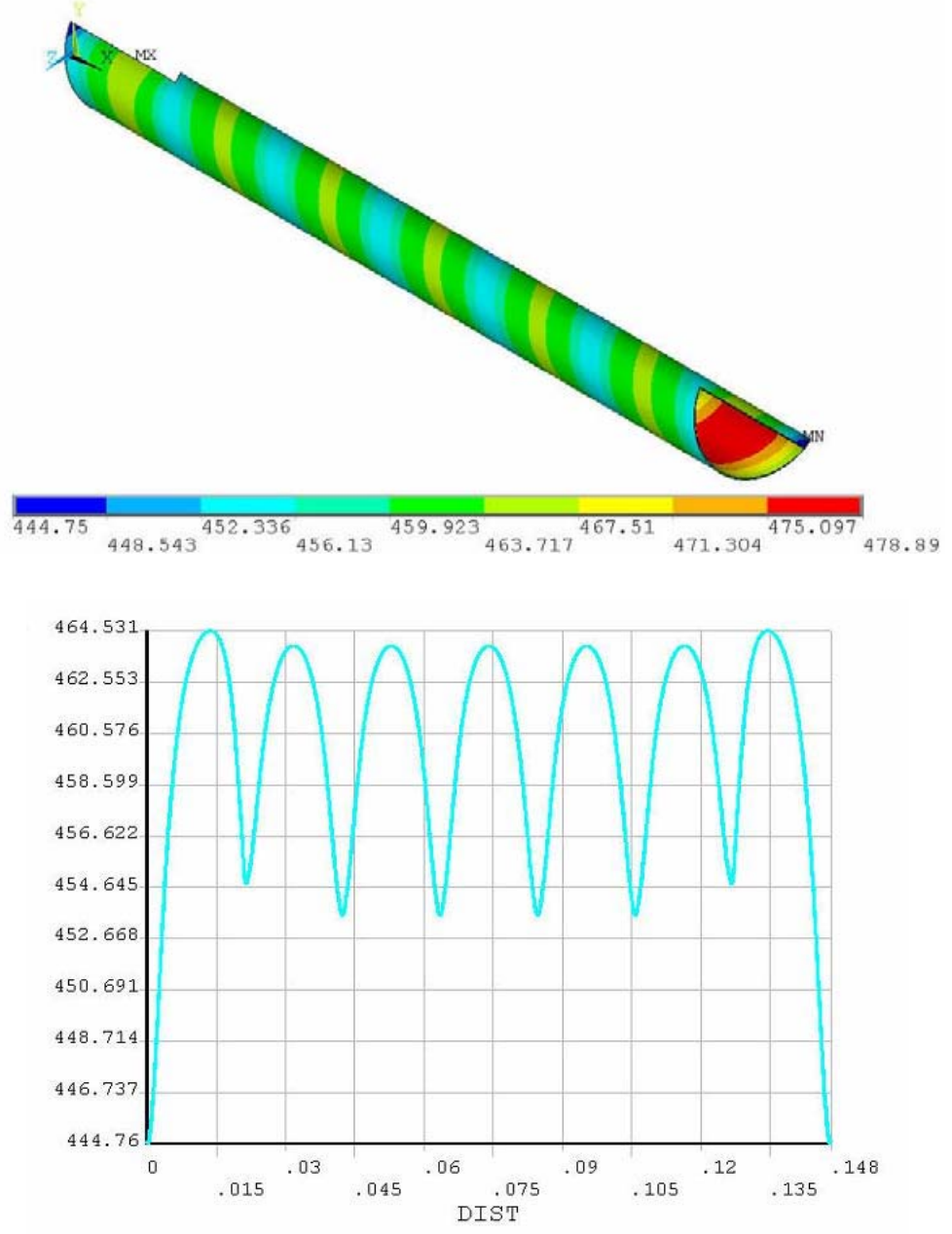

Figure 4-6 Surface temp variation of a section of heater rod with Q" $=1 \mathrm{MW} / \mathrm{m}^{2}$ and $\mathrm{Tb}=370{ }^{\circ} \mathrm{C}$. 
The design of the heating element alters both the heat flux and temperature at the surface of the heater rod. The equation used to discuss such a problem is given by:

$$
\alpha Q=\frac{2 \pi L k\left(T_{i c}-T_{w}\right)}{\ln \left(d_{h} / B\right)}
$$

where $\alpha$ is a correction factor for the local heat flux and $B$ is the physical location of $T_{\text {ic. }}$. However, this is one equation with three unknowns $\left(\alpha, B, T_{w}\right)$. The proper way to solve this problem is to use the results of an experiment coupled with a full CFD simulation of the heater and flow. However, this requires a significant amount meshing nodes and computer memory, and knowledge of the axial position of thermocouples relative to the heating ribbon. Currently this type of analysis is not possible so another method is needed to obtain $T_{w}$. In order to solve this problem, it was assumed that the variation in Q" was negligible and that the variation in measured temperature was mostly due to the radial position of $T_{i c}$. This reduces the problem to one equation and two unknowns ( $\beta$ and $T_{w}$. For this to work, the results should show that B is constant for several different heat transfer experiments, and in particular, differing heat flux. It was decided to use experiments with constant bulk temperature and mass velocity with varying heat flux. Four experiments with $\left(T_{b}=300{ }^{\circ} \mathrm{C}, \mathrm{G}=1400 \mathrm{~kg} / \mathrm{m}^{2} \mathrm{~s}\right.$, and $\mathrm{Q}^{\prime \prime}=250$ $1000 \mathrm{~kW} / \mathrm{m}^{2}$ ) were used to locate the position of $T_{\text {ic. }}$. These four experiments were then modeled in FLUENT, a CFD code, using the assumption of a uniform heat flux. This model revealed the expected wall temperature to be used in the above equation. Since it is assumed that the heat flux is uniform, we now have 1 
equation and 1 unknown. Solving for B for each thermocouple and for each of the four runs results in Figure 4-7.

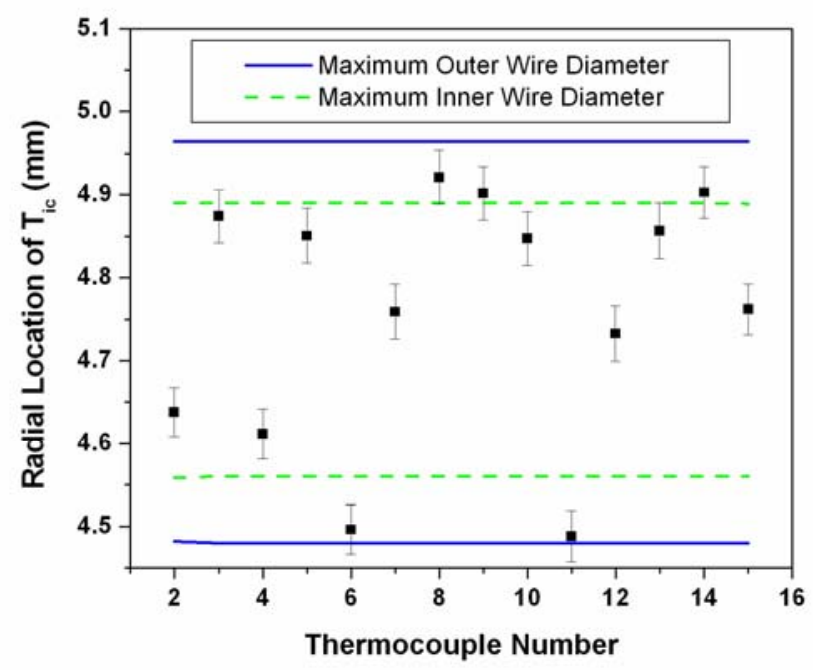

Figure 4-7 Variation in radial thermocouple position assuming the position is the dominant factor in varying relative temperature measurements.

It can be seen that the majority of the thermocouple bead locations are within the acceptable physical location and the variation is relatively small. The farthest outer and inner lines represent the gap in which the thermocouple wire lays. The other two lines are an estimate of the maximum thickness of the thermocouple cladding, as determined by Stern Laboratories. These results are acceptable considering other unknown factors such as varying conductivity, inter facial conductivity, and dimensional uncertainties. These results are used in calculating wall temperature and heat transfer coefficient of all runs.

\subsection{Repeatability}

While instrumental uncertainties limit the accuracy of the heat transfer experiments, it is important to also consider the repeatability of an experiment. 
Figure 4-8 shows that the wall temperature repeatability of the experiments is quite good $\left(< \pm 1.3^{\circ} \mathrm{C}\right)$.

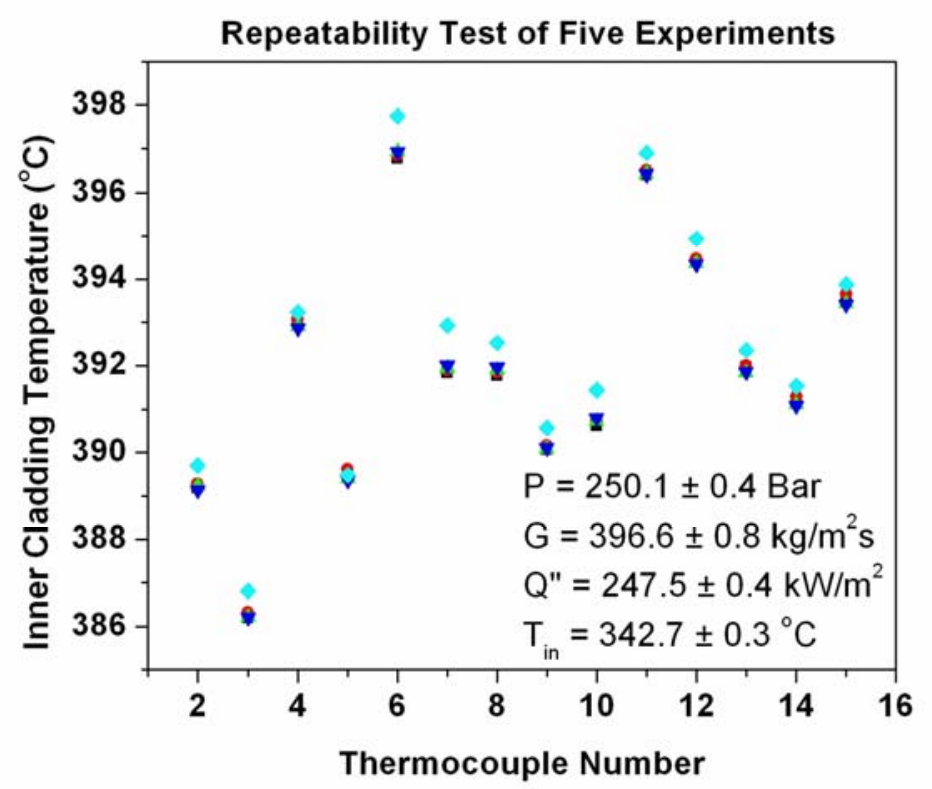

Figure 4-8 Repeatability of five experiments. 


\section{Chapter 5 - Heat Transfer Results and Discussion}

\subsection{Brief Overview}

This section covers four topics: 1) Heat transfer correlations comparison; 2) High mass velocity data; 3) Low mass velocity data; 4) and buoyancy criterion. While all calculations performed were evaluated at local conditions, unless otherwise stated, data for each run is presented as an average of the inner 14 measurements.

The 3D Froude criterion plot (Figure 3-2) can be represented as a 2D plot with constant lines of heat flux. Completed experiments are overlaid on this plot showing how completed experiments relate to potential deteriorated heat transfer (Figure 5-1). Each star represents a range of heat flux experiments for a constant mass velocity and bulk temperature. 


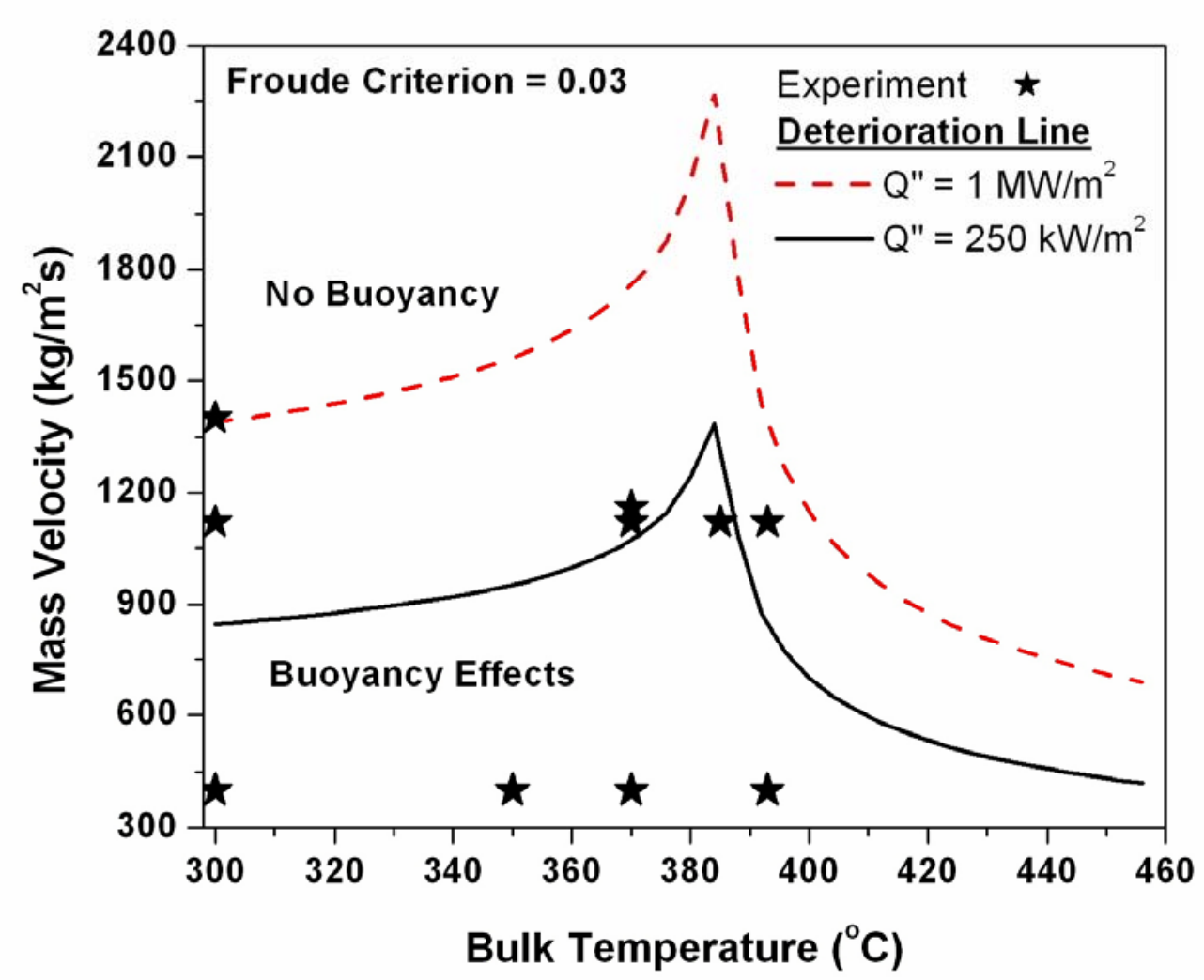

Figure 5-1 Completed experiments in relation to the buoyancy effected region.

\subsection{Heat Transfer Correlations}

Table 6 shows the results of the four Nusselt correlations compared with all 1077 circular geometry data points. Beginning with the Dittus-Boelter correlation, it can be seen that $79 \%$ of that data are captured with a $25 \%$ accuracy. Figure 5-2 shows that such a simplistic Nusselt correlation cannot capture the heat transfer effects seen in the near pseudocritical temperature region. Ideally the data should collapse to line so that experimental data is represented by the correlation. There is, as expected, large differences at the lower Nusselt numbers, or the region in which deterioration is occurring, 
indicating that the Dittus-Boelter correlation is over predicting the heat transfer. This is consistent with results of just about every Nusselt correlation developed. Also of importance in this evaluation are the thermal entry length effects of these experiments. For example, the group of data points at the highest Nusselt numbers (Figure 5-2) is from one experiment and represents the measurements across the heater. The effect of this is for the Nusselt correlation to tend to under predict the heat transfer in the entry region. Since the thermal entry length effects are dependent on the operating conditions, it was decided to not attempt to correct for this.

\begin{tabular}{|c|c|c|c|c|c|c|}
\hline Case & Run & Geometry & Tb & G & Q" & Heat Transfer \\
\hline A & $1-4$ & Circle & 300 & 1425 & $250-1000$ & $\mathrm{~N}$ \\
\hline B & $5-8$ & Circle & 370 & 1160 & $250-1000$ & E \\
\hline C & $9-14$ & Circle & 370 & $1160-680$ & 500 & $\mathrm{~N}, \mathrm{D}$ \\
\hline D & $15-18$ & Circle & 300 & 1120 & $250-1000$ & $\mathrm{~N}$ \\
\hline E & $19-22$ & Circle & 370 & 1120 & $250-1000$ & $\mathrm{E}$ \\
\hline F & $23-25$ & Circle & 393 & 400 & $250-500$ & $\mathrm{~N}$ \\
\hline G & $26-30$ & Circle & 300 & 400 & $125-625$ & $\mathrm{~N}, \mathrm{D}$ \\
\hline H & $32-35$ & Circle & 350 & 400 & $125-500$ & $\mathrm{~N}, \mathrm{D}$ \\
\hline I & $36-39$ & Circle & 385 & 1120 & $250-1000$ & $\mathrm{E}$ \\
\hline J & $40-43$ & Circle & 400 & 1120 & $250-1000$ & $\mathrm{~N}$ \\
\hline K & $44-47$ & Circle & 370 & 400 & $125-500$ & $\mathrm{~N}, \mathrm{D}$ \\
\hline L & $48-62$ & Circle & $300-360$ & 400 & $130-350$ & $\mathrm{~N}, \mathrm{D}$ \\
\hline M & $63-77$ & Circle & $340-350$ & 400 & $125-375$ & $\mathrm{~N}, \mathrm{D}$ \\
\hline N & $78-90$ & Square & 300 & 400 & $125-650$ & $\mathrm{~N}, \mathrm{D}$ \\
\hline O & $94-100$ & Square & 300 & $350-700$ & 125 & $\mathrm{~N}$ \\
\hline P & $101-107$ & Square & 300 & $350-700$ & 250 & $\mathrm{~N}$ \\
\hline Q & $108-114$ & Square & 300 & $350-700$ & 375 & $\mathrm{~N}, \mathrm{D}$ \\
\hline R & $116-122$ & Square & 300 & $350-700$ & 500 & $\mathrm{~N}, \mathrm{D}$ \\
\hline S & $124-129$ & Square & 300 & $407-700$ & 625 & $\mathrm{~N}, \mathrm{D}$ \\
\hline T & $132,131,115,123,130$ & Square & 300 & 400 & $125-625$ & $\mathrm{~N}, \mathrm{D}$ \\
\hline
\end{tabular}

Table 6 Experimental conditions. $\mathrm{N}=$ normal, $\mathrm{E}=$ enhanced, $\mathrm{D}=$ deteriorated. 


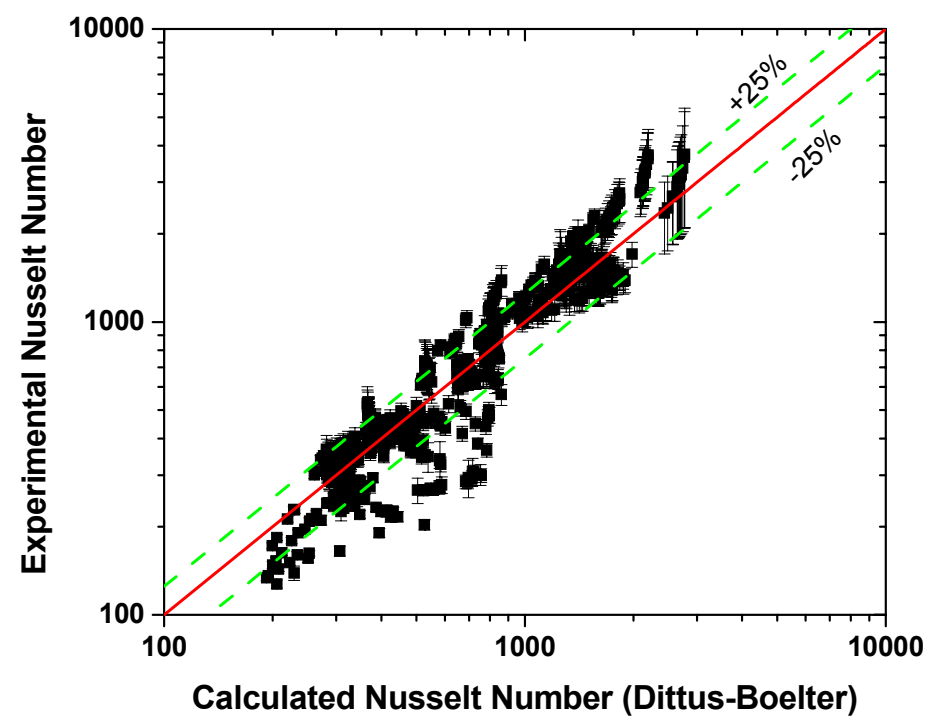

Figure 5-2 Comparison of experimental Nusselt number and Dittus-Boelter correlation.

Jackson's Nusselt correlation captures $86 \%$ of the data with $25 \%$ accuracy (Figure 5-3). This is lower than accuracy found by Jackson, however our calculation includes data that has experienced deterioration and again, there are thermal entry length effects to consider. Jackson's correlation appears to work well in that the data collapses to a straight line (with the exception of low Nusselt data), however, the experiment appears to have a consistently higher Nusselt number than what is predicted. The difference may be due to the fact that this correlation has been developed from circular pipe flow data while our geometry is annular. Experimental research has shown that there is an increased heat transfer in annular geometries for the same overall flow conditions. For example, applying a correction factor suggested by Petukhov et al. [36] results in a $7 \%$ increase in heat transfer for our geometry. Due to the length of the simulated fuel pin (3.3 meters), it was determined necessary to add spacers to hold the 
heater rod in the center of the annular geometry and to prevent oscillations in the heater rod. The affects of the spacers used to support the simulated fuel pin on the heat transfer was considered, with this in mind the spacers were designed to minimize free stream turbulence production while still supporting the heated rod. The spacers were also positioned such that they were as far upstream and downstream from the measurement location as possible to minimize their effect. To determine the impact of the spacers a CFD simulation with FLUENT was conducted at fluid conditions well below the critical point for both geometries. The calculations agreed with the measured data under these conditions and showed similar trends between the circular annular and square annular heat transfer data, suggesting little impact of the spacers on the heat transfer measurements. This is due in part to the design of the spacers, their position in the flow channel, and the fact that the experiments have a large channel cross sectional area, resulting in little change in the free stream turbulence levels. In addition to the CFD analysis several experiments were conducted both with and without thermocouples obstructions in the bulk flow (these thermocouples were similar to the pin spacers of the square annulus) and no measurable effect on the heat transfer was observed. 


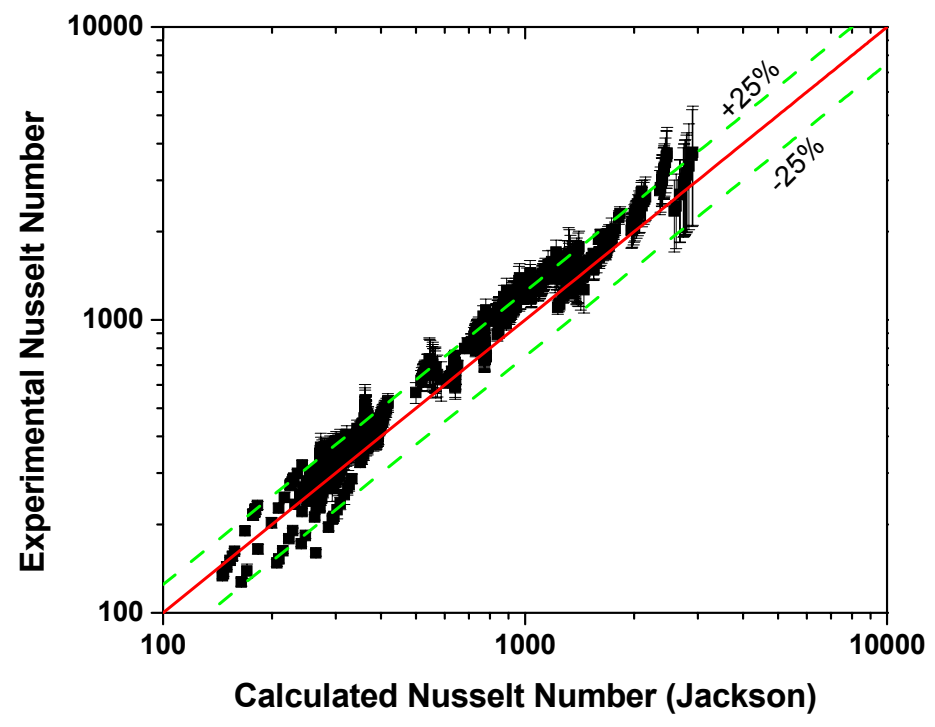

Figure 5-3 Comparison of experimental Nusselt number and Jackson's Nusselt correlation.

Krasnoshchekov's Nusselt correlation captures only $54 \%$ of the data with an accuracy of $25 \%$, which is much lower than expected (Figure 5-4). The Krasnoshchekov correlation appears to form two lines of which the upper line is high mass velocity, high bulk temperature data. These data points are outside the range from which the Krasnoshchekov correlation was developed. Ignoring these data points, the rest of the data still scatters more than the Jackson correlation. 


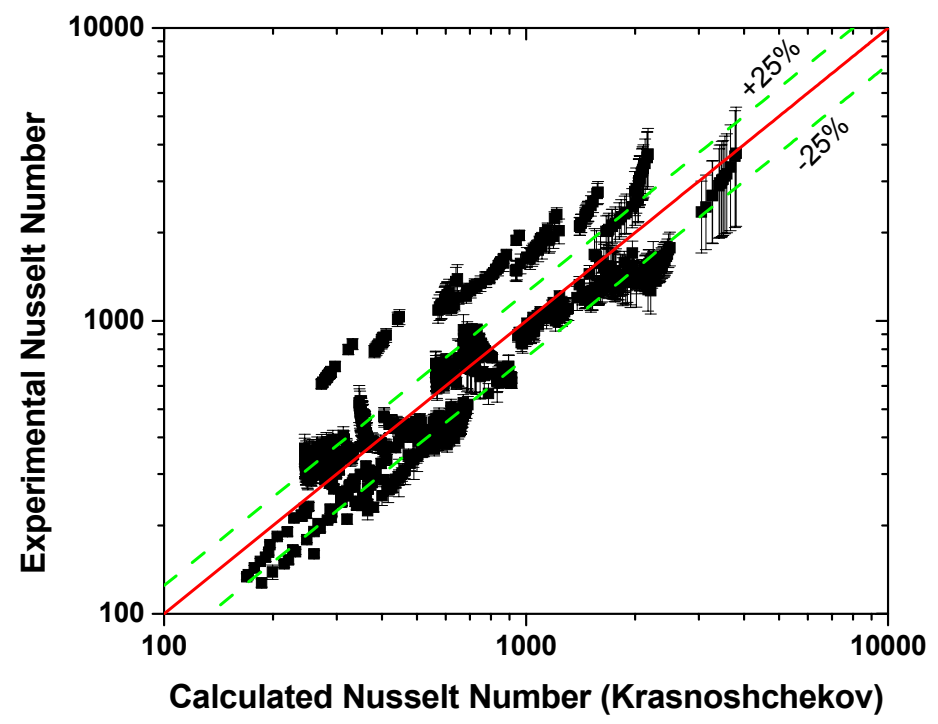

Figure 5-4 Comparison of experimental Nusselt number and Krasnoshchekov correlation

Watt's Nusselt correlation captures only $56 \%$ of the data with an accuracy of 25 $\%$ (Figure 5-5). Even though this number is low, the data collapses to a line extremely well with only a spread in data at low Nusselt numbers, which is to be expected. Watts Nusselt correlation under predicted measurements by $10 \%$ relative to Jackson's. Both the Watt's and Jackson correlation appear to need modification to account for the increased heat transfer of annular heat transfer over pipe geometries. 


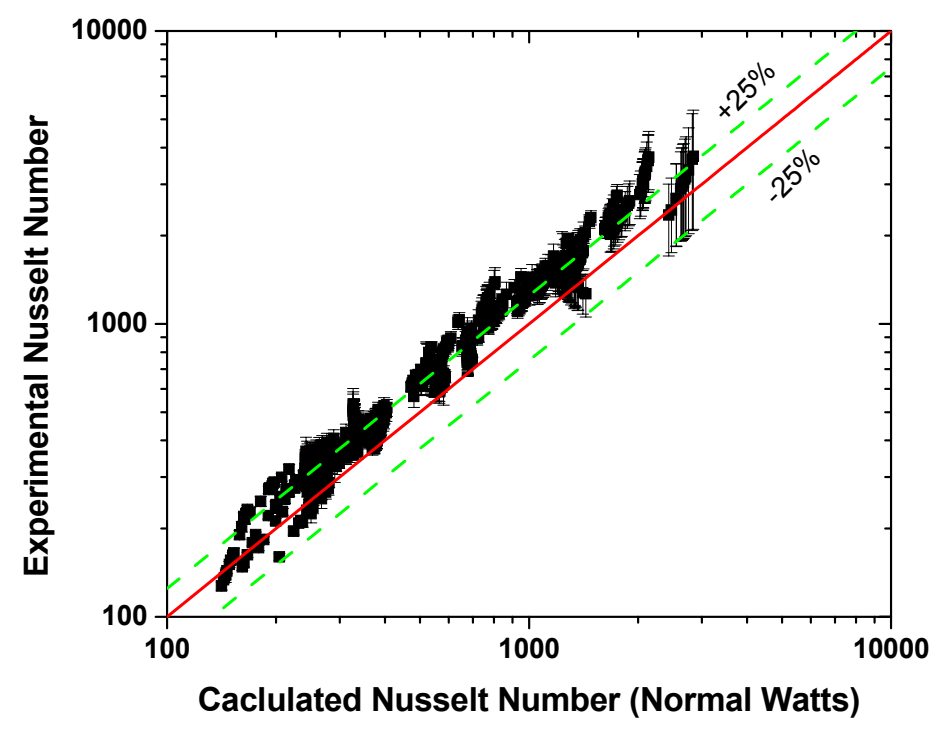

Figure 5-5 Comparison of experimental Nusselt number and Watts Nusselt correlation.

A relatively small test matrix (case $\mathrm{N}$ thru $\mathrm{T}$ ) was performed in the square geometry at low mass velocities to evaluate the onset of deterioration and the performance of selected heat transfer correlations. All data collected for the square geometry is shown in Figure 5-6 and compared with the Jackson and Watts correlation. Similar to results found for the circular geometry, the Jackson correlation is best able capture experimental results under normal heat transfer conditions while the Watts correlation under predicted results relative to Jackson's correlation. 


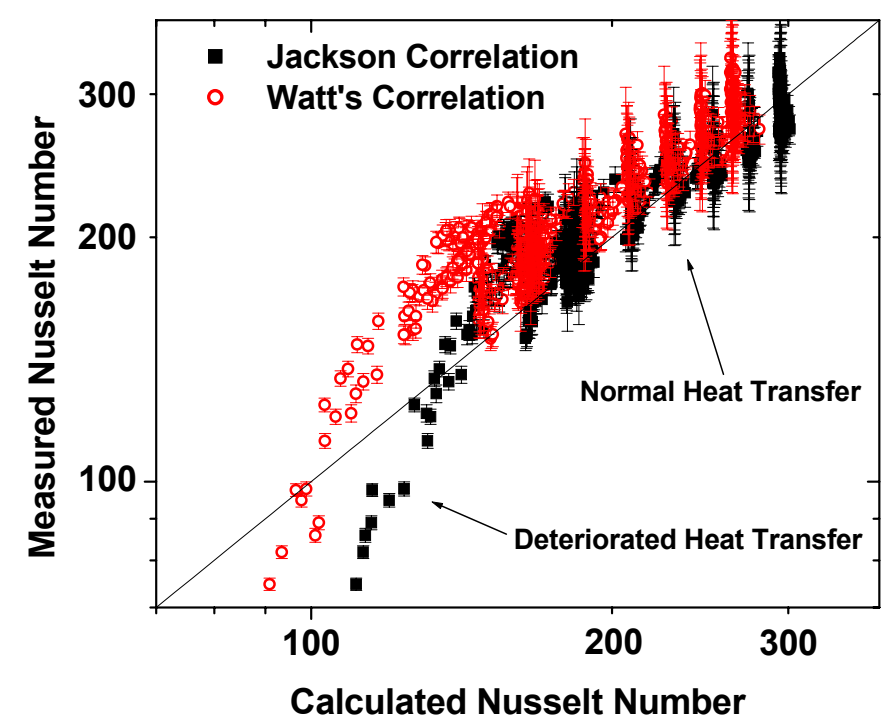

Figure 5-6 Comparison of Watts and Jackson Nusselt correlation (square geometry).

\subsection{Experimental Comparison}

Additional insight can be gained by comparing high and low mass velocity data with results from previous experiments of different geometries under similar conditions. In order to compare high mass velocity data with results from Yamagata et al., the axial heat transfer coefficient was averaged across the heater. The high mass velocity results in a very low enthalpy rise across the heated section resulting in similar heat transfer along the heater. Yamagata et al. experienced an enhancement in heat transfer near the pseudo-critical temperature. An Increase in heat flux led to a reduction in the enhancement as previously described. Comparing the heat transfer coefficient as a function of temperature and heat flux shows that our results are in agreement (Figure 5-7). At $300{ }^{\circ} \mathrm{C}$, both experiments show that heat transfer coefficient is independent of 
heat flux. At $370{ }^{\circ} \mathrm{C}$, the heat transfer coefficient is beginning to show dependence on the heat flux due to the increasing specific heat. At or near the pseudo-critical temperature, the heat transfer coefficient exhibits a maximum. At $400{ }^{\circ} \mathrm{C}$, the enhancement in heat transfer is again reduced due to the reduction in specific heat.
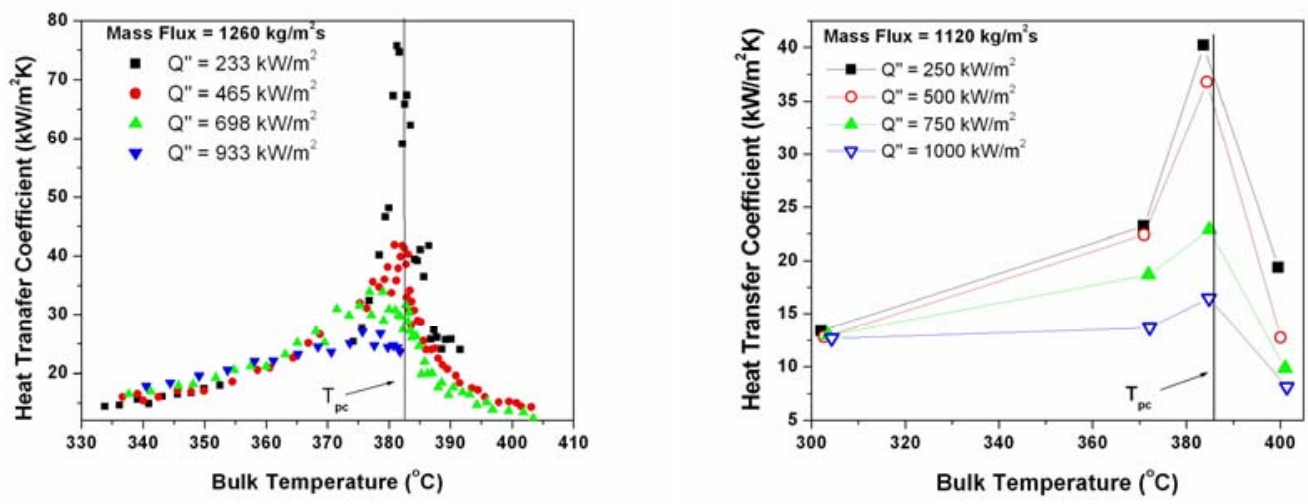

Figure 5-7 High mass velocity comparison of Yamagata et al. and UW data.

No deterioration in heat transfer was seen at high mass velocities (greater than $1000 \mathrm{~kg} / \mathrm{m}^{2} \mathrm{~s}$ ) for our range of bulk temperature and heat flux. However, at low mass velocities of $400 \mathrm{~kg} / \mathrm{m}^{2} \mathrm{~s}$, deterioration in heat transfer was present for a wide range of conditions. When deterioration was present, it almost always occurred over the first portion of the heated section (Figure 5-8a). That is, the inlet wall temperatures are similar to that expected (i.e. as predicted by Jackson's correlation), followed by deterioration and a recovery back to the expected values. This same feature was found in other experiments (watts et al. [51]). Figure 5-8b shows how deterioration in our experiment compares with that found in Shitsman's experiments. An interesting feature is the difference in enthalpy range over which deterioration occurs. Two different processes could be 
occurring. The first is that at our pressure $(25 \mathrm{MPa})$ the heat transfer deterioration is being suppressed. In other words, at higher pressure the property changes that cause deterioration are less significant. The second is that there is a region, prior to the pseudo-critical temperature, in which conditions are favorable for deterioration, and that the difference in results is due to the differing geometries (i.e. hydraulic diameter). For example, Figure 5-8c shows that at a low heat flux of $250 \mathrm{~kW} / \mathrm{m}^{2}$ there is no deterioration over the bulk temperature range of $300-400{ }^{\circ} \mathrm{C}$, however, an increase in heat flux to $500 \mathrm{~kW} / \mathrm{m}^{2}$ results in multiple deterioration points in the region prior to the pseudo-critical temperature.
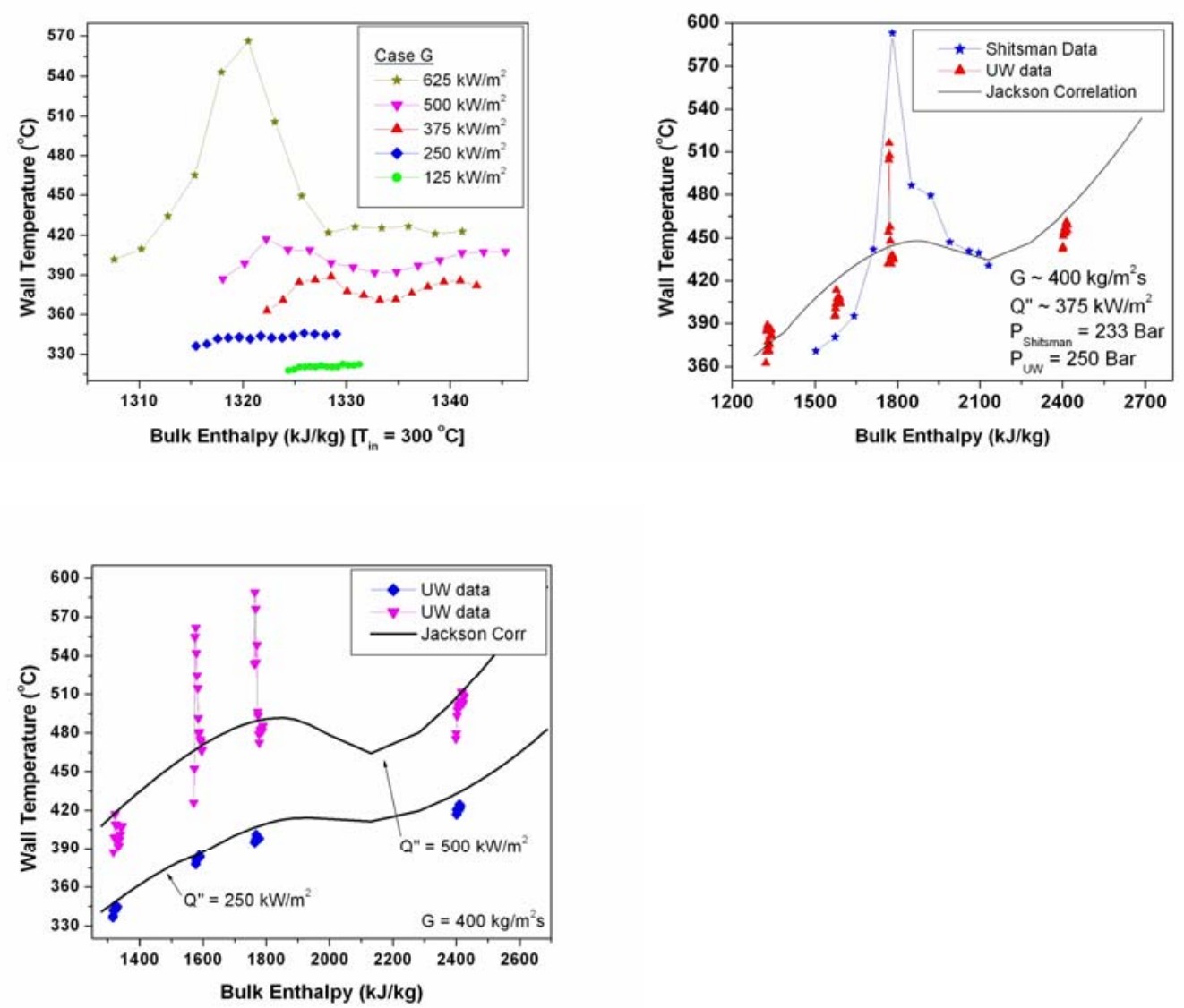

Figure 5-8 $\quad$ (a) Example of the evolution in heat transfer deterioration (UW data). (b) Comparison of UW data and Shitsman data under similar conditions. (c) Example of multiple spikes in wall temperature. 
Experiments performed at identical conditions, less than $2 \%$ deviation, were performed both the circle and square annular flow channel (Table 6: cases $G$ and T). These set of conditions exhibit normal heat transfer effects at a low heat flux $\left(125-250 \mathrm{~kW} / \mathrm{m}^{2}\right)$ and a deteriorated heat transfer at a high heat flux (375-625 $\mathrm{kW} / \mathrm{m}^{2}$ ). Comparison of the heat transfer coefficients shows geometrical differences for both high heat flux conditions (Figure 5-9).
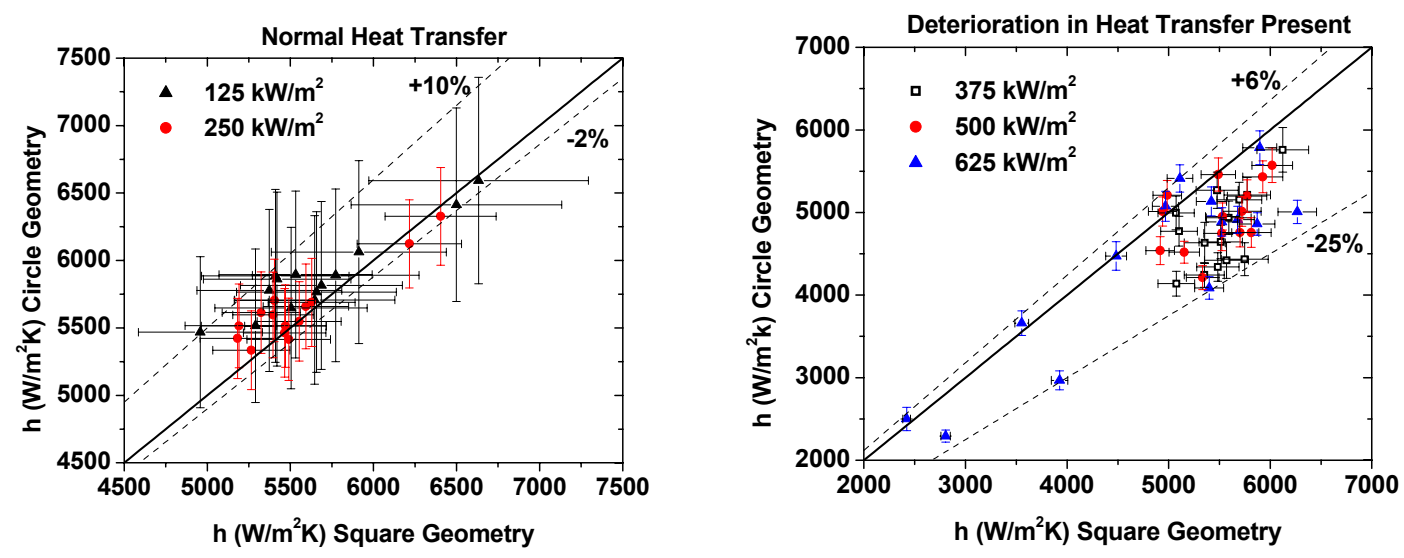

Figure 5-9 Comparison of circle and square annular flow geometry heat transfer.

At a low heat flux and normal heat transfer conditions, the circular geometry heat transfer varies from $2 \%$ less than the square geometry to $10 \%$ greater. However, the uncertainties are on the order of $10 \%$ suggesting that the two geometries statistically produce the same heat transfer. At a high heat flux and conditions of deterioration, the circular geometry heat transfer varies from $6 \%$ greater to $25 \%$ less than that of the square geometry. At these conditions the 
two geometries produce different heat transfer coefficients. A similar observation is seen when comparing circular annular flow with data from Shitsman (Figure 5-8b). That is, at the similar operating conditions, normal heat transfer was in agreement with correlations and experiments of different geometries, whereas conditions of deterioration were found to differ with both. It was proposed that the effects of deterioration, i.e. wall temperature, were dependent on the hydraulic diameter. The reason for these differences in heat transfer remain up for debate, however, continuing work should lead to further insight of the processes occurring under these conditions.

\subsection{Buoyancy Criterion}

In an effort to clearly present data, the locally calculated buoyancy criterion were averaged to get one criterion value for each experiment. Evaluating all of the experiments led to the problem of determining when buoyancy (or deterioration) was actually present. Some experiments exhibited $100{ }^{\circ} \mathrm{C}$ temperature rises while others showed a 5 to $10{ }^{\circ} \mathrm{C}$ change. It was decided that one value for a criterion limit was not very useful so two limits were found. One limit was chosen to be over inclusive, meaning that any experiment that appeared to have a small, localized, increase in temperature was marked as deterioration. Another criterion limit was chosen in which large, localized, temperature spikes were easily visualized, neglecting smaller temperature increases. Figure 5-9 shows the results using Jackson's criterion and Seo's criterion. The y-axis is the calculated criterion value normalized with the average of the two criterion limits. Experiments resulting in criterion values above the limit experienced deterioration 
where as values below the limit exhibited normal heat transfer. The middle band indicates a region in which deterioration may or may not be present.
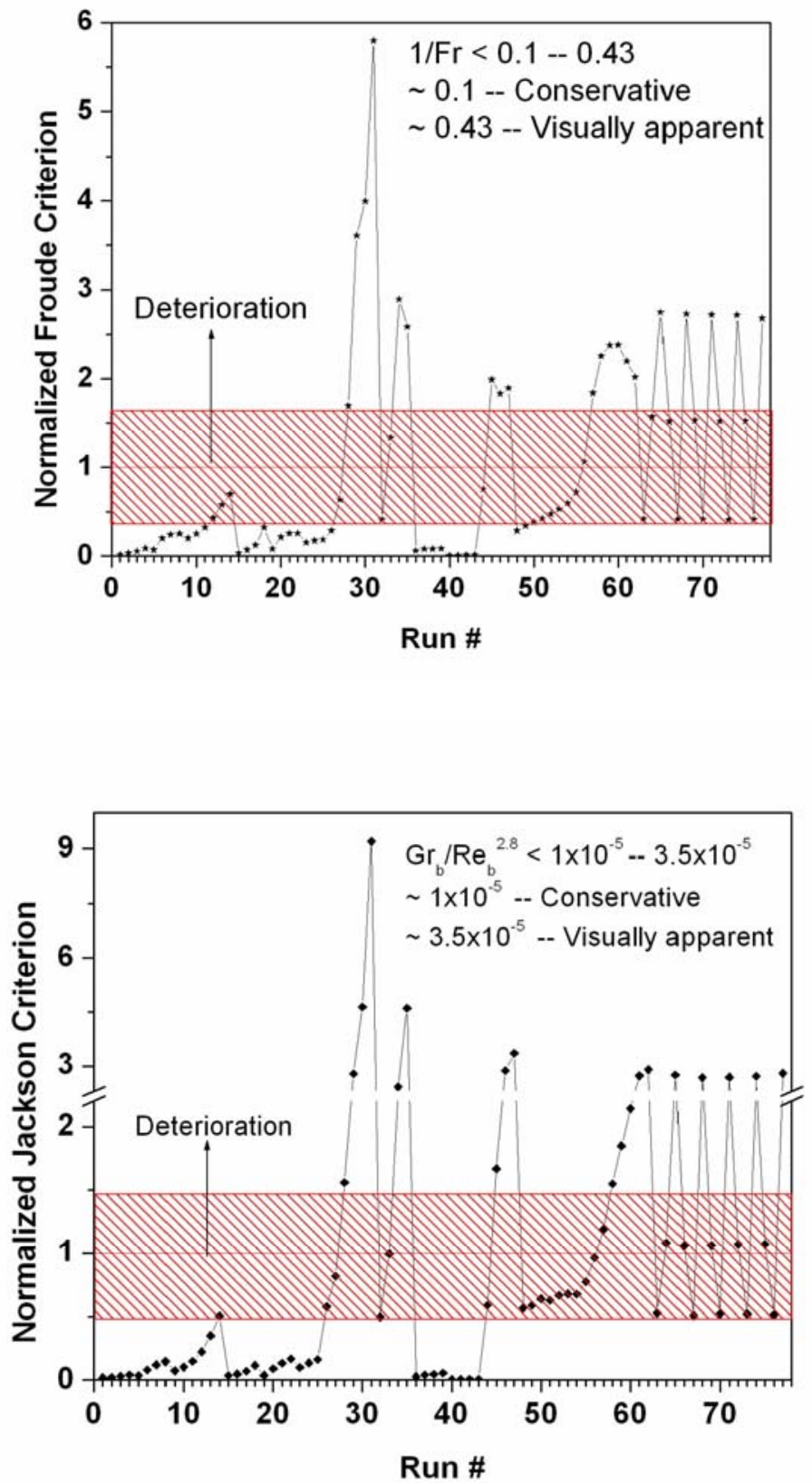

Figure 5-10 Buoyancy criterion evaluated at local conditions in UW experiment.

Seo suggested that the criterion limit was found to be 0.03 based on previous experiments, however this criterion was developed with the Dittus-Boelter 
Correlation, which is not the best correlation. Instead, this paper uses Seo's criterion with Jackson's heat transfer correlation replacing the Dittus-Boelter correlation and replacing property subscripts in equation 6 with wall and bulk instead of film subscripts. In the term including a difference in density and temperature, the wall subscript was used; all other s subscripts were replaced with the bulk subscript. Using this method, a conservative criterion limit of 0.1 was found with the more severe deteriorations occurring at a values greater than 0.43 .

Jackson's criterion is promising in that his suggested criterion limit conservatively captures all experiments with deteriorated heat transfer. Again, a higher limit was taken to encompass only data with significant deterioration. Both criterion exhibit similar trends suggesting that both may be successful at predicting deterioration. However, only Jackson's criterion limit has been proven universal to various experiments, further comparisons are required to evaluate Seo's criterion limit with the modifications described in this paper.

\subsection{Summary}

Jackson's heat transfer correlation shows the best agreement with all UW data. The Watt's correlation may also be applicable with slight modification of the leading coefficient. These correlations work for both high and low mass velocity experiments in the absence of heat transfer deterioration. Accounting for increased heat transfer in annular flows should improve the performance of these Nusselt correlations. 
High mass velocity data exhibits an enhancement in heat transfer centered near the pseudo-critical temperature where there is a large value of specific heat. An increase in heat flux impairs the magnitude of the heat transfer coefficient in the region surrounding the pseudocritical region. These results are consistent with previous investigations in the literature [53].

Low mass velocity data exhibited heat transfer deterioration at subpseudocritical temperatures. This deterioration was present in previous investigations; however, UW data has shown its dependence on geometry. It is believed that deteriorated heat transfer cannot be reproduced with Nusselt correlations due to its dependence on localized conditions such as thermal profile, velocity profile, inlet temperature, pressure, mass velocity, and heat flux. Local computational models to examine the likely effects of variable properties and turbulent transport would be needed.

Both the Froude Number criterion (Seo) and Jackson's criterion are able to predict the onset of buoyancy effects with the proper criterion value. Jackson's suggested criterion value has been found to be valid for our set of operating conditions. A new conservative criterion limit of 0.1 has been suggested for Seo's criterion limit when modified to use Jackson's Nusselt correlation and local property values. Such an approach provides a conservative 
bound on the expected onset of heat transfer degradation with the known inlet flow and heat transfer conditions. 


\section{Reference}

[1] Adrian, R. J., and Earley, W. L. Evaluation of laser-doppler velocimeter performance using mie scattering theory. In Proceedings of the Minnesota Symposium on Laser Anemometry (1975). T-AM Report No. 479.

[2] Albrecht, H., Borys, M., Damaschke, N., and Tropea, C. Laser Doppler and Phase Doppler Measurement Techniques. Springer, 2003.

[3] Allex, P. Density measurements using raman scattering photometry in supercritical water. Master's thesis, University of Wisconsin Madison, 2006.

[4] Bishop, A. A., Sandberg, R. O., and Tong, L. S. Forced convection heat transfer to water at near-critical temperatures and supercritical pressures. Tech. rep., Westinghouse Electric Corporation, November 1964. Report WCAP-2056, Part IV.

[5] Bourke, P. J., and Pulling, D. J. Experimental explanation of deterioration in heat transfer to supercritical carbon dioxide. American Society of Mechanical Engineering (1971), 7. 71-HT-24.

[6] Buongiorno, J. The ineel heat transfer flow loop for development of supercritical water-cooled reactors.

[7] Cheng, X., and Schulenberg, T. Heat transfer at supercritical pressuresliterature review and application to an HPLWR. PhD thesis, Karlsruhe, Germany, 2001. FZKA 6609.

[8] Committee, U. D. N. E. R. A., and the Generation IV International Forum. A technology roadmap for the generation iv nuclear energy systems. Tech. Rep. GIF00200, INEEL, 2002. available at http://www.nuclear.gov/geniv/roadmap.html.

[9] Dittus, F. W., and Boelter, L. M. K. Heat transfer in automobile radiators of the tubular type. University of California Publication in English, Berkeley 2(1930), 443-461.

[10] Duderstadt, J. J., and Hamilton, L. J. Nuclear Reactor Analysis. John Wiley and Sons, Inc., 1976.

[11] Durst, F., Fisher, M., Jovanovic, J., and Kikura, H. Methods to set up and investigate low reynolds number, fully developed turbulent plane channel flows. Journal of Fluids Engineering 120 (September 1998), 496-503. 
[12] Durst, F., Jovanovic, J., and Sender, J. Detailed measurements of the near wall region of turbulent pipe flow. In Turbulent Shear Flows 9 (Berlin, 1993), Springer, pp. 225-240.

[13] Durst, F., Jovanovic, J., and Sender, J. Lda measurements in the nearwall region of a turbulent pipe flow. Journal of Fluid Mechanics 295 (1995), 305-335.

[14] Durst, F., Kikura, H., Lekakis, I., Jovanovic, J., and Ye, Q. Wall shear stress determination from near-wall mean velocity data in turbulent pipe and channel flows. Experiments in Fluids (1996), 417-428.

[15] Durst, F., Martinuzzi, R., Sender, J., and Thevenin, D. Lda measurements of mean velocity, rms value, and high-order moments of turbulence intensity fluctuations in flow fields with strong velocity gradients. In 6th International Symposium on Application of Laser Techniques to Fluid Mechanics (Lisbon, Portugal, 1992), pp. 5.1.1-5.1.6.

[16] Dyadyakin, B. V., and Popov, A. S. Heat transfer and thermal resistance of tight seven-rod bundle, cooled with water flow at supercritical pressures. Transactions of VTI, 11 (1977), 244-253. In Russian.

[17] Eckbreth, A. C. Laser Diagnostics for combustion temperature and species. Abacus Press, Cambridge, Mass, 1988.

[18] Glushchenki, L. F., and Gandzyuk, O. F. Temperature conditions of the wall of an annular channel with internal heating at supercritical pressures. High Temperatures 10, 4 (1972), 734-738.

[19] Glushchenki, L. F., Kalachev, S. I., and Gandzyuk, O. F. Determining the conditions of existence of deteriorated heat transfer at supercritical pressures of the medium. Thermal Engineering 19, 2 (1972), 107-111.

[20] Hall, W. B., and Jackson, J. D. Laminarization of turbulent pipe flow by buoyancy forces. In American Society of Mechanical Engineering, Papers (1969), American Society of Mechanical Engineers (ASME), pp. 1-8. Paper number 69- HT-55.

[21] Jackson, J., Hall, W., Fewster, J., Watson, A., and Watts, M. Heat transfer to supercritical pressure fluids. Design Report 34, U.K.A.E.A., 1975.

[22] Jackson, J. D., and Hall, W. B. Forced convection heat transfer to fluids at supercritical pressure. In Turbulent forced convection in channels and bundles, vol. 2. Hemisphere Publishing Company, 1979, pp. 563-611. 
[23] Jackson, J. D., and Hall, W. B. Influence of buoyancy on heat transfer to fluids flowing in vertical tubes under turbulent conditions. In Turbulent forced convection in channels and bundles, vol. 2. Hemisphere Publishing Company, 1979, pp. 613-640.

[24] Jackson, J.D. Studies of buoyancy-influenced turbulent flow and heat transfer in vertical passages. $13^{\text {th }}$ International Heat Transfer Conference, Sydney, Autralia, 13-18 August 2006, Key-Note lecture 24.

[25] Kestin, J., Sengers, J., and Kangmar-Parsi, B. Thermophysical properties of fluid h2o. J. Phys. Chem. Ref. Data 13, 175 (1984).

[26] Knapp, K. K., and Sabersky, R. H. Free convection heat transfer to carbon dioxide near the critical point. International Journal of Heat and Mass Transfer 9 (1966), 41-51.

[27] Komita, H., Morooka, S., Yoshida, S., Mori, H., 2003. Study on the heat transfer to the supercritical pressure fluid for supercritical water cooled power reactor development. Proc. of $10^{\text {th }}$ Int. Topical Meating on Nuclear Reactor Thermal Hydraulics (NURETH 10), Seoul, Korea.

[28] Krasnoshchekov, E. A., Petukhov, B. S., and Protopopov, V. S. An investigation of heat transfer to fluids flowing in pipes under supercritical conditions. In International Heat Transfer Conference (University of Colorado, Boulder, CO, USA, January 8-12 1961), pp. 569-578. Paper 67.

[29] Kurganov, V. A., Ankudinov, V. B., and Kaptilnyi, A. G. Experimental study of velocity and temperature fields in an upward flow of carbon dioxide of a supercritical pressure in a vertical heated tube. Teplofzika Vysokikh Temperaur24, 6 (1986), 811-818.

[30] McAdams, W. H., Kennel, W. E., and Addoms, J. N. heat transfer to superheated steam at high pressures. American Society of Mechanical Engineers72, 4 (1950), 421-428.

[31] Menon, R., and Lai, W. T. Key considerations in the selection of seed particles for Idv measurements. In Fourth International Conference on Laser Anemometry (August 1991). Available from TSI.

[32] Miropolskiy, Z. L., and Baigulov, V. I. Investigation in heat transfer, velocity and temperature profiles with carbon dioxide flow in a tube over the nearly critical region of parameters. In Proceeding of the 5th International heat transfer conference (1974), Japanese Society of Mechanical Engineering, pp. 177-181. tokyo, Japan. 
[33] of Mechanical Engineers, A. S. Measurement of fluid flow in pipes using orifice, nozzle, and venturi. ASME MFC 3M-1989. New York: The Society, 1990.

[34] Oka, Y., and Koshizuka, S., Eds. Design concept of once-through cycle supercritical-pressure light water reactors (November 6-9 2000). Paper No. 101.

[35] Ornatskiy, A. P., Glushchenko, L. F., and Gandzyuk, O. F. An experimental study of heat transfer in externally heat annuli at supercritical pressures. Heat Transfer Soviet Res. 46 (1972), 25-29.

[36] Petukhov, B.S., Roizen, L.I., 1964. Generalized relationship for heat transfer in a turbulent flow of gas in tubes of annular section. High Temperature 2, 65-68.

[37] Pioro, I., Khartabil, H. F., and Duffey, R. B. Heat transfer to supercritical fluids flowing in channels-emperical correlations (survey). Nuclear Engineering and Design 230 (2004), 69-91.

[38] Pioro, I. L., and Duffey, R. B. Experimental heat transfer to water flowing in channels at supercritical pressures (survey). In Global 2003: Atoms Prosperity: Updating Eishouwer Global Vision for Nuclear Energy (November 16-20 2003), American Nuclear Society, pp. 2342-2361.

[39] Pioro, I. L., Khartabil, H. F., and Duffey, R. B. Heat transfer at supercritical pressures (survey). In Heat transfer at supercritical pressures (survey) (2003), The 11th International Conference on Nuclear Energy, pp. 1-12. Tokyo, Japan.

[40] [Proceedings of the 1st international symposium of supercritical water cooled reactor design and technology. Heat and Mass transfer at supercritical Parameters (the short review of researches in Russia: theory and experiments) (November 2000). University of Tokyo.

[41] Proceedings of the 1st international symposium of supercritical water cooled reactor design and technology. Heat transfer to supercritical pressure fluids flowing in tubes (November 2000). University of Tokyo.

[42] P. O. Ring Division, Static O-ring Sealing. Chapter 4.

[43] Seo, K. Study on the phenomena of the supercritical flow and heat transfer. Internal Document, 2004. 
[44] Seo, K. W. Heat Transfer Mechanism in Supercritical Fluids: Analysis and Model Developments. PhD thesis, Pohang University, December 2005.

[45] Seo, K. W. Studies of supercritical heat transfer and flow phenomena. In Studies of supercritical heat transfer and flow phenomena (October 2-6 2005), The $11^{\text {th }}$ NUclear REactor Thermal Hydraulics (NURETH). 162.

[46] Shedd, T. Internal communications.

[47] Shiralkar, B. and Griffith, P. 1970. The effect of swirl, inlet conditions, flow direction and tube diameter on the heat transfer of fluids at supercritical pressure. J. Heat Transfer, vol 92, 465-474.

[48] Shitsman, M. E. Impairment of the heat transfer at supercritical pressures. High Temperatures (Teplofzika Vysokikh Temperaur ctp. 267-275) 1, 2 (1963), 237- 44.

[49] Silin, V. A., Voxnesensky, V. A., and Afrov, A. M. The light water integral reactor with natural circulation of the coolant at supercritical pressure $b-$ 500 skdi. Nuclear Engineering and Design, 144 (1993), 327-336.

[50] Stanley, H. E. Phase Transition and Critical Phenomena. Oxford, 1971.

[51] Watts, M. J., and Chou, C. Mixed convection heat transfer to supercritical pressure water. In Proceeding of the 7th International Heat Transfer Conference (1982), pp. 495-500. Munchen, Germany.

[52] Wood, R. D., and Smith, J. M. Heat transfer in the critical regiontemperature and velocity profile in turbulent flow. AICHE 10, 2 (1964), 180-186.

[53] Yamagata, K., Nishikawa, K., Hasegawa, S., and Fujii, T. Forced convective heat transfer to supercritical water flowing in tubes. International Journal of Heat and Mass Transfer 15, 12 (1971), 25752593.

[54] Zarate, J. A., Capizzani, M., and Roy, R. P. Velocity and temperature wall laws in a vertical concentric annular channel. International Journal of Heat and Mass Transfer 41, 2 (January 1998), 287-292.

[55] Zheng, F. Thermophoresis of spherical and non-spherical particles: A review of theories and experiments. Advances in Colloid and Interface Science 97, 1-3 (march 2002), 255-278. 


\section{Appendix A - Heater X-ray Images}
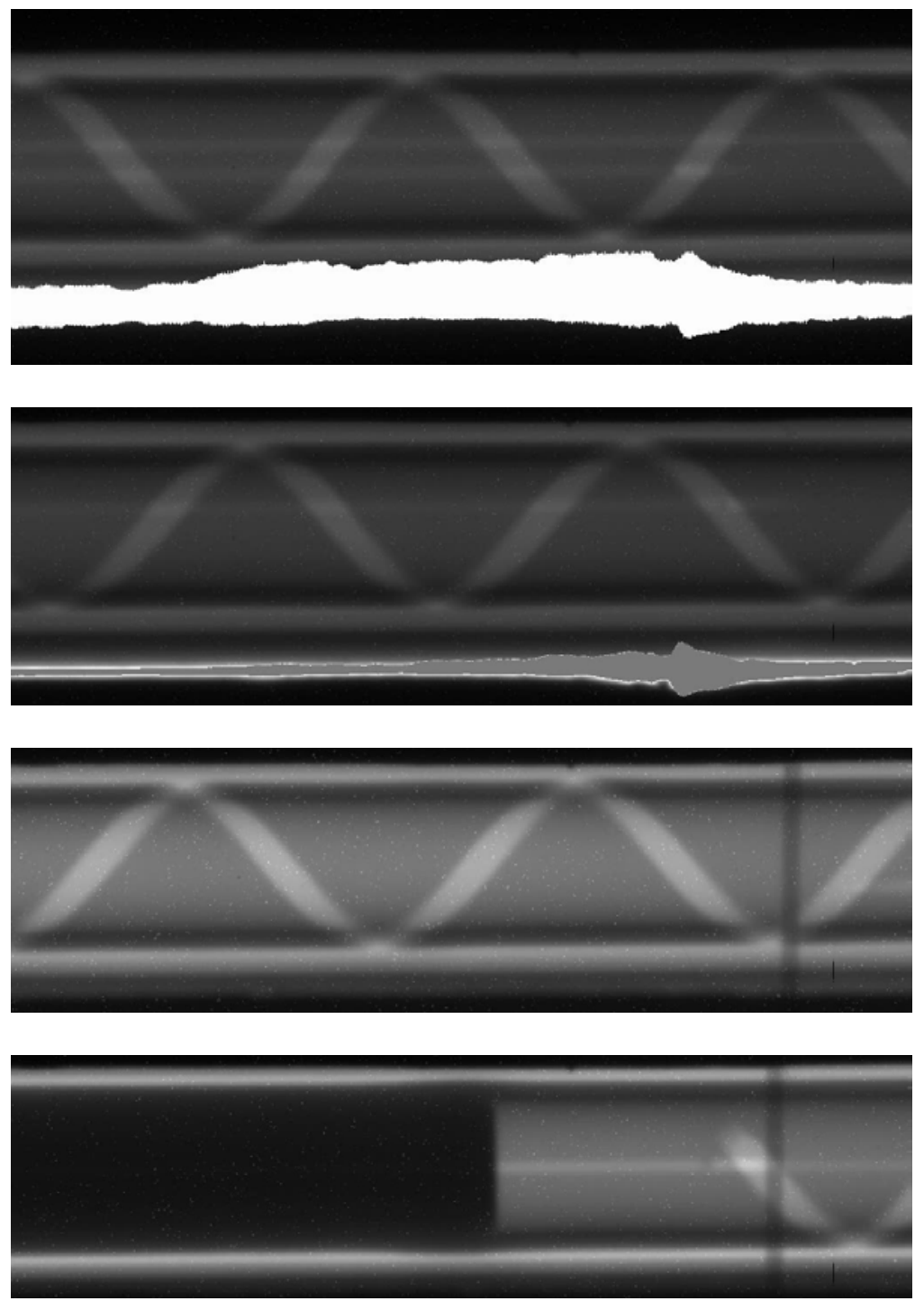

X-ray images of the heating element with in the heater rod. Pictures centered at the end point of thermocouples: a) B, b) E, c) X, d) A (end of heated element).

The heating element gap (ribbon) is depicted as the light gray colored sinusoidal strip. The darker gray middle is the actual heated material. The internal thermocouple wires can be faintly be seen as the light gray colored lines running the length of the heater. Only wires positioned in the center of rod can be visualized (i.e. away from the top and bottom of the pictures). 


\section{Appendix B - Heater End Dimensions}

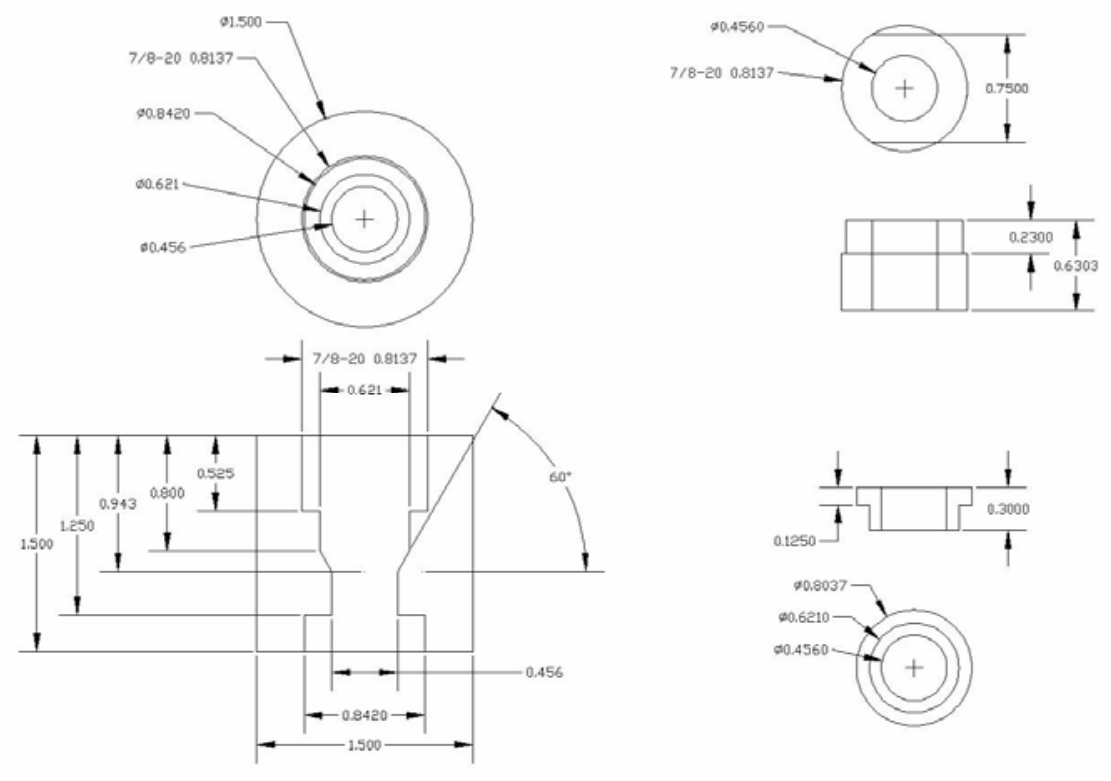

Details of fixed pressure boundary of the protruding heater rod.
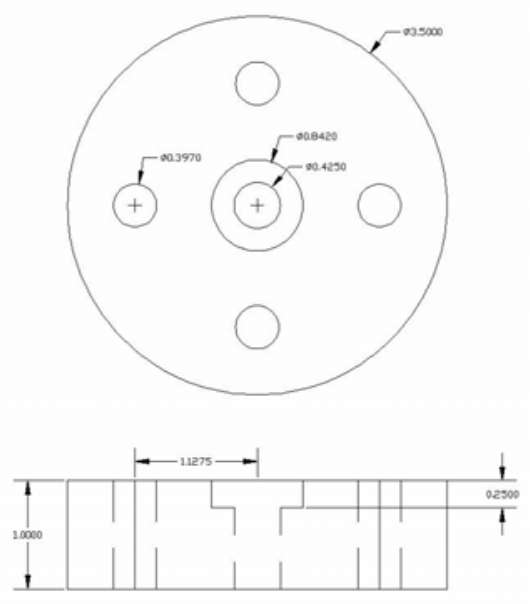
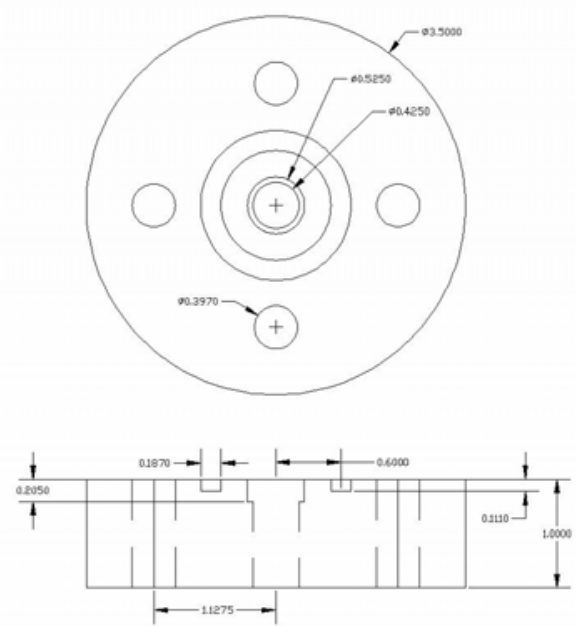

Details of pressure boundary allowing for differential thermal expansion of the protruding heater rod. 


\section{Appendix C - Facility Layout}

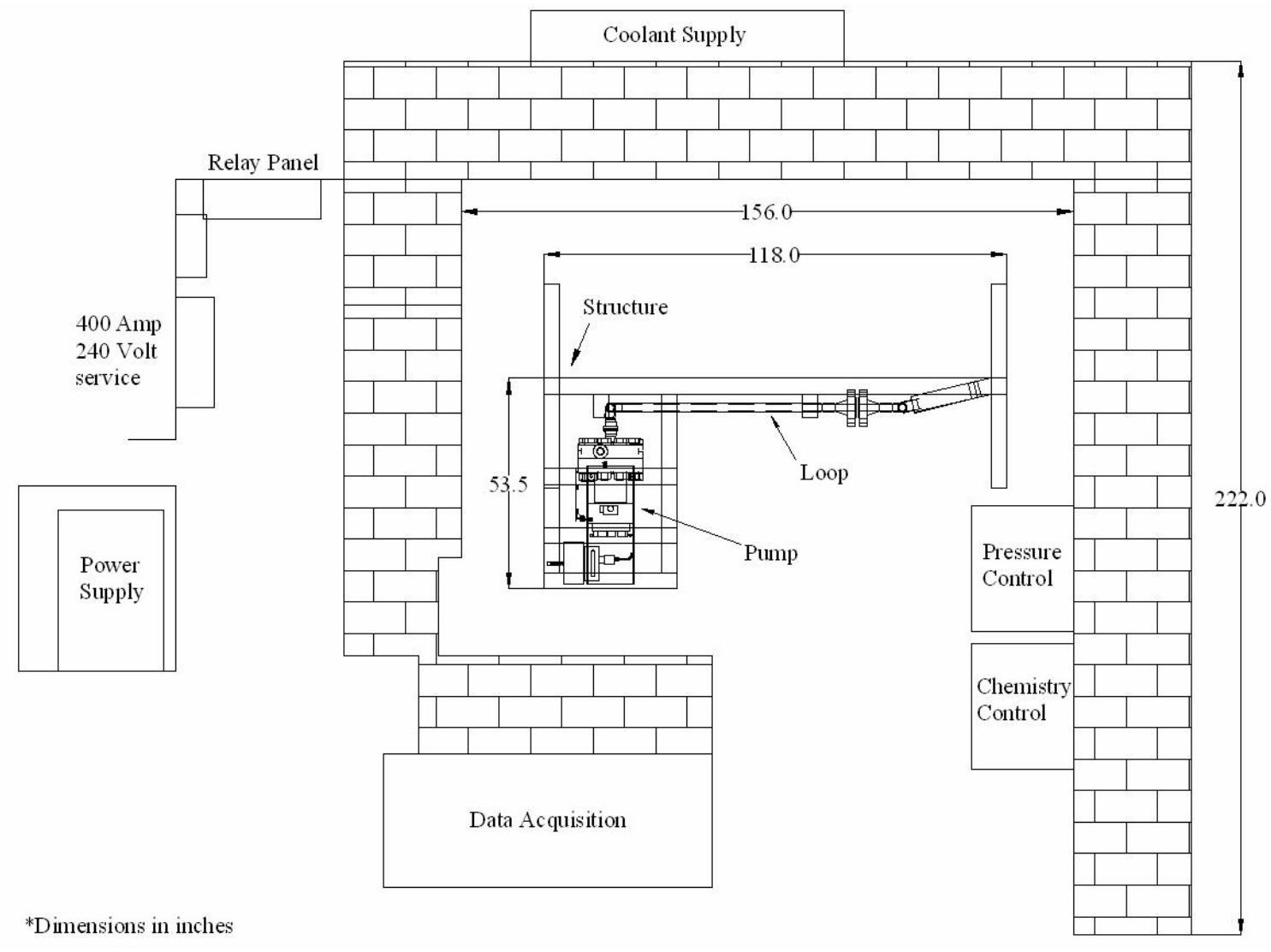



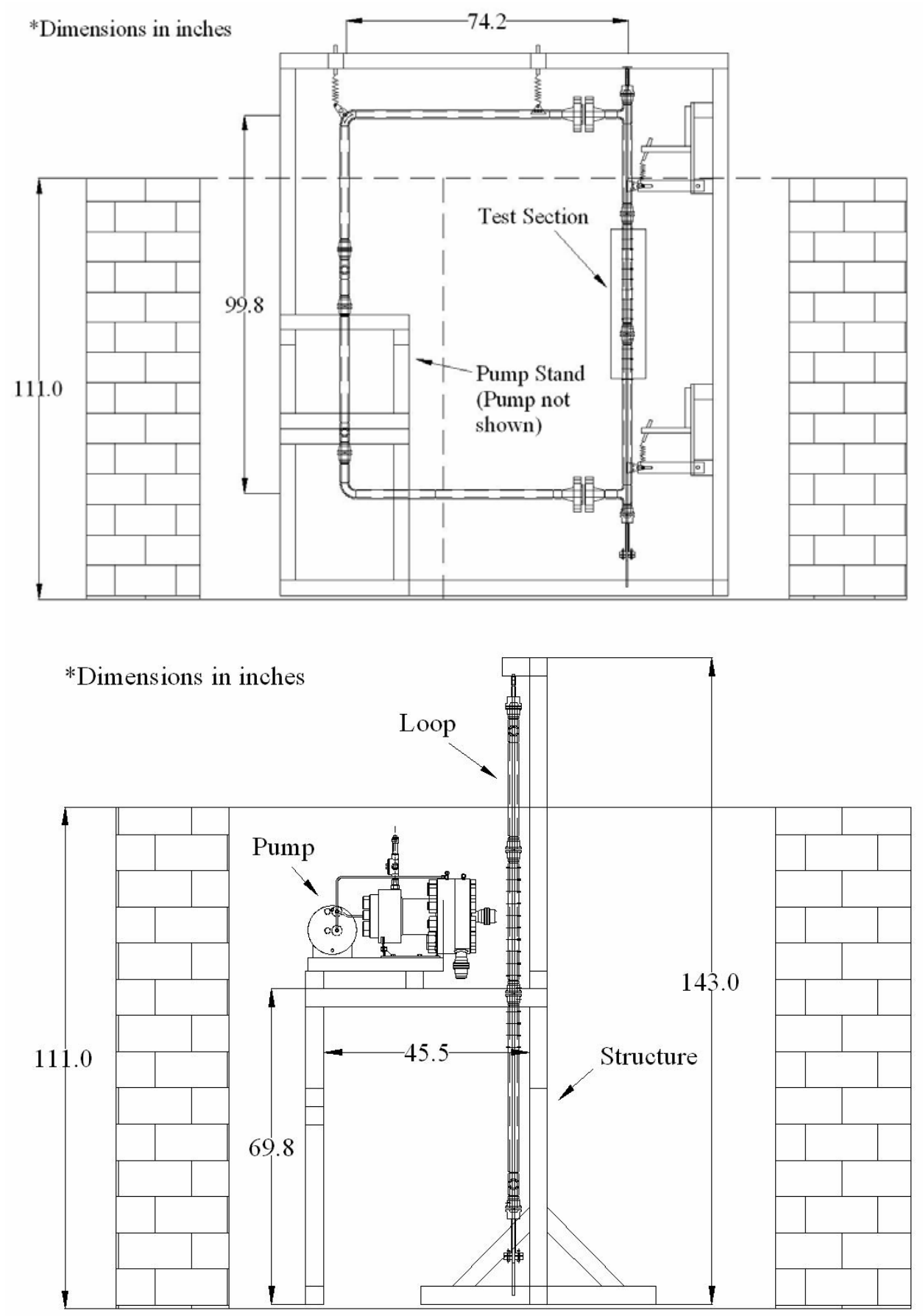


\section{Appendix D - LabVIEW Code}

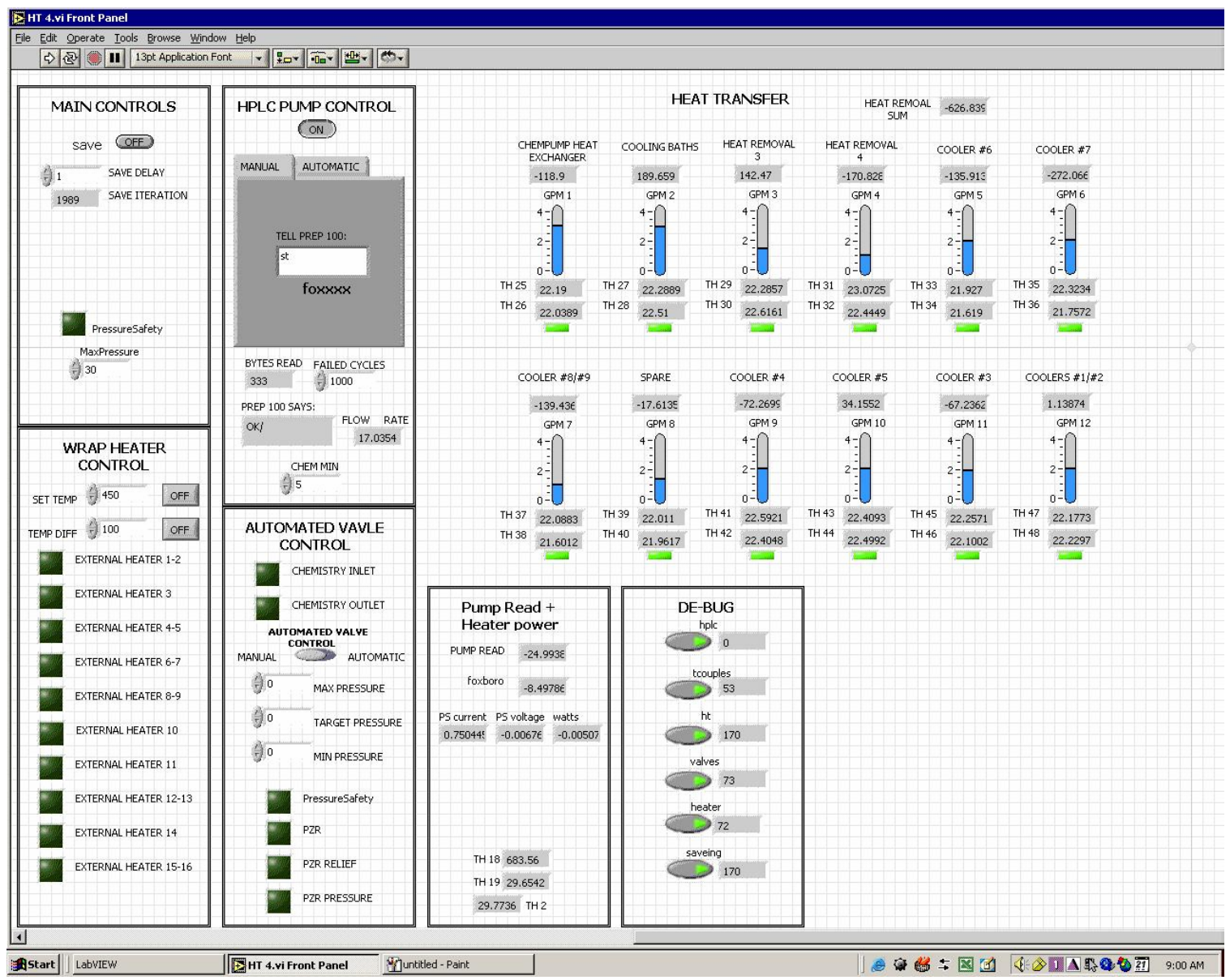




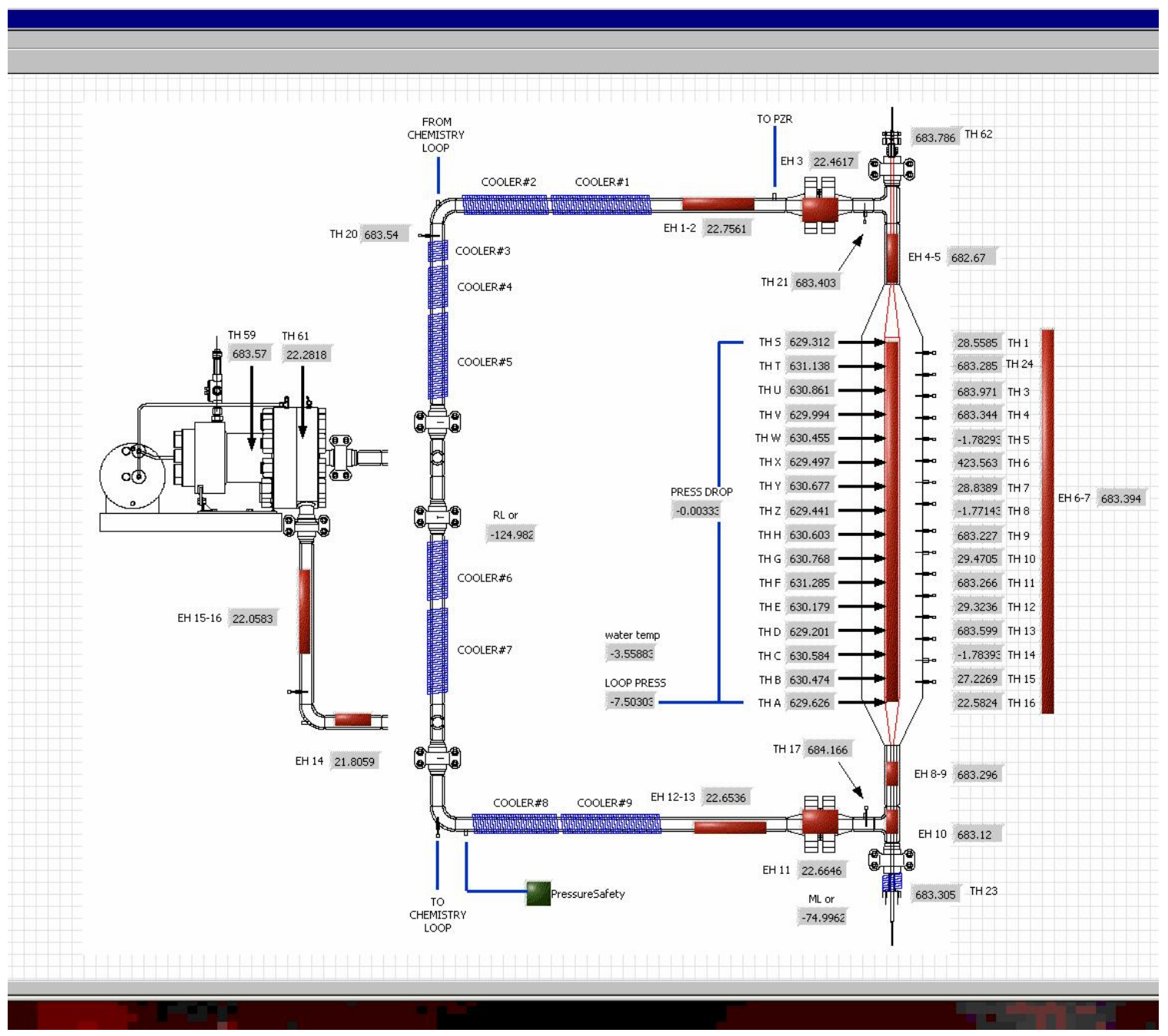




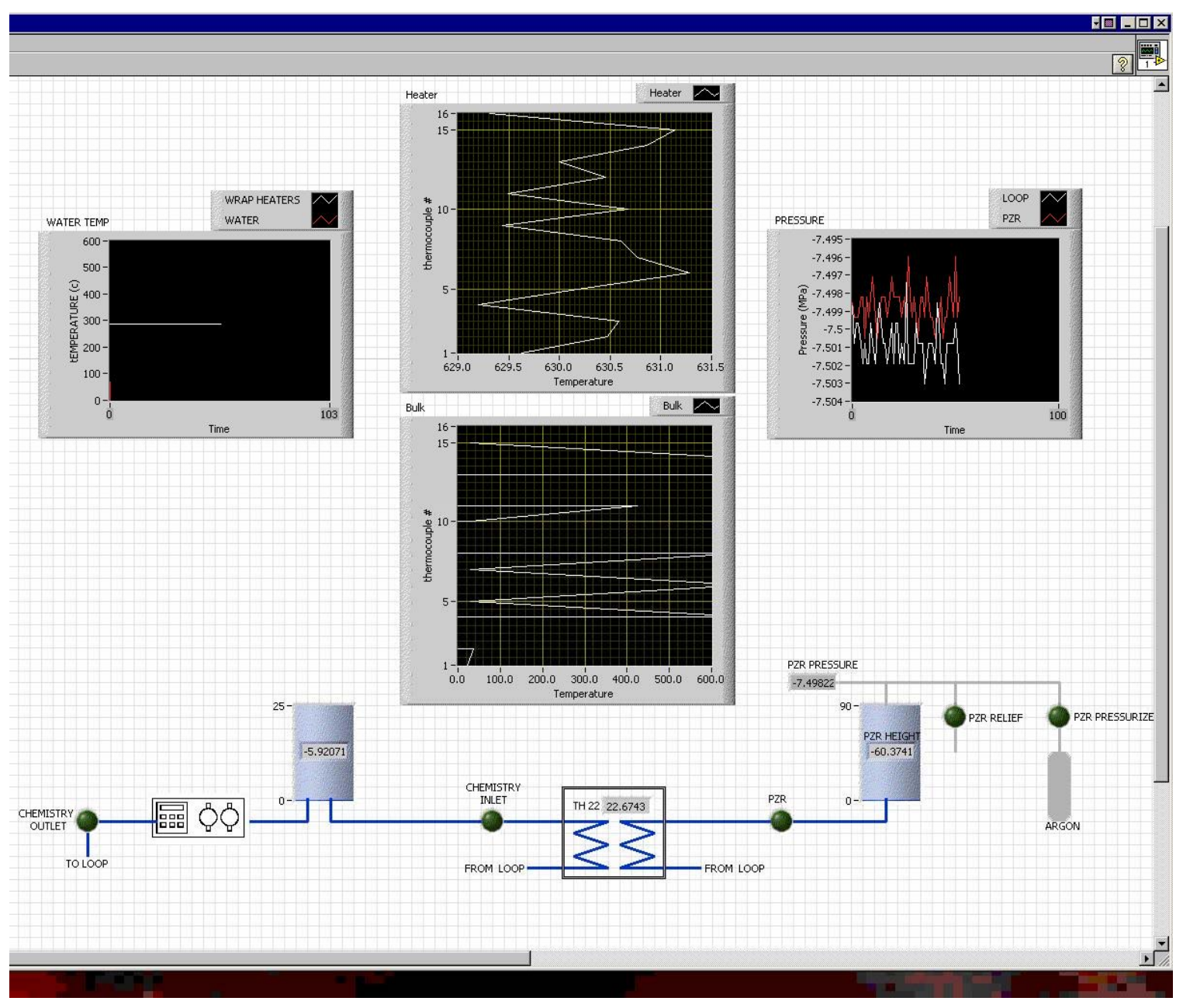




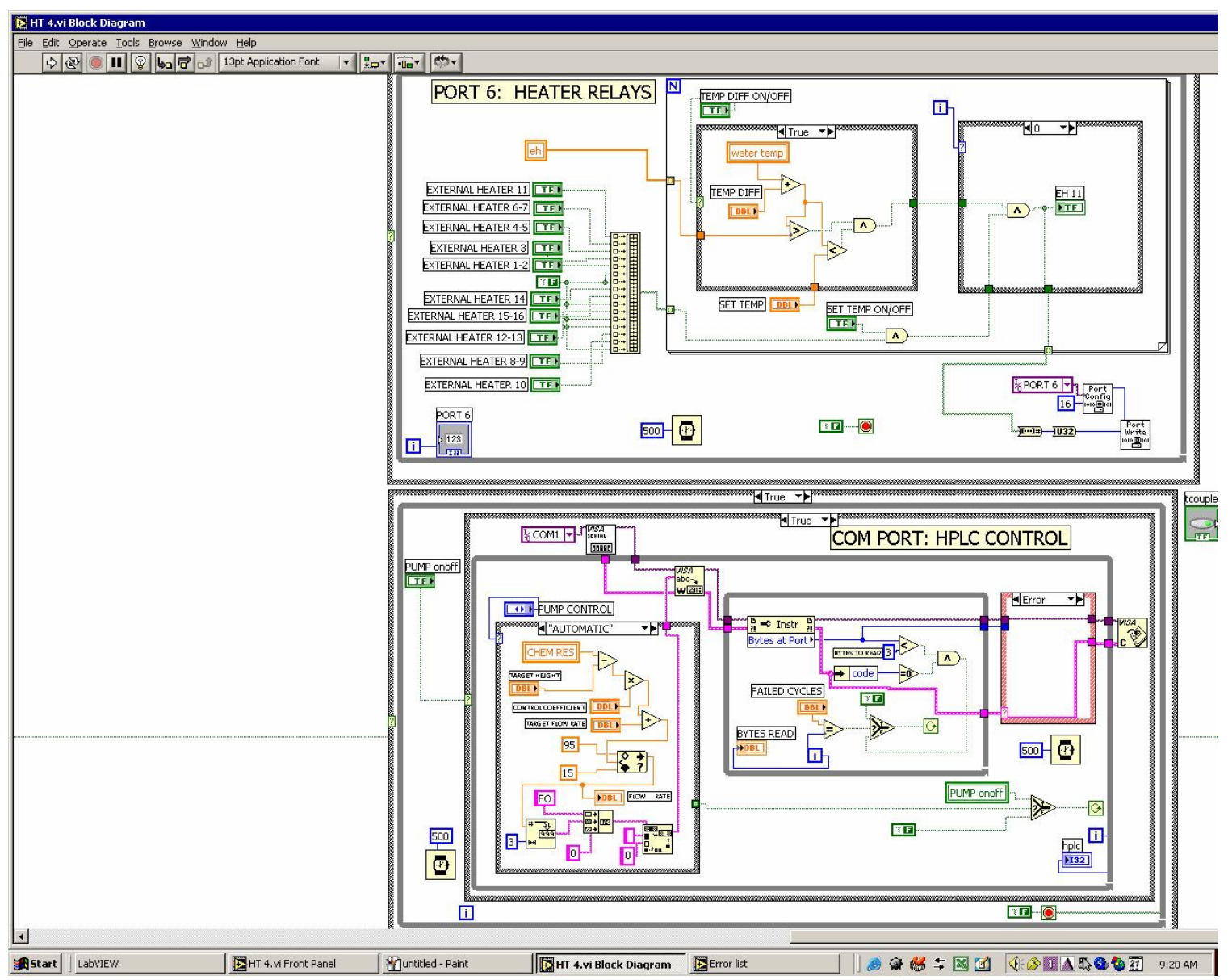




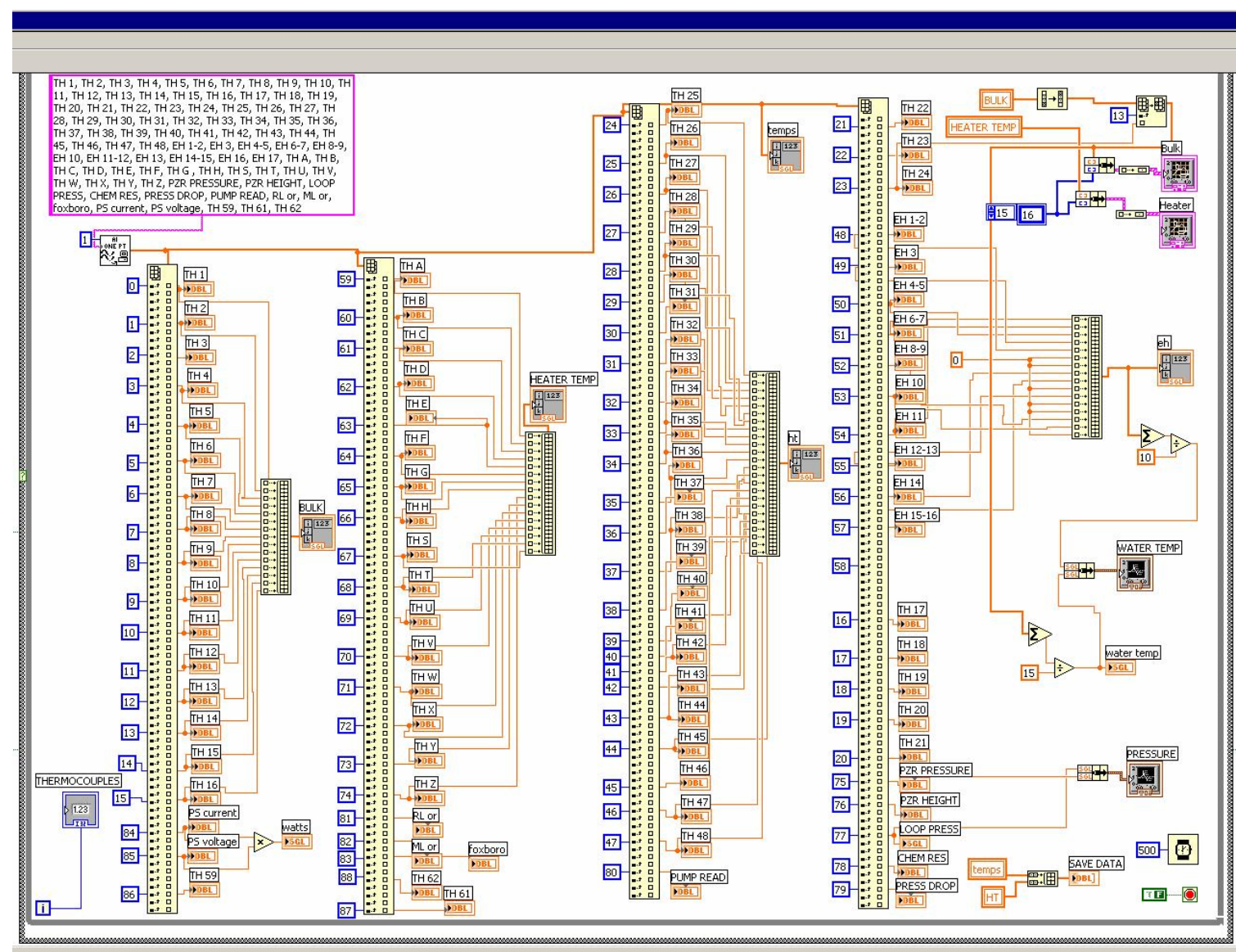




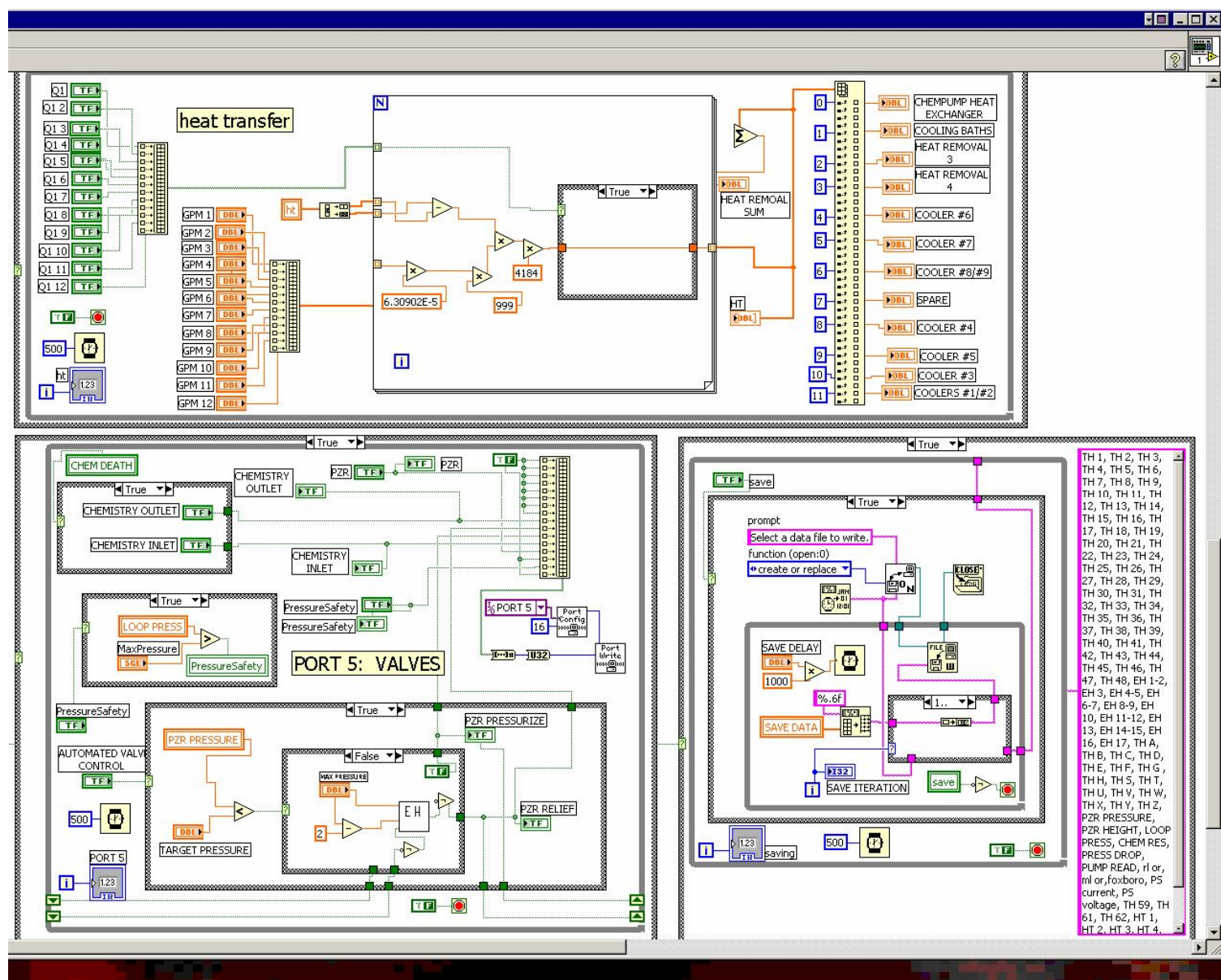




\section{Appendix E - Heater Surface Roughness Measurements}

\begin{tabular}{|l|l|l|l|}
\hline & $\mathrm{Ra}(\mu \mathrm{m})$ & $\mathrm{Ry}(\mu \mathrm{m})$ & $\mathrm{Rz}(\mu \mathrm{m})$ \\
\hline pre & .4 & 2.7 & 1.8 \\
\hline & .5 & 5.4 & 2.7 \\
\hline & .4 & 3.6 & 2.1 \\
\hline & .4 & 2.4 & 1.5 \\
\hline & .5 & 3 & 1.6 \\
\hline & .3 & 2.1 & 1.3 \\
\hline & .3 & 2.3 & 1.3 \\
\hline post & .46 & & 3.27 \\
\hline & .28 & & 2.38 \\
\hline & .48 & & 3.36 \\
\hline & .31 & & 2.59 \\
\hline & .36 & & 2.93 \\
\hline
\end{tabular}

Heater rod surface roughness measurements prior to use and following circular annular heat transfer measurements. 


\section{Appendix F - Heat Transfer Uncertainty Example}

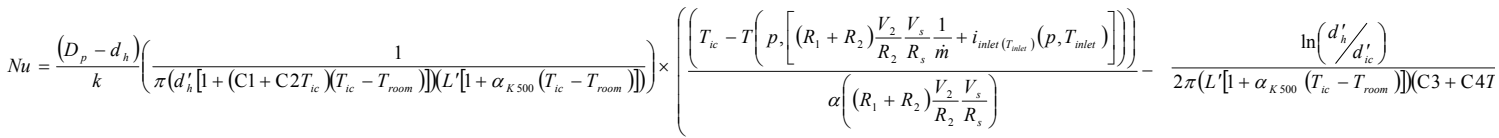

$$
\begin{aligned}
& \dot{m}=C_{d} \frac{\pi}{4}\left(d_{0}^{\prime}\left[1+\alpha_{625\left(T_{i n}\right)}\left(T_{i n}-T_{\text {rom }}\right)\right]\right]^{2} \sqrt{\frac{2\left(\frac{V_{o}}{R_{o}}(C 8)-C 9\right) \rho_{T_{i n}}\left(p, T_{\text {inter }}\right)}{\left(1-\left(d_{0}^{\prime} / D_{p}^{\prime}\right)^{4}\right)}} \quad \alpha_{625\left(T_{n}\right)}=\mathrm{C} 5+\mathrm{C} 6 T_{i n}+\mathrm{C} 7 T_{i n}{ }^{2}
\end{aligned}
$$

\begin{tabular}{|c|c|c|c|c|c|c|c|c|c|c|c|c|c|c|c|c|}
\hline \multicolumn{17}{|c|}{ Normal Heat Transfer (high mass velocity) } \\
\hline Run & Th & Nus & Nus_sig & d_ic & $\mathbf{P}$ & Vo & Vs & V2 & Tin & Tclad & d_h & C1 & C2 & C3 & C4 & C5 \\
\hline 16 & 2 & 708 & 41 & -15.25 & -0.02 & -0.03 & 0.17 & 0.17 & 25.28 & -25.70 & 2.81 & -0.03 & -0.03 & -1.28 & -1.97 & 0.00 \\
\hline 16 & 3 & 687 & 38 & -14.81 & -0.02 & -0.06 & 0.15 & 0.15 & 23.91 & -24.12 & 2.62 & -0.03 & -0.03 & -0.80 & -1.21 & 0.00 \\
\hline 16 & 4 & 662 & 36 & -14.13 & -0.02 & -0.08 & 0.16 & 0.16 & 22.28 & -22.52 & 2.34 & -0.02 & -0.03 & -1.16 & -1.80 & 0.00 \\
\hline 16 & 5 & 651 & 35 & -13.82 & -0.02 & -0.11 & 0.14 & 0.14 & 21.57 & -21.66 & 2.26 & -0.02 & -0.03 & -0.75 & -1.14 & 0.00 \\
\hline 16 & 6 & 639 & 34 & -13.23 & -0.02 & -0.13 & 0.16 & 0.16 & 20.88 & -21.09 & 2.12 & -0.02 & -0.03 & -1.26 & -1.98 & 0.00 \\
\hline 16 & 7 & 646 & 35 & -13.94 & -0.02 & -0.16 & 0.14 & 0.15 & 21.26 & -21.38 & 2.20 & -0.02 & -0.03 & -0.88 & -1.35 & 0.00 \\
\hline 16 & 8 & 622 & 32 & -12.31 & -0.02 & -0.17 & 0.13 & 0.13 & 19.81 & $\begin{array}{l}-19.77 \\
\end{array}$ & 1.99 & -0.02 & -0.03 & -0.59 & -0.89 & 0.00 \\
\hline 16 & 9 & 647 & 34 & -13.16 & -0.02 & -0.21 & 0.14 & 0.14 & 21.35 & -21.40 & 2.22 & -0.02 & -0.03 & -0.66 & -1.01 & 0.00 \\
\hline 16 & 10 & 624 & 32 & -12.39 & -0.02 & -0.22 & 0.13 & 0.13 & 19.96 & -19.96 & 2.01 & -0.02 & -0.03 & -0.70 & -1.07 & 0.00 \\
\hline 16 & 11 & 612 & 32 & -12.61 & -0.02 & -0.24 & 0.15 & 0.15 & 19.27 & -19.38 & 1.88 & -0.02 & -0.03 & -1.16 & -1.84 & 0.00 \\
\hline 16 & 12 & 586 & 29 & -11.75 & -0.02 & -0.24 & 0.13 & 0.13 & 17.76 & $\begin{array}{l}-17.68 \\
\end{array}$ & 1.67 & -0.02 & -0.03 & -0.75 & -1.17 & 0.00 \\
\hline 16 & 13 & 616 & 32 & -12.83 & -0.02 & -0.29 & 0.13 & 0.13 & 19.49 & -19.46 & 1.94 & -0.02 & -0.03 & -0.66 & -1.02 & 0.00 \\
\hline 16 & 14 & 628 & 32 & -12.15 & -0.02 & -0.33 & 0.13 & 0.13 & 20.25 & -20.25 & 2.05 & -0.02 & -0.03 & -0.63 & -0.96 & 0.00 \\
\hline 16 & 15 & 597 & 30 & -11.02 & -0.02 & -0.32 & 0.13 & 0.13 & 18.38 & -18.34 & 1.76 & -0.02 & -0.03 & -0.74 & -1.16 & 0.00 \\
\hline 16 & & 637 & 34 & -13.10 & -0.02 & -0.19 & 0.14 & 0.14 & 20.82 & -20.91 & 2.13 & \begin{tabular}{|l|}
-0.02 \\
\end{tabular} & -0.03 & -0.86 & -1.33 & 0.00 \\
\hline & & & & C6 & $\begin{array}{l}\mathrm{C} 7 \\
\end{array}$ & C8 & C9 & $\mathrm{L}$ & R1 & R2 & Rs & Ilphak50 & Cd & Do & $\mathrm{Dp}$ & Ro \\
\hline & & & & 0.00 & 0.00 & 0.00 & 0.00 & -1.06 & 1.28 & -1.38 & -10.74 & \begin{tabular}{|l|} 
\\
\end{tabular} & -0.18 & 0.00 & 2.20 & 0.01 \\
\hline & & & & 0.00 & 0.00 & 0.00 & 0.00 & -0.90 & 1.10 & -1.18 & -9.19 & -0.03 & -0.34 & -0.01 & 2.14 & 0.02 \\
\hline & & & & 0.00 & 0.00 & 0.00 & 0.00 & -0.98 & 1.19 & -1.29 & -9.99 & -0.03 & -0.47 & -0.01 & 2.06 & 0.03 \\
\hline & & & & 0.00 & 0.00 & 0.00 & 0.00 & -0.86 & 1.04 & -1.12 & -8.74 & -0.03 & -0.61 & -0.01 & 2.03 & 0.04 \\
\hline & & & & 0.00 & 0.00 & 0.00 & 0.00 & -0.99 & 1.21 & -1.30 & -10.11 & -0.03 & -0.74 & -0.01 & 1.99 & 0.04 \\
\hline & & & & 0.00 & 0.00 & 0.00 & 0.00 & -0.89 & 1.09 & -1.17 & -9.10 & -0.03 & -0.91 & -0.02 & 2.01 & 0.05 \\
\hline & & & & 0.00 & 0.00 & 0.00 & 0.00 & -0.78 & 0.96 & -1.04 & -8.05 & -0.03 & -0.98 & -0.02 & 1.94 & 0.06 \\
\hline & & & & 0.00 & 0.00 & 0.00 & 0.00 & -0.83 & 1.02 & -1.10 & -8.56 & -0.03 & -1.21 & -0.02 & 2.02 & 0.07 \\
\hline & & & & 0.00 & 0.00 & 0.00 & 0.00 & -0.81 & 1.01 & -1.09 & -8.43 & -0.03 & -1.27 & -0.02 & 1.95 & 0.07 \\
\hline & & & & 0.00 & 0.00 & 0.00 & 0.00 & -0.94 & 1.16 & -1.25 & -9.68 & -0.03 & -1.37 & -0.03 & 1.91 & 0.08 \\
\hline & & & & 0.00 & 0.00 & 0.00 & 0.00 & -0.79 & 0.98 & -1.06 & -8.25 & -0.03 & -1.39 & -0.03 & 1.83 & 0.08 \\
\hline & & & & 0.00 & 0.00 & 0.00 & 0.00 & -0.80 & 1.00 & -1.07 & -8.33 & -0.03 & -1.66 & -0.03 & 1.93 & 0.10 \\
\hline & & & & 0.00 & 0.00 & 0.00 & 0.00 & -0.80 & 1.00 & -1.08 & -8.38 & -0.03 & -1.87 & -0.03 & 1.97 & 0.11 \\
\hline & & & & 0.00 & 0.00 & 0.00 & 0.00 & -0.80 & 1.00 & -1.08 & -8.41 & -0.03 & -1.82 & -0.03 & 1.87 & 0.11 \\
\hline & & & & 0.00 & 0.00 & 0.00 & 0.00 & -0.87 & 1.07 & -1.16 & -9.00 & -0.03 & -1.06 & -0.02 & 1.99 & 0.06 \\
\hline \multicolumn{17}{|c|}{ Normal Heat Transfer (Low mass velocity) } \\
\hline Run & Th & Nus & Nus_sig & d_ic & $\mathbf{P}$ & Vo & Vs & V2 & Tin & Tclad & d_h & C1 & C2 & C3 & $\mathrm{C4}$ & C5 \\
\hline 23 & 2 & 1332 & $9 \overline{7}$ & -19.94 & 4.43 & -0.02 & 0.31 & 0.20 & 0.00 & -92.30 & 2.65 & -0.06 & -0.09 & -1.59 & -2.91 & 0.00 \\
\hline 23 & 3 & 1353 & 99 & -21.18 & 4.61 & -0.05 & 0.29 & 0.19 & 0.00 & -95.22 & 2.82 & -0.06 & -0.09 & -1.09 & -1.97 & 0.00 \\
\hline 23 & 4 & 1215 & 81 & -17.61 & 3.56 & -0.06 & 0.29 & 0.18 & 0.00 & -77.07 & 1.94 & -0.05 & -0.08 & -1.37 & -2.53 & 0.00 \\
\hline 23 & 5 & 1145 & 72 & -15.82 & 3.08 & -0.07 & 0.24 & 0.16 & 0.00 & -68.51 & 1.57 & -0.05 & -0.08 & -0.81 & -1.49 & 0.00 \\
\hline 23 & 6 & 1161 & 75 & -16.23 & 3.19 & -0.09 & 0.28 & 0.18 & 0.00 & -70.81 & 1.64 & -0.05 & -0.08 & -1.47 & -2.73 & 0.00 \\
\hline 23 & 7 & 1183 & 77 & -17.39 & 3.34 & -0.11 & 0.26 & 0.17 & 0.00 & -73.44 & 1.78 & -0.05 & -0.08 & -1.04 & -1.91 & 0.00 \\
\hline 23 & 8 & 1145 & 72 & -15.50 & 3.08 & -0.12 & 0.24 & 0.16 & 0.00 & -68.78 & 1.57 & -0.05 & -0.08 & -0.70 & -1.28 & 0.00 \\
\hline 23 & 9 & 1178 & 77 & -16.26 & 3.32 & -0.15 & 0.25 & 0.16 & 0.00 & -73.07 & 1.76 & -0.05 & -0.08 & -0.78 & -1.42 & 0.00 \\
\hline 23 & 10 & 1179 & 77 & -16.52 & 3.32 & -0.17 & 0.26 & 0.17 & 0.00 & -73.34 & 1.77 & -0.05 & -0.08 & -0.88 & -1.61 & 0.00 \\
\hline 23 & 11 & 1094 & 67 & $\begin{array}{r}-15.10 \\
\end{array}$ & 2.76 & -0.16 & 0.26 & 0.17 & 0.00 & -63.47 & 1.30 & -0.05 & -0.08 & $\begin{array}{r}-1.32 \\
\end{array}$ & -2.47 & 0.00 \\
\hline 23 & 12 & 1044 & 61 & -13.97 & 2.46 & -0.17 & 0.23 & 0.15 & 0.00 & -57.81 & 1.07 & -0.05 & -0.07 & -0.85 & -1.57 & 0.00 \\
\hline 23 & 13 & 1083 & 66 & -14.86 & 2.70 & -0.19 & 0.24 & 0.15 & 0.00 & -62.22 & 1.27 & -0.05 & -0.07 & -0.73 & -1.34 & 0.00 \\
\hline 23 & 14 & 1153 & 74 & -15.36 & 3.15 & -0.24 & 0.25 & 0.16 & 0.00 & -70.66 & 1.64 & -0.05 & -0.08 & -0.75 & -1.37 & 0.00 \\
\hline 23 & 15 & 1063 & 63 & -13.15 & 2.58 & -0.22 & 0.25 & 0.15 & 0.00 & -60.25 & 1.17 & -0.05 & -0.07 & -0.84 & -1.56 & 0.00 \\
\hline \multirow[t]{9}{*}{23} & & 1166 & 76 & -16.35 & 3.26 & -0.13 & 0.26 & 0.17 & 0.00 & -71.93 & 1.71 & \begin{tabular}{|c|}
-0.05 \\
\end{tabular} & -0.08 & -1.02 & -1.87 & 0.00 \\
\hline & & & & C6 & C7 & $\mathrm{C} 8$ & C9 & $\mathrm{L}$ & R1 & R2 & Rs & Iphak50 & $\mathrm{Cd}$ & Do & $\mathrm{Dp}$ & Ro \\
\hline & & & & 0.00 & 0.00 & 0.00 & 0.00 & -1.79 & 2.16 & -2.33 & -18.14 & -0.07 & -0.14 & 0.00 & 4.15 & 0.01 \\
\hline & & & & 0.00 & 0.00 & 0.00 & 0.00 & -1.66 & 2.01 & -2.17 & -16.90 & -0.07 & -0.29 & -0.01 & 4.22 & 0.03 \\
\hline & & & & 0.00 & 0.00 & 0.00 & 0.00 & -1.62 & 1.96 & -2.11 & -16.44 & -0.07 & -0.36 & -0.06 & 3.80 & 0.03 \\
\hline & & & & 0.00 & 0.00 & 0.00 & 0.00 & -1.38 & 1.68 & -1.81 & -14.12 & -0.06 & -0.44 & -0.01 & 3.59 & 0.04 \\
\hline & & & & 0.00 & 0.00 & 0.00 & 0.00 & -1.60 & 1.94 & -2.09 & -16.32 & -0.07 & -0.57 & -0.01 & 3.65 & 0.05 \\
\hline & & & & 0.00 & 0.00 & 0.00 & 0.00 & -1.49 & 1.81 & -1.95 & -15.30 & -0.06 & -0.71 & -0.01 & 3.72 & 0.07 \\
\hline & & & & 0.00 & 0.00 & 0.00 & 0.00 & -1.36 & 1.65 & -1.78 & -13.95 & -0.06 & -0.78 & -0.01 & 3.61 & 0.07 \\
\hline
\end{tabular}




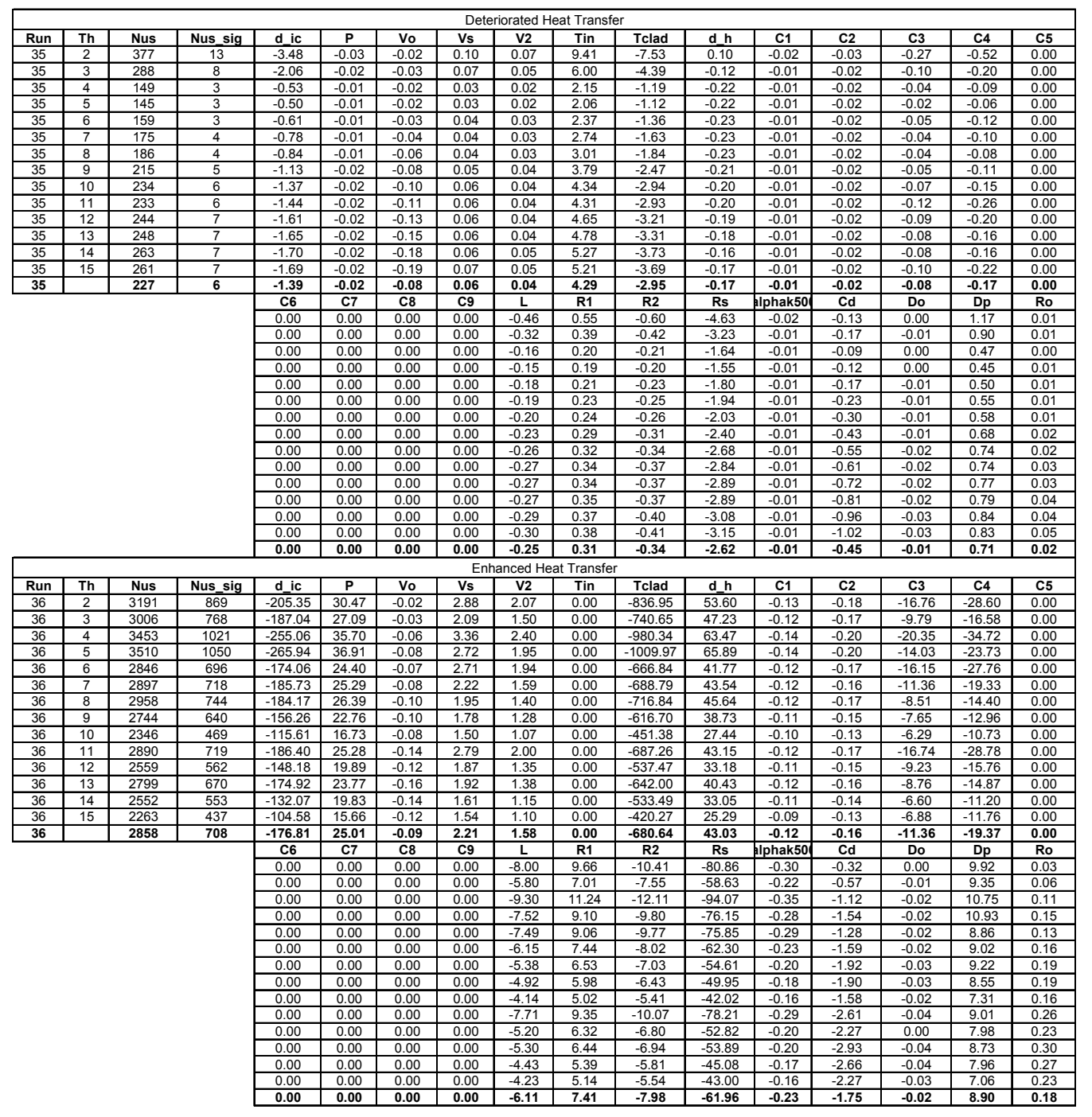

